\title{
Cost Minimization for Hot Gas Defrost System
}

\author{
A Thesis \\ Presented to \\ The Faculty of California Polytechnic State University, \\ San Luis Obispo
}

In Partial Fulfillment

Of the Requirements for the Degree

Master of Science in Mechanical Engineering

By:

Jarubutr Dansilasirithavorn

June 2009 
(C) 2009

Jarubutr Dansilasirithavorn

ALL RIGHTS RESERVED 


\section{COMMITTEE MEMBERSHIP}

TITLE:

DATE SUMMITED:

COMMITTEE CHAIR:
AUTHOR:

Cost Minimization for Hot Gas Defrost System

Jarubutr Dansilasirithavorn

June 2009

Jesse Maddren, Ph.D., P.E.

Associate Professor

Department of Mechanical Engineering

Cal Poly, San Luis Obispo

COMMITTEE MEMBER: Glen Thorncroft, Ph.D. Associate Chair

Department of Mechanical Engineering

Cal Poly, San Luis Obispo

COMMITTEE MEMBER: Andrew Kean, Ph.D.

Assistant Professor

Department of Mechanical Engineering

Cal Poly, San Luis Obispo 


\section{Abstract}

\section{Cost Minimization for Hot Gas Defrost System Jarubutr Dansilasirithavorn}

Frost accumulation on evaporator coils has been a serious problem that decreases the efficiency of refrigeration systems. Many defrost methods have been used and hot gas defrost is the most common for industrial refrigeration applications. However, it is not a simple task to run an efficient hot gas defrost system. The duration and frequency of the defrost cycle should be properly determined so that the frost is melted but no additional heat transfer is transferred to the refrigerated space.

An experimental investigation was conducted at the Classic Salads Facility in Salinas, California. A single coil was instrumented to study frost build up and defrost during normal operation.

The finite difference method is used to numerically model the temperature of the coil during a defrost cycle. A separate model was developed to determine the pressure drop across evaporator coil with and without frost. Both models are used to determine the presence of frost on the coil tested at Classic Salads.

The pressure drop data did not show an increase in the pressure drop over time, indicating there was no frost accumulation during testing at Classic Salads. Also, comparison between the finite difference model and the experimental temperature data indicate that there was minimal frost. These results indicate that energy savings could be achieved if an accurate defrost termination was implemented. 


\section{Acknowledgments}

First, I would like to thank Dr. Jesse Maddren of Cal Poly, San Luis Obispo for his genuine support and guidance in helping me to accomplish this project. I also would like to thank Doug Scott and Ryan Hoest, from VaCom technologies, for giving me the opportunity to work on this project and guiding me throughout. Additionally, special recognition goes to Dr. Andrew Kean, Dr. Glen Thorncroft and many other professors from the Mechanical Engineering Department who have assisted me at each stage of the project's development. Last but not least, I would like thank my mom, my aunt, my uncle and everyone in my family for their encouragement and contributions in the completion of this thesis.
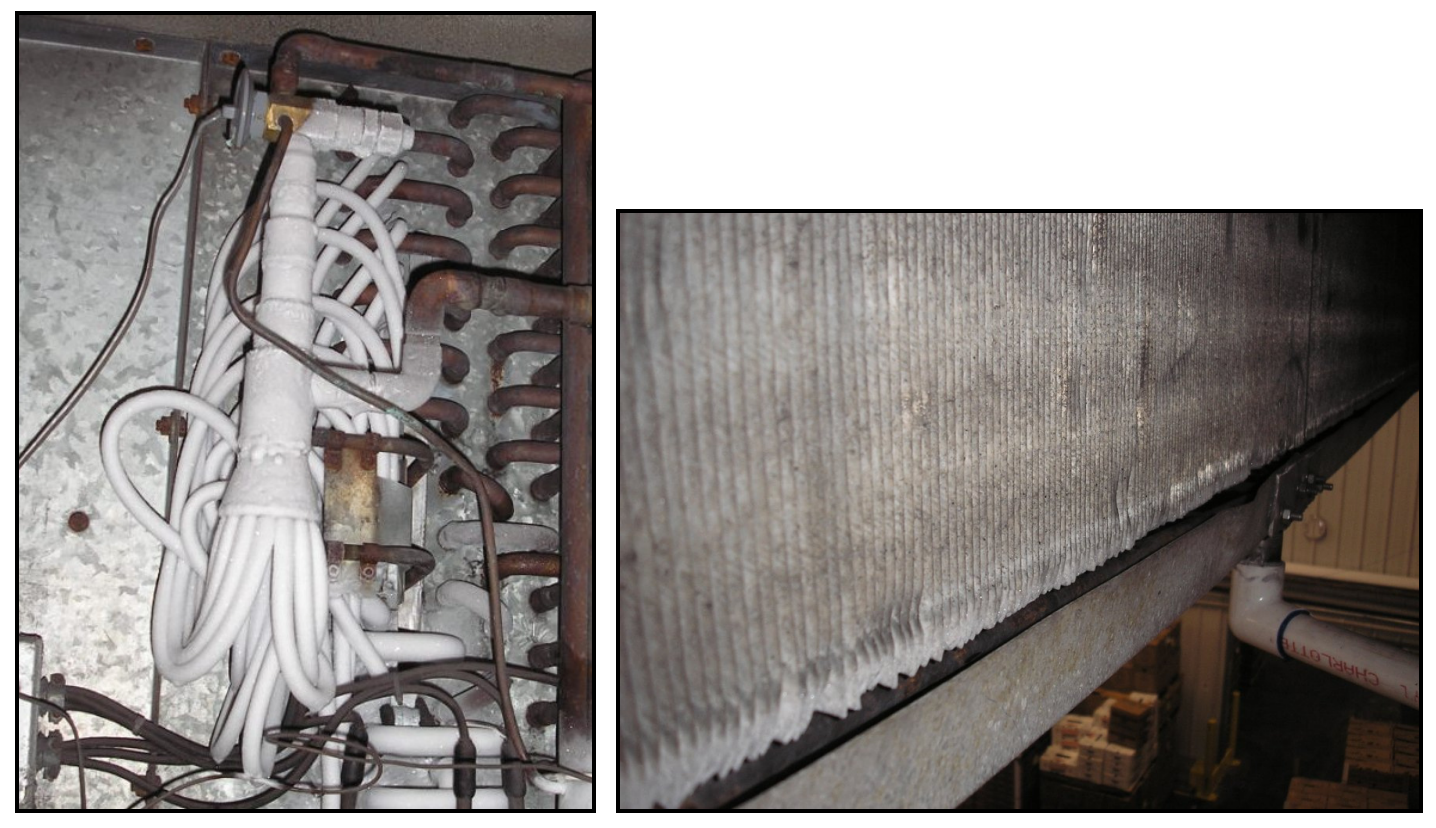


\section{Table of Contents}

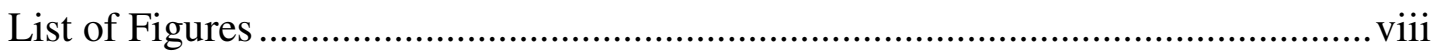

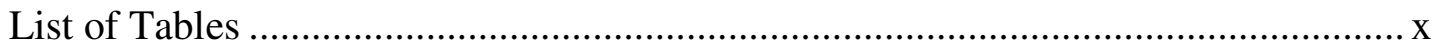

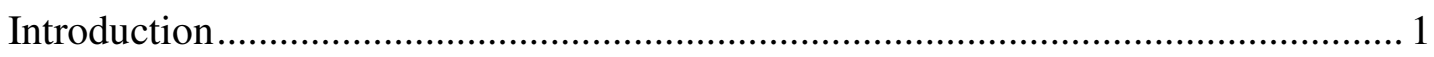

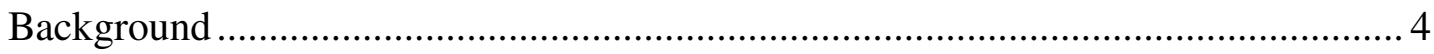

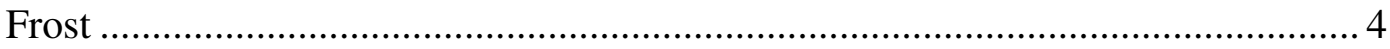

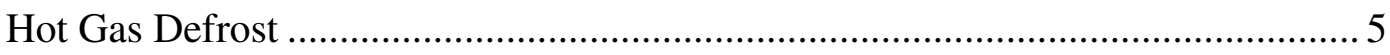

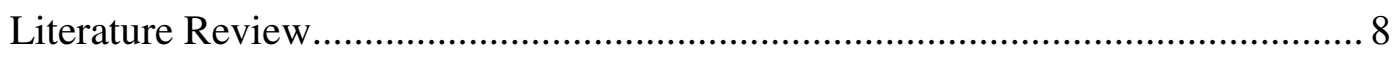

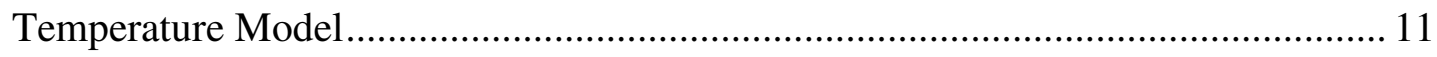

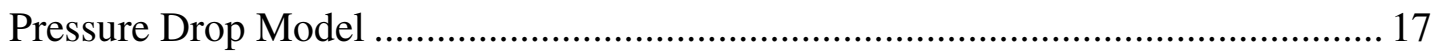

Testing

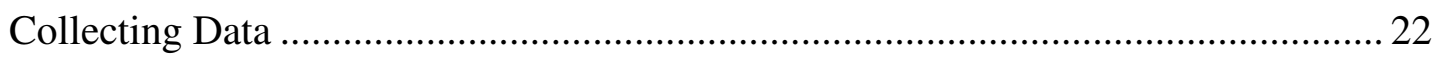

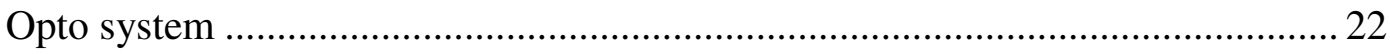

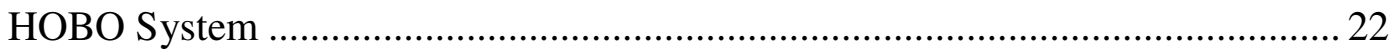

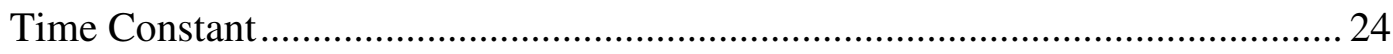

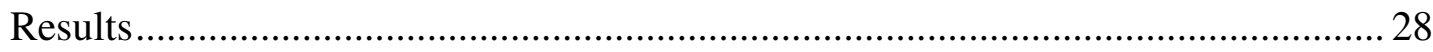

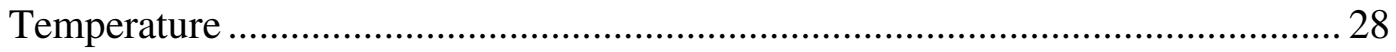

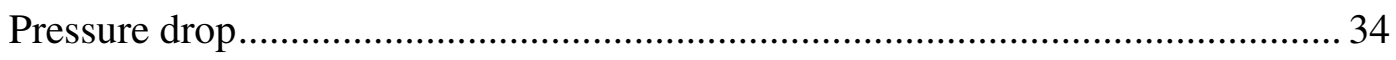

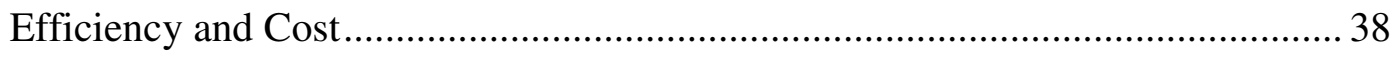

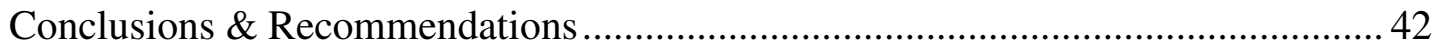

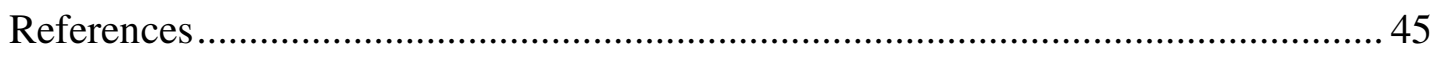

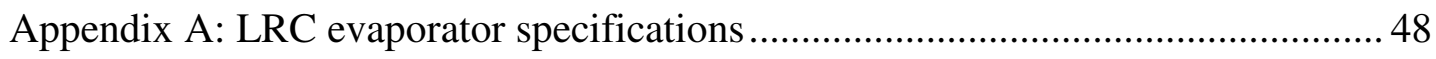

Appendix B: Opto22 system and ICTD temperature probe specifications..................52 
Appendix C: HOBO data logger specifications ............................................. 55

Appendix D: Pressure transducer specifications.............................................. 57

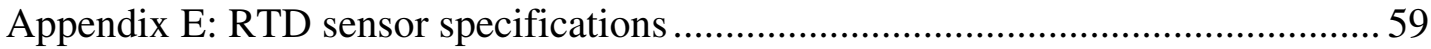

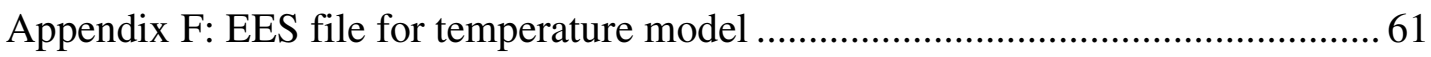

Appendix G: EES file for pressure drop model .............................................6 69

Appendix H: Weather data during experiment ............................................... 71 


\section{List of Figures}

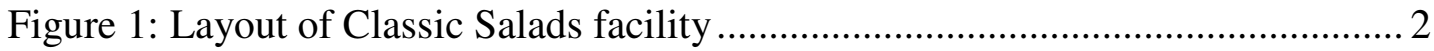

Figure 2: Refrigeration unit with hot gas defrost arrangement ............................ 5

Figure 3: Representation of a fin-tube section for a plate-fin heat exchanger........... 11

Figure 4: Schematic of the domain for fin-tube section .................................... 12

Figure 5: Isometric view with staggered arrangement...................................... 18

Figure 6: Friction factor $f_{\text {tube }}$ for staggered tube bundle arrangement .................... 19

Figure 7: The evaporator inside the Organic Room that was tested ......................... 21

Figure 8: HOBO data recorder for temperature sensors and pressure transducer ..... 23

Figure 9: Temperature data to determine sensor time constant .............................. 25

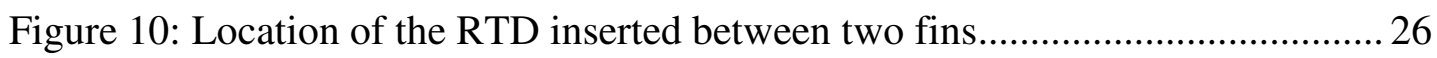

Figure 11: Locations of RTD on evaporator tube sheet......................................... 27

Figure 12: Temperature data from Opto22 and HOBO systems during the defrost

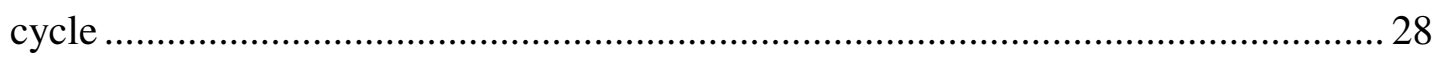

Figure 13: Comparison between temperature data and model............................... 30

Figure 14: Fin temperature during hot gas defrost with $1 \mathrm{~mm}$ of frost...................... 31

Figure 15: Fin temperature during hot gas defrost with $0.5 \mathrm{~mm}$ of frost................... 32

Figure 16: Heat transfer during hot gas defrost with $0.5 \mathrm{~mm}$ of frost ..................... 33

Figure 17: Heat transfer during hot gas defrost with $1 \mathrm{~mm}$ of frost ........................ 33

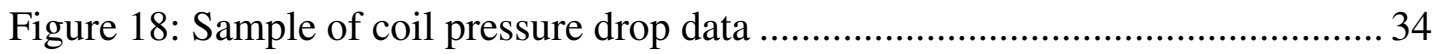

Figure 19: Pressure drop as a function of volumetric flow rate ............................. 35

Figure 20: Pressure drop as a function of volumetric flow rate for different frost

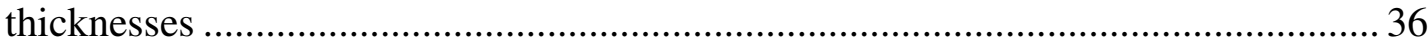


Figure 21: Pressure drop as a function of volumetric flow rate for different frost

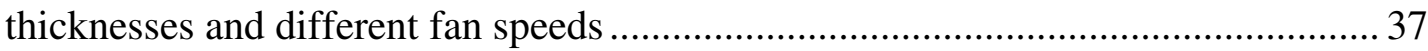

Figure 22: Hot gas defrost efficiency as a function of defrost time for different

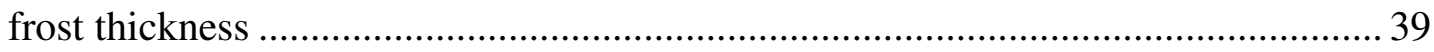

Figure 23: Hot gas defrost cost as a function of defrost time for different frost

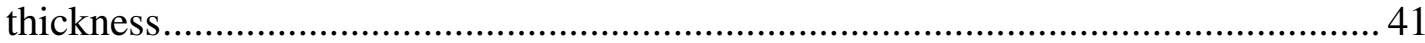




\section{List of Tables}

Table 1: Temperature probe specifications for HOBO and Opto systems ............... 24

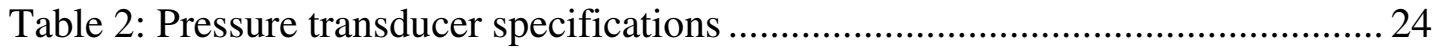

Table 3: Evaporator coil flow rate and pressure drop as a function of frost

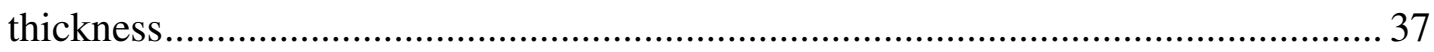




\section{Nomenclature}

Name

A

$\mathrm{A}_{\mathrm{c}}$

$\mathrm{A}_{\mathrm{c}, \mathrm{t}}$

$\mathrm{Cp}$

D

$f$

$\mathrm{g}_{\mathrm{m}}$

$\mathrm{G}_{\mathrm{c}}$

$\mathrm{h}$

$\mathrm{h}_{\mathrm{c}}$

$\mathrm{k}$

$\mathrm{m}$

$\mathrm{P}$

Q

r

$\mathrm{Re}$

$\mathrm{S}_{\mathrm{T}}$

$\mathrm{t}$

$t$

$\mathrm{T}$

V

$\mathrm{X}$

Z

\section{Description}

Air-side surface area

Minimum free flow area

Minimum free flow area (for tube bank)

Specific heat

Diameter

Friction factor

Mass transfer coefficient

Maximum mass velocity

Specific enthalpy

Convection coefficient

Thermal conductivity

Mass fraction

Pressure

Overall energy transfer

Radius

Reynolds number

Transverse pitch

Time

Thickness

Temperature

Volume

Node spacing in the axial direction

Coordinate 


\section{Greek Symbol}

$\Delta$

$\rho$

$\eta_{\text {defrost }}$

\section{Subscript}

$\mathrm{amb}$

$\mathrm{H}_{2} \mathrm{O}$,e

$\mathrm{H}_{2} \mathrm{O}$, $\mathrm{s}$

ig

\section{Difference}

Density

Defrost efficiency

\begin{abstract}
Ambient
Water vapor in the conditioned space

Water vapor at the surface of the frost

Fusion
\end{abstract}




\section{Introduction}

VaCom Technologies is a consulting refrigeration controls company with headquarters in Laverne, CA. They also have an office in San Luis Obispo, CA. They design and install control systems to reduce energy consumption for industrial refrigeration facilities. One of their clients is Classic Salads located in Salinas, CA. The Classic Salads facility was recently retrofitted with new energy saving systems such as variable speed drives on the evaporator coils and floating head pressure control on the condenser. Nevertheless, VaCom Technologies is still interested in reducing energy expense by minimizing the defrost frequency and duration. Due to company workloads and the complexity of this problem, VaCom Technologies contacted Cal Poly for assistance.

The system at Classic Salads is a single stage R22 refrigeration system with four Carrier 5H80 reciprocating compressors and one Frick RWBII-134 screw compressor. There are a total of 26 evaporators, with groups of 2 or 3 in each zone, as shown in Figure 1. There are 6 auxiliary coils, 3 in the Finished Product room and 3 in the Raw Product room, while the rest are direct expansion coils. All of the evaporators are defrosted with hot gas refrigerant except the 6 auxiliary coils which use air to defrost. 


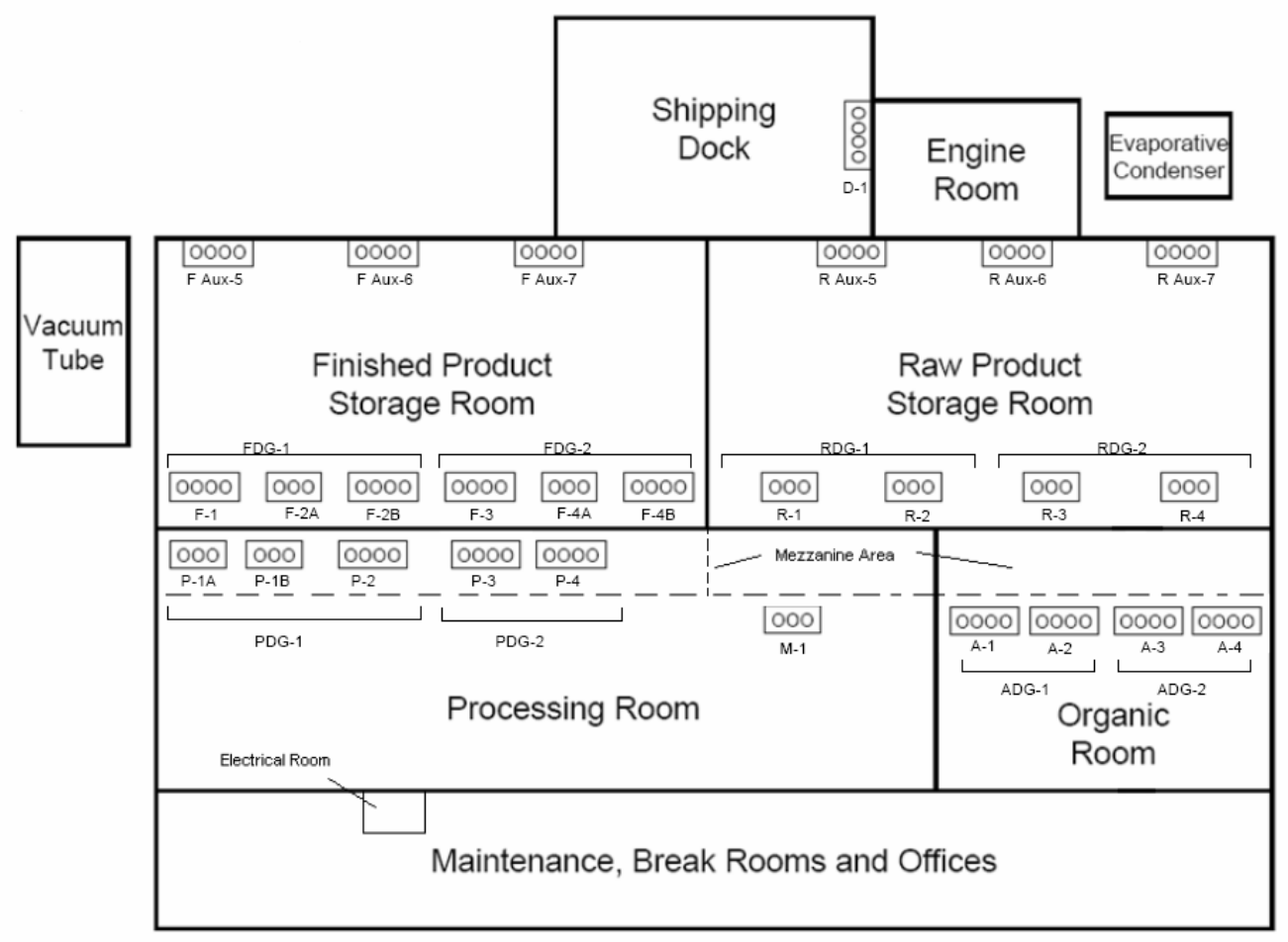

Figure 1: Layout of Classic Salads facility

Each zone is scheduled to defrost for either 20 or 30 minutes, 4 or 6 times per day, depending on the location within the facility. For example, in the organic room, the product is brought in through an automatic door that is located next to the evaporator coils. The humidity from the outside tends to make the frost build up quicker in comparison to the other zones. Classic Salads schedules defrost based on experience to make sure that the system runs properly. If the coil ices up, then the evaporator must be shut down for an extended period of time to melt the ice.

Additional heat added to the coil, beyond what is required to melt the frost, and must be removed by the refrigeration system. This increases the refrigeration 
load and also the cost of operating the system. The objective of this study is to determine when to initiate and/or terminate the defrost cycle. If the defrost time is too short then there will be some frost remaining on the coil when the normal operation resumes. Energy will be wasted if the defrost time is too long.

Due to limited time and resources, the experimental investigation is limited to the study of a single coil for a 1 week period. Results from the experiments will be composed to mathematical models of the coil. 


\section{Background}

Refrigeration is the process of removing heat from a space or a substance and rejecting it to the surroundings. The main goal of this process is to lower the temperature of a space or a substance. Refrigeration has been used in wide a range of applications from air conditioning to food preservation. One of the key components of the refrigeration system is the evaporator. In food storage applications, the evaporator sometimes operates below freezing temperature $\left(<32^{\circ} \mathrm{F}\right)$ and frost can accumulate on the coil.

\section{Frost}

Frost accumulation will occur when the surfaces of the operating evaporative coil are below $32^{\circ} \mathrm{F}$ and the entering air dew point temperature is higher than the coil surface temperature [1]. There is a special case when moisture in the air condenses to liquid water and then freezes to ice. Although, normally the water vapor will transform directly into a solid phase, frost.

There are two major concerns when the frost formation occurs. First, when the frost layers grow, the air passages of the evaporator are narrowed. This will increase the resistance to the air flow. This frost layer will reduce the ability of the evaporator fan to move air through the coil and fan energy consumption will increase. Second, frost accumulation increases the resistance to heat transfer due to 
the low conductivity of the frost layer [2]. Both of these factors reduce the effectiveness of the evaporator. Therefore, the frost must be removed periodically.

\section{Hot Gas Defrost}

There are many methods for defrosting, such as electric resistance heating, off-cycle (air defrost), reversed cycle, etc. For most industrial refrigeration applications, hot gas defrost is the most common method to remove frost from the evaporator. The basic concept behind hot gas defrost is to stop the cold refrigerant supply and then release high-pressure, high-temperature refrigerant from the compressor discharge to the evaporator. The evaporator will temporary function as a condenser during the defrost process [3]. A schematic of the typical lay-out for a hot gas defrost system is shown in Figure 2.

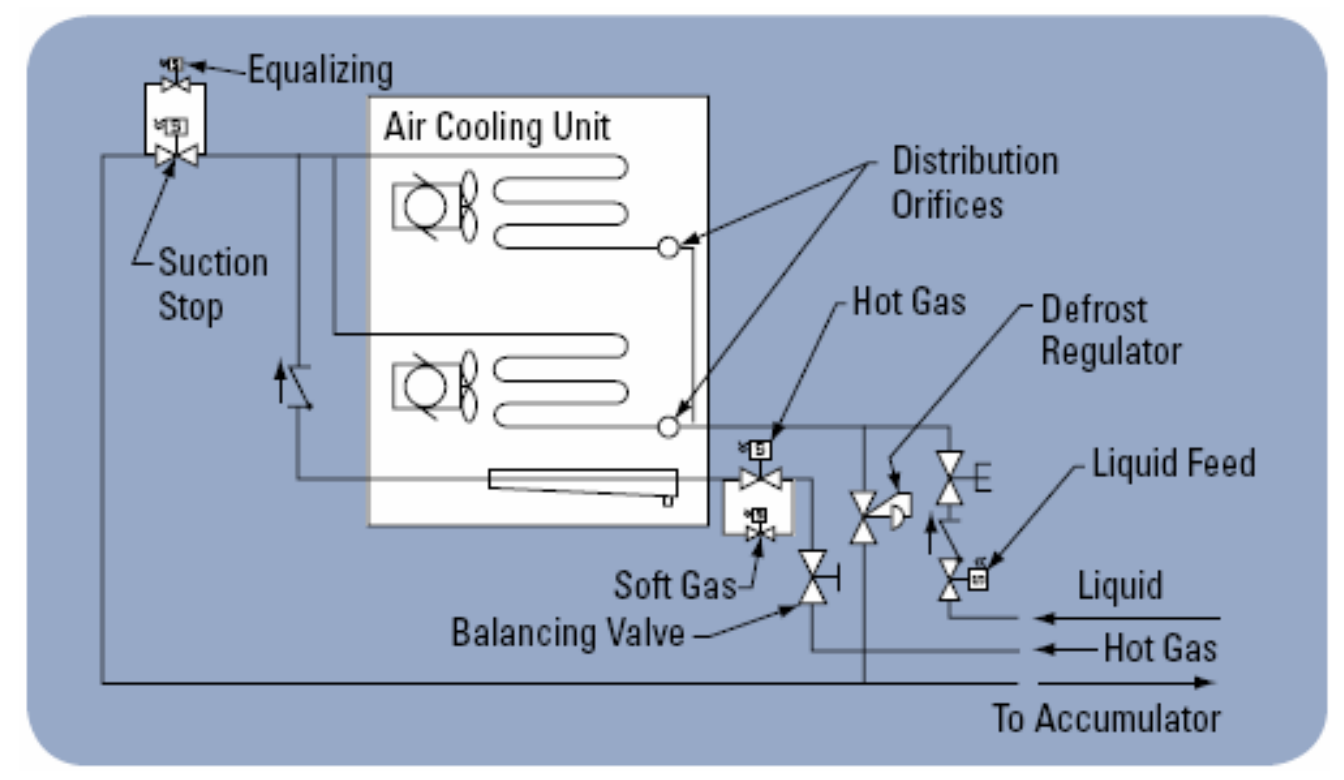

Figure 2: Refrigeration unit with hot gas defrost arrangement 
The processes of a typical hot gas defrost system are as follows:

\section{Refrigeration (normal operation) phase:}

- Saturated liquid refrigerant runs through the liquid feed valve into the evaporator

- Heat from the space is absorbed and the majority of the refrigerant is vaporized

- Saturated vapor from the evaporator outlet flows to the accumulator

\section{Pump out phase (approximately 10 to 30 minutes):}

- The liquid feed valve is closed

- The evaporator fans will continue to run in order for the liquid inside the coil to vaporize which will prevent pressure shocks damage

- At the end of this phase, the fans are turned off and the suction stop valve will be closed

\section{Soft gas phase:}

- For safety purposes, a solenoid valve is installed parallel to the hot gas valve to allow the hot gas to flow slowly into the coil

- The main hot gas valve is opened while the solenoid valve is closed at the end of this phase 


\section{Hot gas phase (approximately 5 to 30 minutes):}

- The hot gas flows to warm the drain pan first before going into the coil

- The defrost regulator controls the pressure rise inside the coil

- The hot gas continues to flow until either:

1) The hot gas pre-set time is reached or

2) A sensor terminates this phase and closes the hot gas valve

\section{Equalization phase:}

- For safety purposes, an equalizing valve is installed parallel to the hot gas valve to slowly decrease the pressure inside the coil

- At the end of this phase, the equalizing valve is closed and the suction stop and liquid feed valves are opened.

\section{Fan delay phase:}

- The fans remain off allowing any remaining water to re-freeze to prevent any blow-over when the fans turn on again

\section{Resume refrigeration phase:}

- The fans are energized back to normal operation until the next defrost cycle is initiated 


\section{Literature Review}

There are two ways for frost to build up on the evaporator coil. The first type is when tiny frost particles accumulate due to impaction on the evaporator coil surfaces. The tiny frost particles are created from the supersaturated air stream that suddenly cools. This type frost can build up very quickly due to its low density. It forms when the moisture content in the air is high, for example, evaporative coils near doors that open to the outside.

The second mechanism is through the diffusion of water vapor onto the cold surface due to the difference in the concentration of water between the air stream and the frost layer. This forms a layer of frost with high density. Due to the dense structure, this type of frost must be removed periodically. This high density frost occurs in places where the air temperature is low, along with low moisture content. This type of frost forms on evaporator coils located inside a refrigerated warehouse where food products are stored for a long period of time [1]. It is important to periodically remove the frost on the coil surface regardless of the frost formation mechanism, so that the evaporator can continue to operate normally.

There are many research studies for the prediction of frost growth. Nevertheless, the frost formation is still an open research topic because there are many different types of models, different assumptions and different experimental conditions. Most of the frost prediction models can be categorized into three main 
groups [4]. The first group uses molecular diffusion applied to the frost layer. Then, empirical correlations on the air side are used to calculate heat and mass transfer to predict the frost growth characteristics [5]. The second group applies an improved model to predict the frost properties by using the empirical correlations from the air flow boundary layer equations [6]. The third group uses molecular diffusion in the frost layer combined with the boundary layer equations to analyze the frost formation [7].

There are some studies that do not follow the previous mentioned groups. Some of these studies focus on the analysis of simple geometries that resemble a portion of a heat exchanger, such as a laminar flow analysis over parallel cold plates [8], a frost formation study on a vertical plate [9], and an experimental analysis on a cold cylindrical surface [10]. Some researchers have worked to develop realistic and complex frost growth models. For example, Tso et al. created a more comprehensive model by deriving equations for non-steady-state and quasi-steady state heat transfer through a tube-fin heat exchanger [11]. Lenic et al. developed a transient twodimensional mathematical model of frost formation to predict the frost growth rate and a change in the thermal conductivity of the frost layer [12].

Although there are many frost growth models, the majority of them do not focus on when to initiate or terminate the hot gas defrost cycle. Hoffenbecker et al developed a model of the hot gas defrost process [13]. For practical applications, this 
method is easier to implement than other models and it still can produce reasonable results, which is why Hoffenbecker's model is chosen for this project.

Many models have been developed and experiments have been conducted to study how to detect the frost build up and how the frost accumulation affects the system performance. The pressure drop across the coil has been used numerous times to predict frost growth, especially in heat pump applications. For example, Yao et al. developed a distributed mathematical model of the airside heat exchanger under frost conditions in an air source heat pump unit [14]. Liu et al. created a transient one dimensional model to predict frost growth and validated it experimentally for a heat pump unit [15]. Both researchers show that pressure drop increases dramatically once the frost accumulates. As a result, pressure drop is investigated as a frost detection method in this application as well.

Not many studies focus on cost estimation of the hot gas process. Cole is one of the few researchers who has developed models to analyze the cost of the hot gas defrost process [16]. 


\section{Temperature Model}

In industrial refrigeration systems, air-cooled evaporators are constructed of multiple rows of tubes along with fins that are arranged perpendicular to the tubes. The fin-tube evaporator can be modeled as a hexagon shape due to the symmetry of the geometry as shown in Figure 3a. This can be further approximated as a circular disc as shown in Figure 3b.

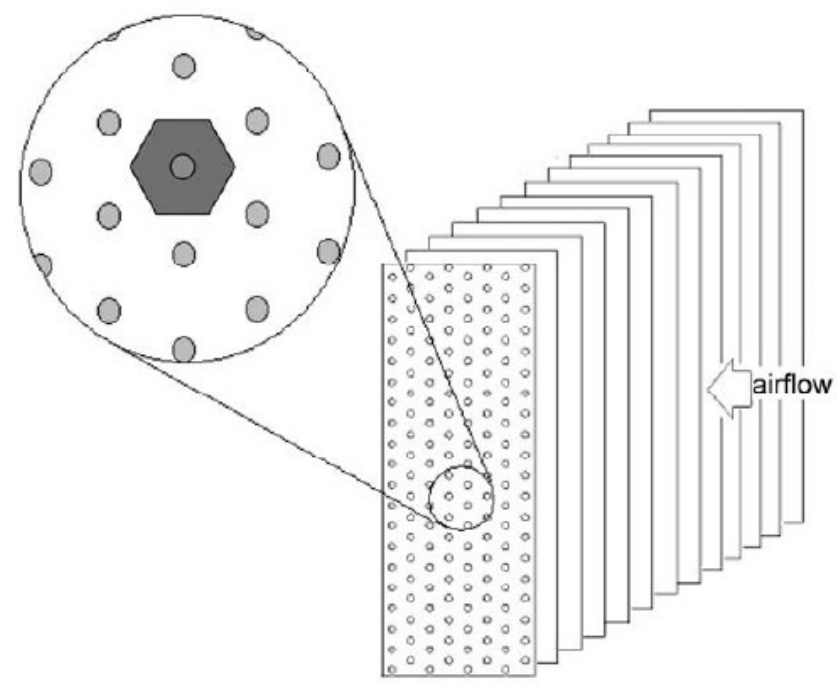

(a)

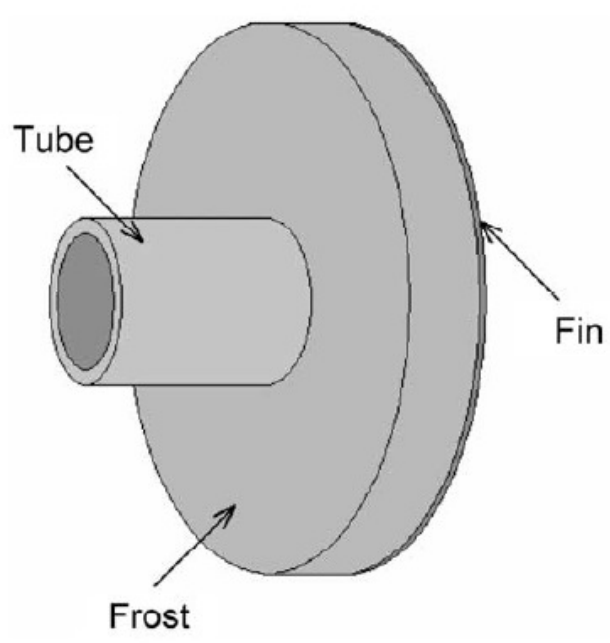

(b)

Figure 3: Representation of a fin-tube section for a plate-fin heat exchanger (a) and approximation as a circular disc (b) [13]

During the hot gas defrost, the condensing high pressure gas from either the high pressure receiver or the compressor discharge will warm the inside tube surface along with the fins that attach to the tubes. Thermal energy is conducted through the 
fin to melt the frost. Due to gravity, the melted frost will fall down from the coil to the drain pan. Some of the frost will also evaporate to the surrounding air.

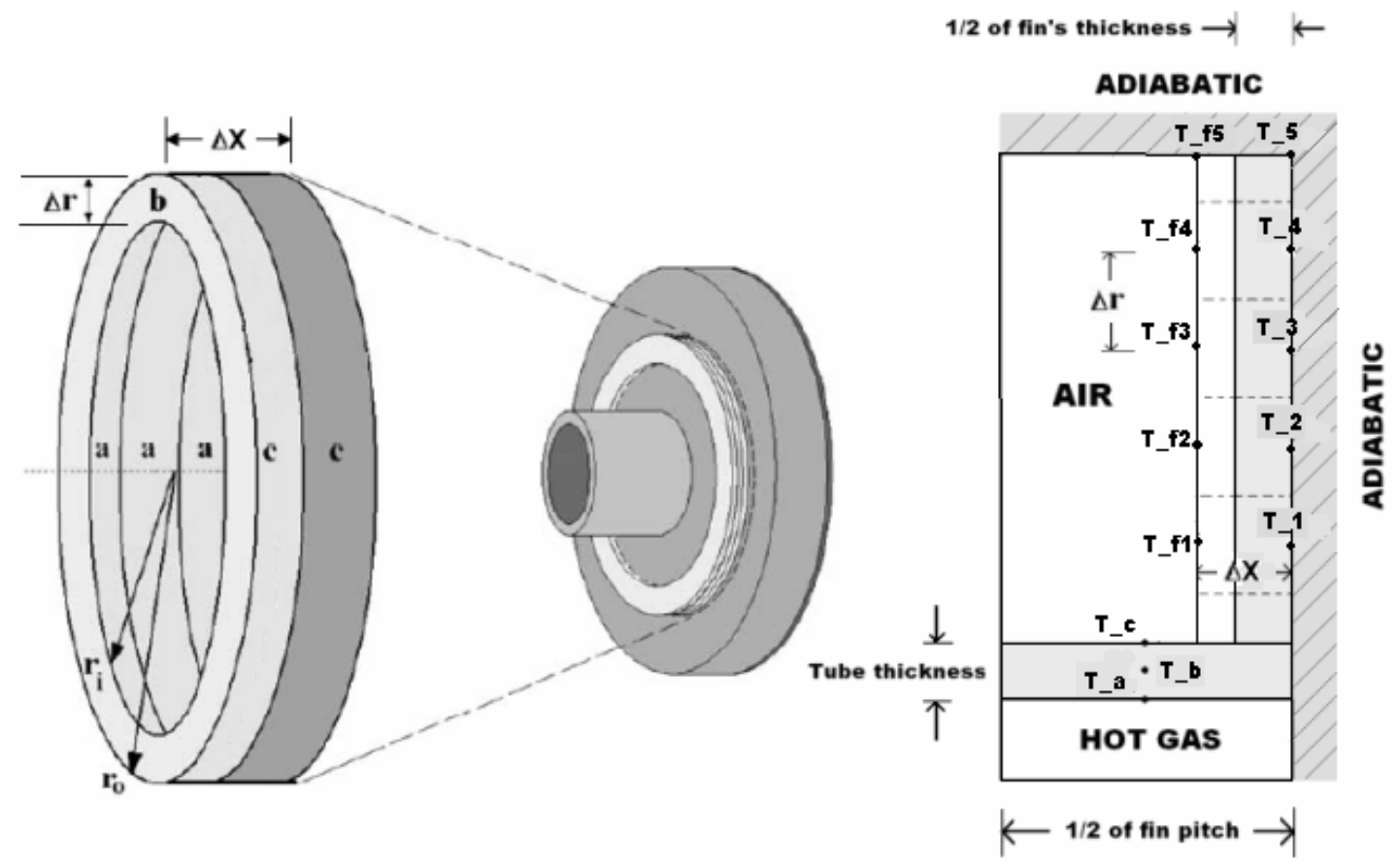

(a)

(b)

Figure 4: Schematic of the domain for fin-tube section (a) [13] and two-dimensional finite difference thermal model (b)

During the hot gas process, there are many important heat and mass transfer mechanisms that occur: condensation of high-pressure and high-temperature gaseous refrigerant inside the coil tubes; conduction through the coil tubes and fins; sensible heating of and melting of accumulated frost; and evaporation of moisture from the surface coil to the surrounding space [13]. 
A thermal model of the geometry shown in Figure 3 was developed to study the hot gas defrost process. The fin-tube was modeled as a two-dimensional, transient conduction problem. The heat equation for two-dimensional, axisymmetric conduction is

$$
\rho \mathrm{C}_{p} \frac{\partial T}{\partial t}=\frac{1}{r} \frac{\partial}{\partial r}\left(k r \frac{\partial T}{\partial r}\right)+\frac{\partial}{\partial z}\left(k \frac{\partial T}{\partial z}\right)
$$

The geometry is sub-divided into smaller regions, as shown in Figure 4, and the heat transfer problem is solved using the finite difference method. The boundary conditions for a control volume about each node are:

- Boundary a: thermal conduction from the adjoining nodes at the inner radius.

- Boundary b: conduction/convection in the axial direction at the left side

- Boundary c: thermal conduction to the adjoining nodes at the outer radius

- Boundary d: thermal conduction in the axial direction at the right side

An adiabatic boundary condition is applied at the outer radius and the right side of the model as shown in Figure 4b. The boundary condition at the inside tube wall is assumed to be constant temperature due to the condensing refrigerant. The boundary condition on the left side is convective heat and mass transfer to the surrounding air. 
The two dimensional axisymmetric, partial differential equation is solved using a finite difference approach. The difference equation for node $T_{-} 1$ is

$$
\begin{aligned}
\rho V\left(\frac{d h}{d t}\right)= & k_{f i n} 2 \pi \frac{\Delta x}{2} \frac{\left(T_{c}-T_{1}\right)}{\operatorname{In}\left(r_{1} / r_{c}\right)}-k_{\text {fin }} 2 \pi \frac{\Delta x}{2} \frac{\left(T_{1}-T_{2}\right)}{\operatorname{In}\left(r_{2} / r_{1}\right)}- \\
& {\left[2 \pi\left(\left(\frac{r_{2}+r_{1}}{2}\right)^{2}-\left(\frac{r_{1}+r_{c}}{2}\right)^{2}\right) \frac{\left(k_{\text {fin }}+k_{\text {frost }}\right)}{\left(k_{\text {frost }} t_{\text {fin }}+2 k_{\text {fin }} t_{\text {frost }}\right)}\left(T_{1}-T_{\text {frost } 1}\right)\right] . }
\end{aligned}
$$

The first term on the left hand side of equation (2) represents the change in energy stored in the node. This can be simplified by changing $d h=\mathrm{C}_{\mathrm{p}} d \mathrm{~T}$ and assuming that $\mathrm{C}_{\mathrm{p}}$ is constant. The first and second terms on the right hand side of equation (2) represent thermal conduction in the radial direction. The third term on the right hand side represents the thermal conduction between adjacent nodes from the fin to the frost at the same radial location. The energy balance at different radial locations along the fin will have a similar set up. 
The energy balance equation for frost at node T_f1 (see Figure 4b) can be expressed as

$$
\begin{aligned}
\rho V\left(\frac{d h}{d t}\right)= & k_{\text {frost }} 2 \pi \frac{\Delta x}{2} \frac{\left(T_{c}-T_{\text {frost_1 }}\right)}{\operatorname{In}\left(r_{1} / r_{c}\right)}-h_{c} \pi\left(\left(\frac{r_{2}+r_{1}}{2}\right)^{2}-\left(\frac{r_{1}+r_{c}}{2}\right)^{2}\right)\left(T_{\text {frost_1 }}-T_{\text {amb }}\right)- \\
& k_{\text {frost }} 2 \pi \frac{\Delta x}{2} \frac{\left(T_{\text {frost_1 }}-T_{\text {frost_2 }}\right)}{\operatorname{In}\left(r_{2} / r_{1}\right)}-\dot{\mathrm{Q}}_{\text {evap }}+ \\
& {\left[2 \pi\left(\left(\frac{r_{2}+r_{1}}{2}\right)^{2}-\left(\frac{r_{1}+r_{c}}{2}\right)^{2}\right) \frac{\left(k_{\text {fin }}+k_{\text {frost }}\right)}{\left(k_{\text {frost }} t_{\text {fin }}+2 k_{\text {fin }} t_{\text {frost }}\right)}\left(T_{1}-T_{\text {frost_1 }}\right)\right], }
\end{aligned}
$$

where $\quad\left[\dot{\mathrm{Q}}_{\text {evap }}=g_{m} \pi\left(\frac{r_{2}+r_{1}}{2}\right)^{2}-\left(\frac{r_{1}-r_{c}}{2}\right)^{2}\left(m_{\mathrm{H}_{2} \mathrm{O}, \mathrm{s}}-m_{\mathrm{H}_{2} \mathrm{O}, \mathrm{e}}\right) h_{i g}\right]$.

Equation 4 is the latent energy transfer rate due to evaporation, where $\mathrm{m}_{\mathrm{H} 2 \mathrm{O}, \mathrm{s}}$ represents the mass fraction of water vapor at the surface of the frost and $\mathrm{m}_{\mathrm{H} 2 \mathrm{O}, \mathrm{e}}$ represents the mass fraction of water vapor in the surrounding air. Both mass fraction values can be determined from mass transfer book by Mills [17]. The energy balance at different radial locations in the frost will be similar. However, this time the energy storage term cannot be simplified any further since the frost control volume undergoes a phase change from ice to liquid during the defrost process. The discrete equations are solved using the Engineering Equation Solver, or EES [18].

One assumption for this model is that the thermal resistance of frost remains constant over time. However, when the frost melts, it is replaced by water or a layer 
of air, which cause a change in the thermal resistance. It is difficult to model the change in thermal resistance under these conditions because of the uncertainty in determining the substance/phase within the layer as a function of time. This approach was taken in order to develop a reasonably accurate yet somewhat simple model. 


\section{Pressure Drop Model}

As frost accumulates on the evaporator, the air side pressure drop will increase. As a result, the heat transfer from the system will decrease due to the lower air flow rate. It was postulated that the presence of frost could be detected by measuring the pressure drop across the coil. Therefore, a model was developed to predict the air-side pressure drop with and without frost.

The pressure drop across the coil is determined by combining the pressure drop due to the tubes and the pressure drop due to the fins

$$
\Delta \mathrm{P}_{\text {coil }}=\Delta \mathrm{P}_{\text {fin }}+\Delta \mathrm{P}_{\text {tube }}
$$

or

$$
\Delta \mathrm{P}_{\text {coil }}=f_{\text {fin }} \frac{A_{\text {fin }}}{A_{c}} \frac{G_{c}^{2}}{2 \rho}+f_{\text {tube }} \frac{A_{\text {tube }}}{A_{c, t}} \frac{G_{c}^{2}}{2 \rho}
$$

Where $G_{c}$ is the maximum mass velocity, $A_{c}$ is the minimum flow area, $A_{c, t}$ is minimum flow area for the tube bank only, and $\mathrm{A}_{\text {fin }}$ and $\mathrm{A}_{\text {tube }}$ are the surface areas for the fins and tubes respectively. 


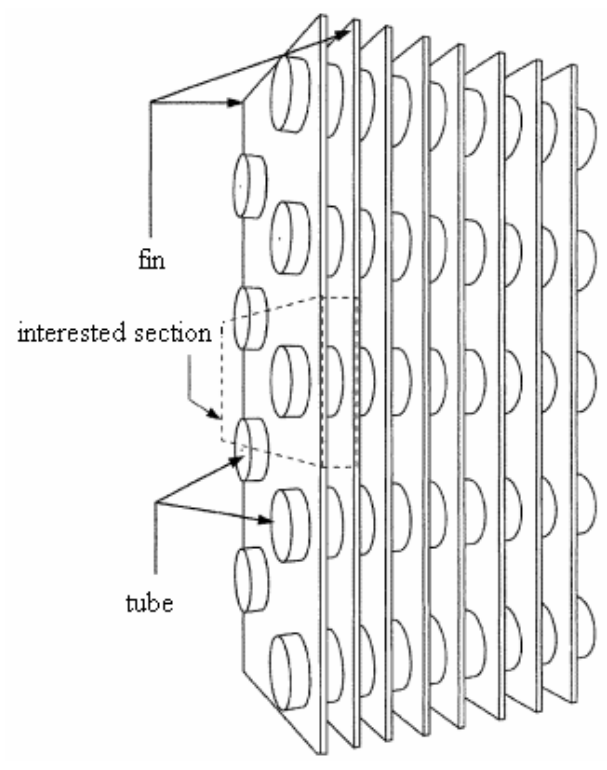

(a)

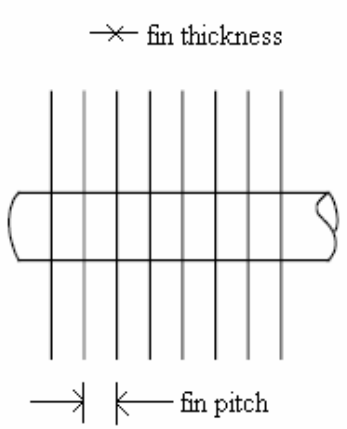

(b)

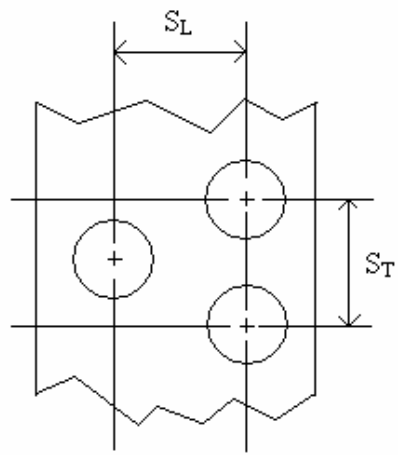

(c)

Figure 5: Isometric view with staggered arrangement (a), front view that parallel the air-flow (b), side view which perpendicular to the air-flow (c) of the evaporator

This model neglects the pressure losses at the inlet and outlet of the evaporator. The friction factor for the fin is approximated by an empirical correlation equation [19]:

$$
f_{\text {fin }}=0.508 \mathrm{Re}_{\mathrm{D}}^{-0.521}\left(\frac{\mathrm{S}_{\mathrm{T}}}{\mathrm{D}}\right)^{1.138}
$$

where

$$
\operatorname{Re}_{\mathrm{D}}=\frac{\mathrm{G}_{\mathrm{c}} \mathrm{D}}{\mu},
$$


$\mathrm{S}_{\mathrm{T}}$ is defined as the transverse pitch or tube spacing normal to the air flow (shown in Figure $5 \mathrm{c}$ ), and $\mu$ is defined as the viscosity of air. The Reynolds number is based on the tube outer diameter and the maximum fluid velocity occurring within the tube bank. The maximum velocity is defined as

$$
V_{\max }=\frac{S_{T}(\text { fin pitch }- \text { fin thickness })}{\left(S_{T}-D_{\text {tube }}\right)(\text { fin pitch }- \text { fin thickness })} V .
$$

Some researchers use the friction factor for the tube based on the Zukauskas correlation for both normal and staggered banks of tubes. For this pressure drop model, the friction factor for the tube can be approximate from Figure 6 [20],

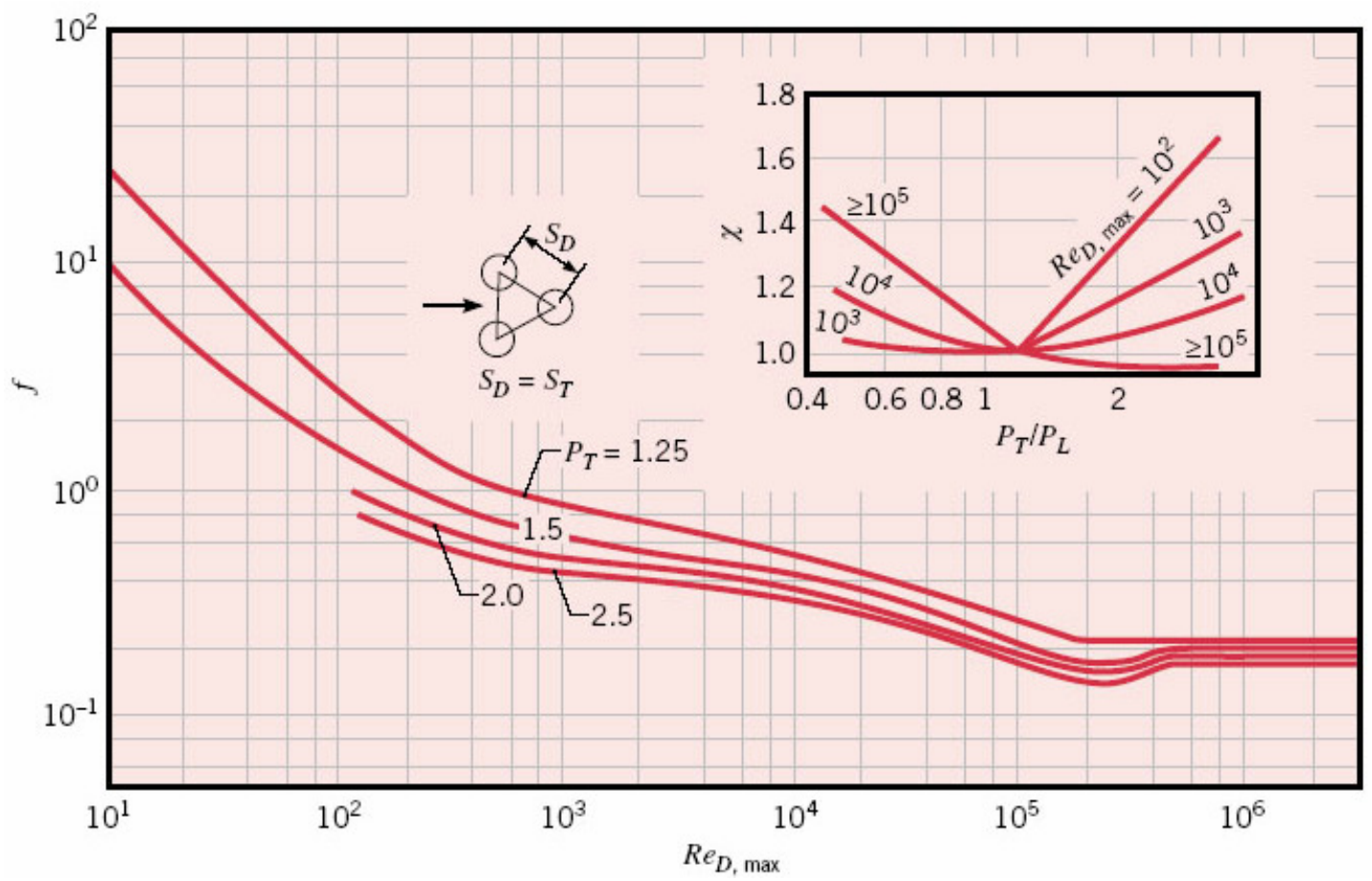

Figure 6: Friction factor $f_{\text {tube }}$ for staggered tube bundle arrangement [20] 
where $\mathrm{P}_{T}$ is defined as $\mathrm{S}_{\mathrm{T}} / \mathrm{D}$ which is the dimensionless transverse pitch.

The pressure drop for the coil with frost is modeled by assuming that the frost layer simply increases the fin thickness and the tube outer diameter. The frost layer is assumed to have uniform thickness and the increased roughness of the frost layer is neglected. 


\section{Testing}

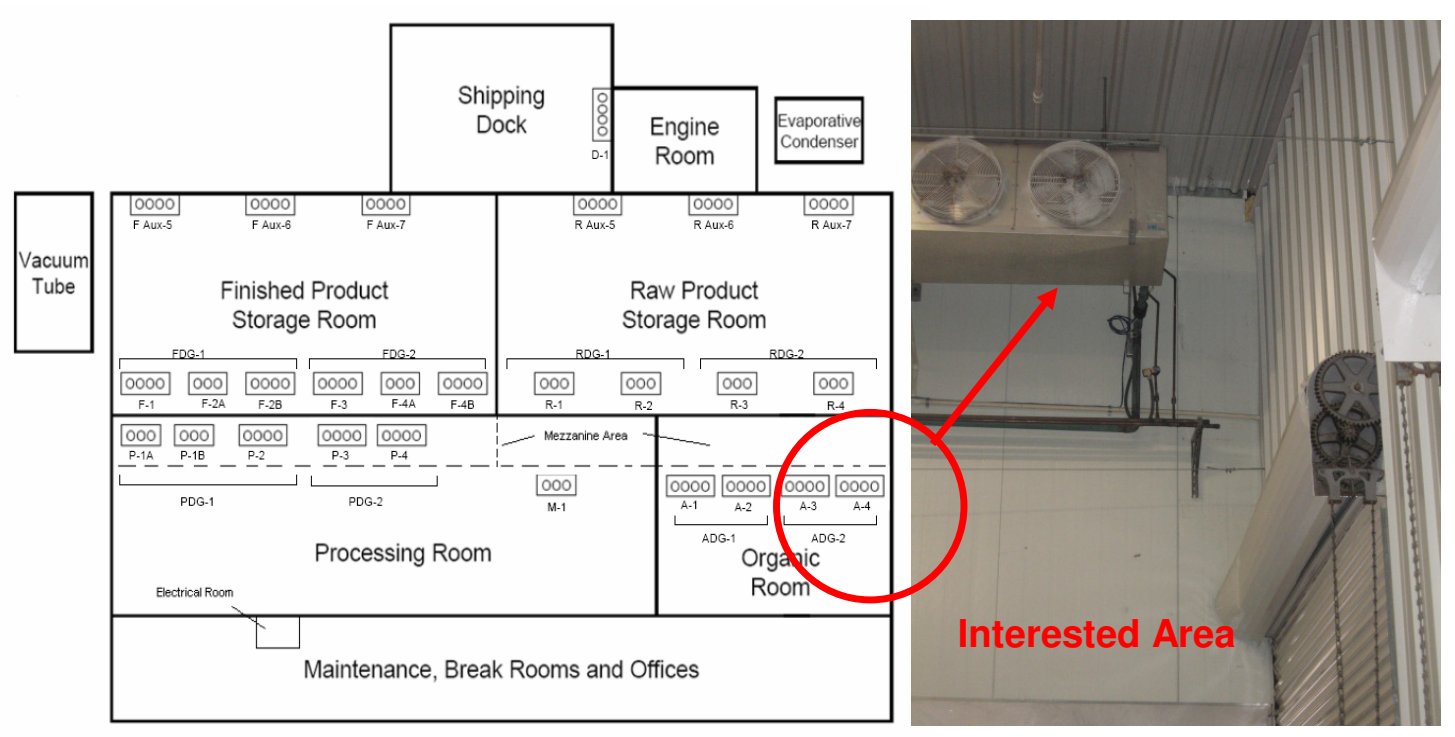

Figure 7: The evaporator inside the Organic Room that was tested

As mentioned previously, the evaporator coils in the organic room tend to accumulated more frost than the coils in the other rooms. This is because the evaporators are located near the automatic door that is frequently opened to bring product into the facility. The moisture from the outside air makes it more likely that frost will accumulate on the evaporators in this space. Therefore, one of the evaporators in the Organic room, shown in Figure 7, was chosen for testing. 


\section{Collecting Data}

\section{Opto system}

The Opto22 system is used as the main control system for the Classic Salads facility [21]. The following is the list of sensors connected to the Opto22 system:

- Zone temperature - air temperature measured at the inlet of the coil

- Zone suction temperature - refrigerant temperature measured at the outlet of the coil

- AU VFD SR - fan speed

- Zone coil temperature - temperature measured at the tube sheet on evaporator

- Discharge pressure - main system discharge pressure at the outlet of the condenser Two wire RTD are used to measure temperature for the Opto22 system.

\section{HOBO System}

The coil was instrumented with additional sensors and the output from these sensors was recorded with a HOBO U12-006 model data logger, which is shown in Figure 8 . The HOBO data logger has 4 channels and can record up to 43,000 measurements [22]. The coil was instrumented with 3 temperature sensors and 1 pressure transducer. Data was logged from November 9, 2008 at 8 am to November 15, 2008 at $7 \mathrm{pm}$. The temperature sensors were two wire RTD. Each RTD utilized a 
separate circuit box to produce 4-20 mA current signal. The specifications for the temperature sensors and the pressure transducer are shown in Table 1 and Table 2, respectively.

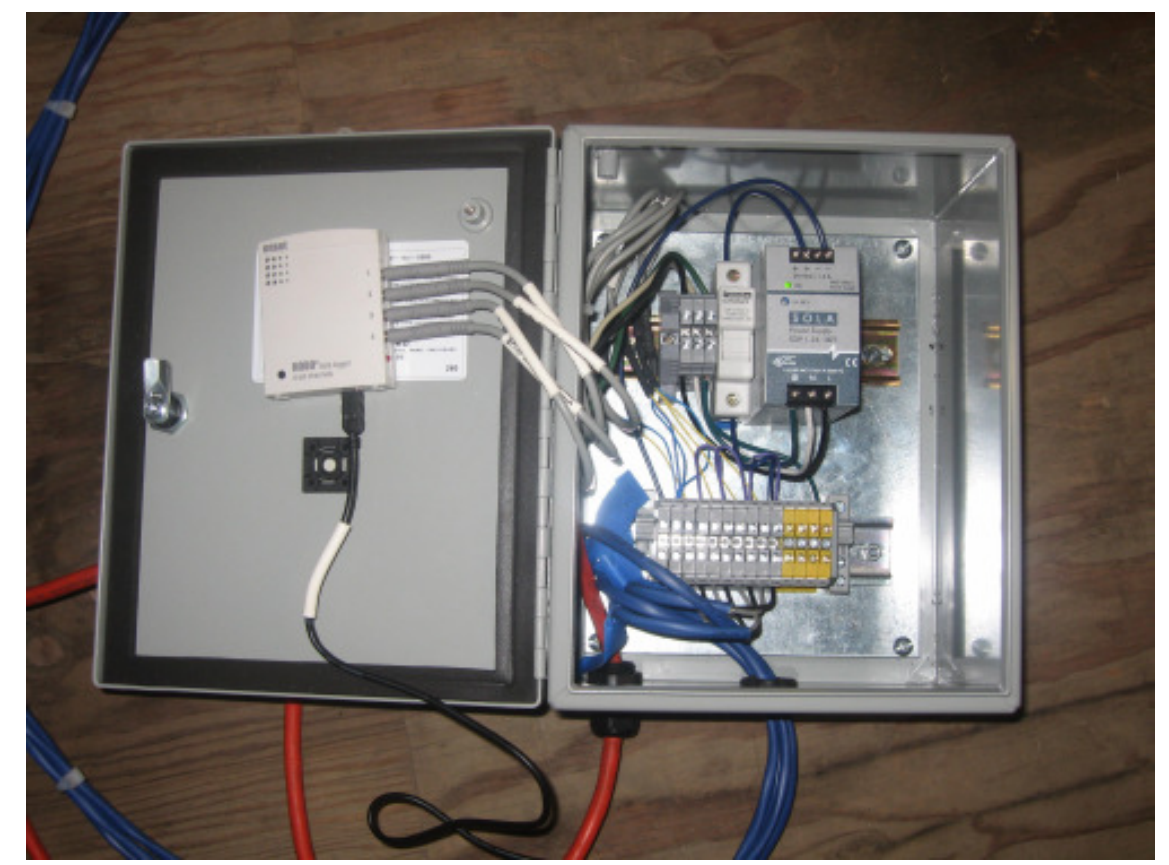

Figure 8: HOBO data recorder for temperature sensors and pressure transducer

The pressure transducer range is unidirectional from 0 to $0.5 \mathrm{InchWg}$. The output is the same as temperature sensor's output, which is 4-20 mA. The high pressure port was exposed to the ambient air while the lower pressure port was connected to a tube with the exposed end placed between the coil and the fan. This arrangement effectively measures the static pressure difference across the coil. 
Table 1: Temperature probe specifications for $\mathrm{HOBO}$ and Opto systems

\begin{tabular}{|c|c|c|}
\hline & $\mathrm{HOBO}$ & Opto \\
\hline Input Temperature Range & $-30^{\circ} \mathrm{C}$ to $130{ }^{\circ} \mathrm{F}$ & $-40^{\circ} \mathrm{C}$ to $100^{\circ} \mathrm{C}$ \\
\hline Output & $\begin{array}{c}4 \mathrm{~mA} @-30{ }^{\circ} \mathrm{F} \\
20 \mathrm{~mA} @ 130{ }^{\circ} \mathrm{F}\end{array}$ & $\begin{array}{l}233 \mu \mathrm{A} @-40{ }^{\circ} \mathrm{C} \\
373 \mu \mathrm{A} @ 100{ }^{\circ} \mathrm{C}\end{array}$ \\
\hline Input Response Time & $63.2 \%$ at 95 seconds & $63.2 \%$ at 150 seconds \\
\hline Output Accuracy & $\pm 0.3{ }^{\circ} \mathrm{C} @ 0{ }^{\circ} \mathrm{C}$ & $\pm 0.5^{\circ} \mathrm{C} @ 25^{\circ} \mathrm{C}$ \\
\hline Thermal Time Constant & 1.58 minutes & 2.5 minutes typical (still air) \\
\hline Dimensions & $\begin{array}{c}\text { Cylinder tip: 1" }(2.54 \mathrm{~cm}) \mathrm{L}, \\
0.25 "(0.635 \mathrm{~cm}) \mathrm{D}\end{array}$ & $\begin{array}{c}\text { Cylinder tip: } 0.70 "(1.78 \mathrm{~cm}) \mathrm{L}, \\
0.375^{\prime \prime}(0.95 \mathrm{~cm}) \mathrm{D}\end{array}$ \\
\hline
\end{tabular}

Table 2: Pressure transducer specifications

\begin{tabular}{|c|c|}
\hline \multicolumn{2}{|c|}{ Model: 264 0R5WD } \\
\hline Range & $\begin{array}{c}0 \text { to } 0.5 \\
\text { InchWg }\end{array}$ \\
\hline Output & $4-20 \mathrm{~mA}$ \\
\hline Circuit & 2 wires \\
\hline $\begin{array}{c}\text { Operating } \\
\text { Temperature }\end{array}$ & 0 to $175^{\circ} \mathrm{F}$ \\
\hline
\end{tabular}

All the data from the Opto22 system is recorded every 2.3 seconds. As for the HOBO system, all the temperature and pressure drop data were recorded at one minute intervals due to the limited storage capability of the logger.

\section{Time Constant}

The temperature sensors used by the HOBO data logger and the Opto22 system have different diameter size and consequently the response time will be different. There was no available information about thermal time constant for the 
RTD used by the HOBO data logger. Therefore, an experiment was conducted to determine the response time.

The experiment was conducted in the thermal science lab at Cal Poly. A computer data acquisition system using Labview was used to record the data. The RTD was placed inside a freezer until the temperature reading was constant. The RTD was then removed from the freezer and held in air. The resulting temperature data is shown in Figure 9.

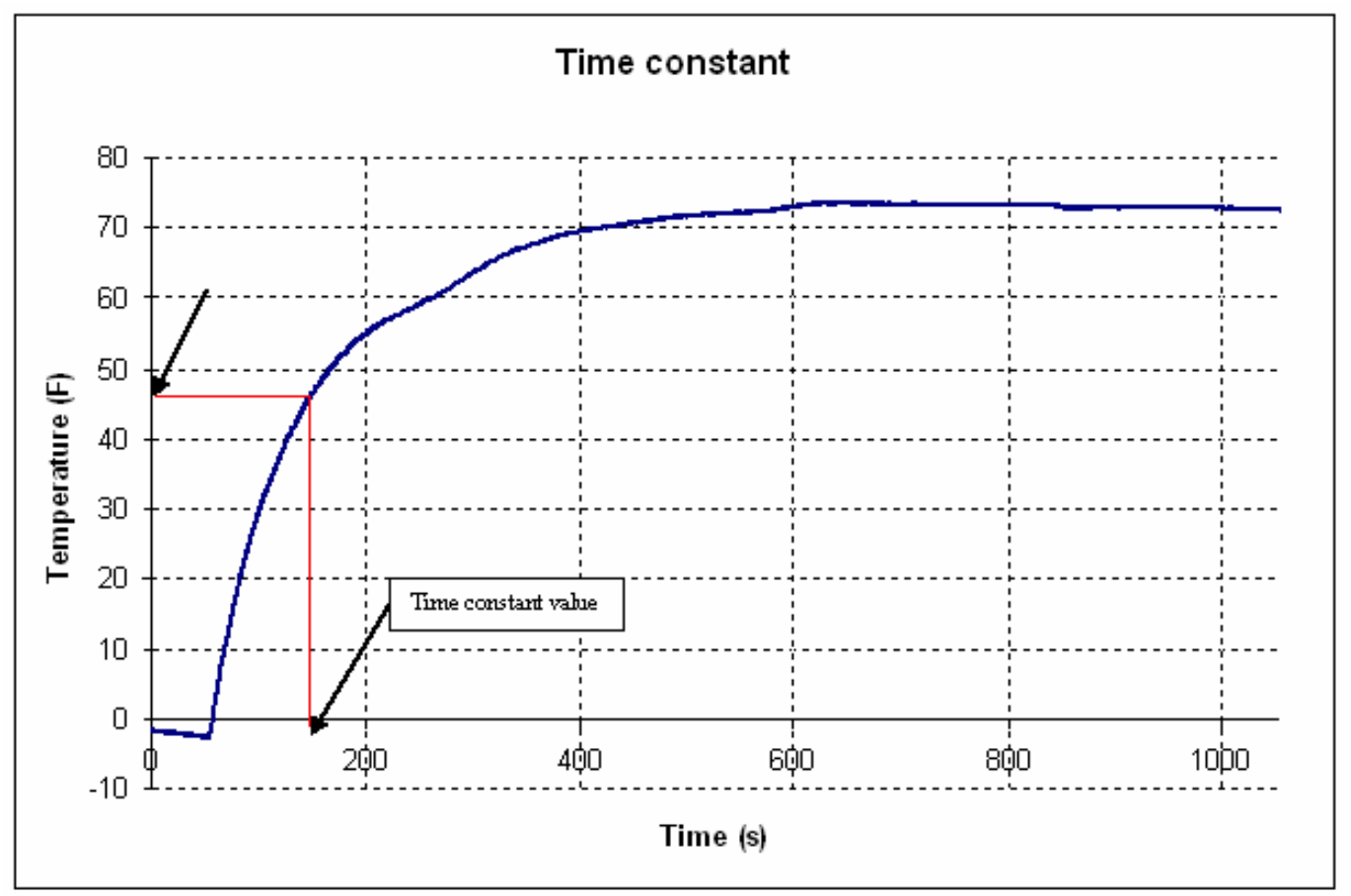

Figure 9: Temperature data to determine sensor time constant

The time constant is the time it takes the sensor to achieve $63.2 \%$ of the temperature change or $0.632 *(73+2)^{\circ} \mathrm{F}$, which is $47.4^{\circ} \mathrm{F}$ for this experiment. From 
Figure 9, the time constant is determined to be approximately 95 seconds. The first 53 seconds is when the RTD is still inside the refrigerator at a temperature of approximately $-2^{\circ} \mathrm{F}$. After that, the RTD is taken out from the refrigerator to the ambient air, which is at approximately $73^{\circ} \mathrm{F}$. The time to reach steady state is approximately 600 seconds. This is approximately $37 \%$ faster than the response time of the temperature sensor used by the Opto22 system (see Table 1).

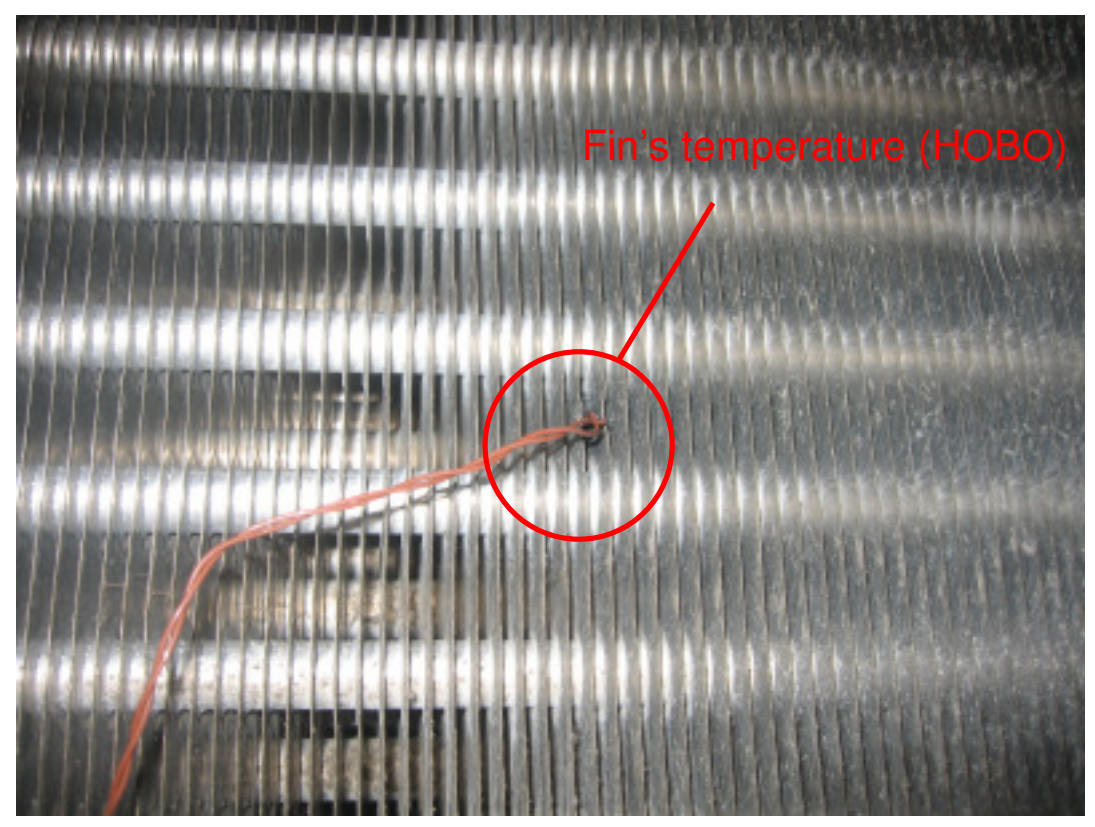

Figure 10: Location of the RTD inserted between two fins 


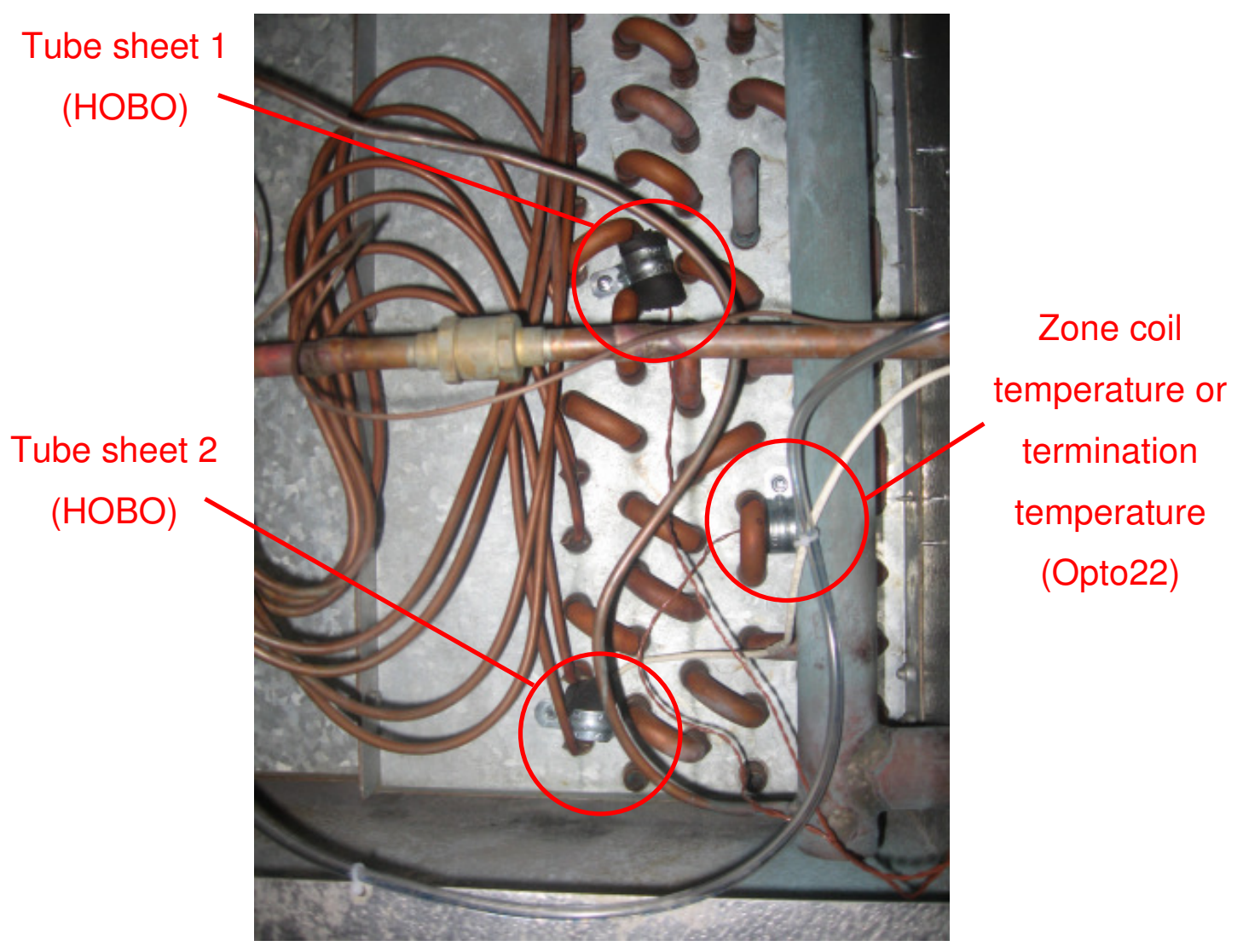

Figure 11: Locations of RTD on evaporator tube sheet 


\section{Results}

\section{Temperature}

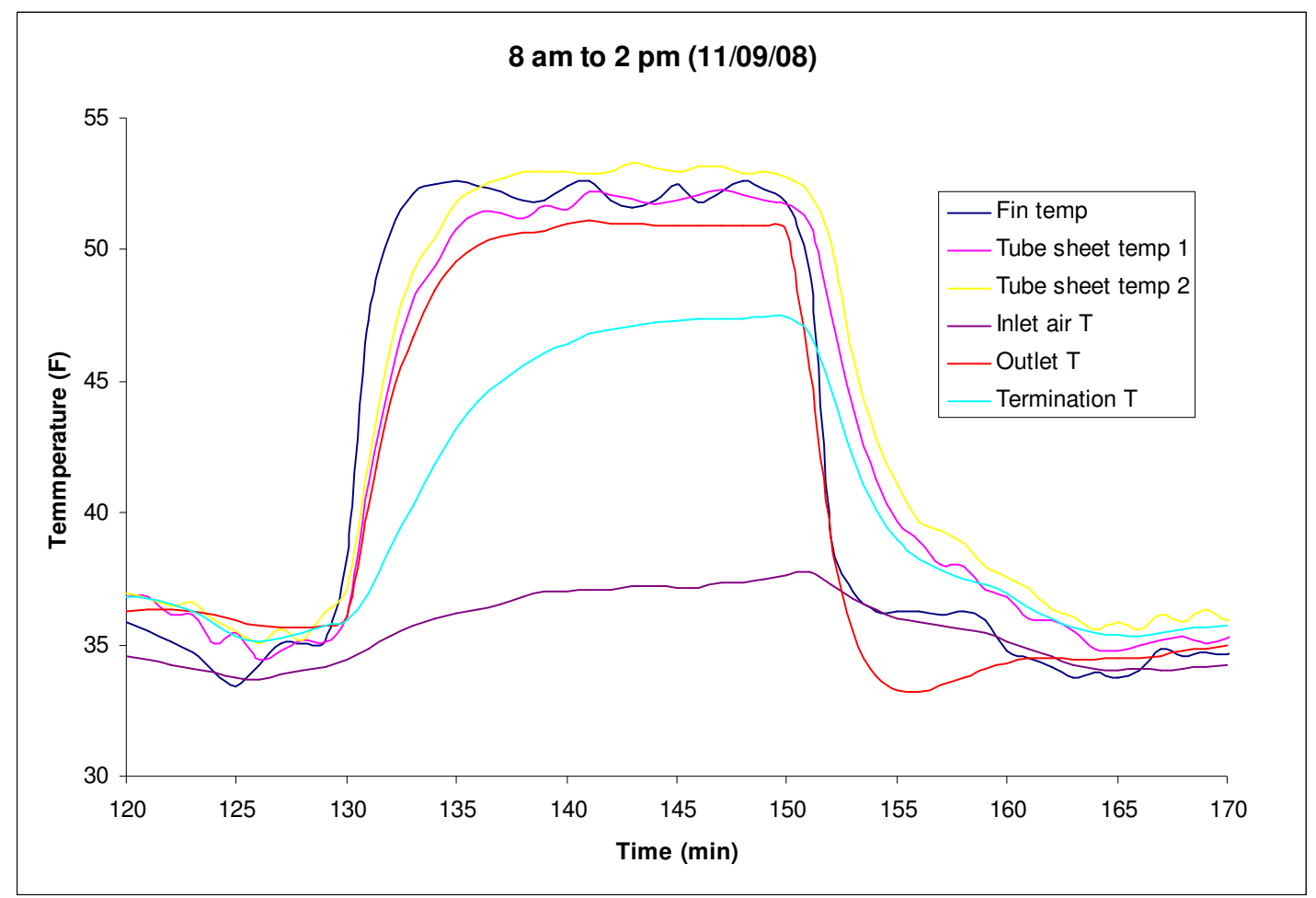

Figure 12: Temperature data from Opto22 and HOBO systems during the defrost cycle

A sample of the measured temperatures during a defrost cycle is shown in Figure 12. From the HOBO system, Fin temp represents the temperature reading between two fins, as shown in Figure 10. Tube sheet temp 1 and Tube sheet temp 2 are the temperature sensors attached at the middle and at the bottom of the tube sheet, as shown in Figure 11. From the Opto22 system, the inlet air temperature refers to the air temperature at the inlet to the coil. The outlet temperature is the 
sensor attached to the suction line of the coil. The termination temperature is attached on the tube sheet which is shown in Figure 11.

Note that none of the temperature readings are below $32^{\circ} \mathrm{F}$ which indicates that there might not be much frost accumulated. This result is representative for data collected during the entire week. The temperature readings from the tube sheet seem to be more stable in comparison to the reading for the sensor between the fins. This may be due to the insulation that covering around the temperature sensors on the tube sheet, while the temperature sensor attached between the fins is exposed to the surrounding air.

The termination temperature sensor (Opto22 system) attached to the tube sheet responded slowly compared to the HOBO temperature sensors that were also attached to the tube sheet. The Opto22 sensor took more than 10 minutes to reach steady state while it took about 5 minutes for the HOBO sensors. Also, the Opto22 temperature measurement is approximately 5 degrees lower in comparison to the measurements made by the HOBO sensors. The reason for these different values is unknown.

The temperature sensor attached between the fins appeared to have a quick response time compared to the other sensors. This indicates that temperature sensor between the fins should yield a more accurate representation of the temperature of 
the coil surface where the frost accumulates. The experimental temperature data was compared to the results from the model described previously.

The time has been adjusted between the two, so the temperature model and the experimental data begin at the same time when the defrost cycle has been initiated. The temperature sensor has a finite response time and so the slope is not as steep in comparison to the thermal model. Once that consideration has been taken into account, there appears to be good agreement between the data and the results from the model for a frost thickness layer of $0.25 \mathrm{~mm}$ or less.

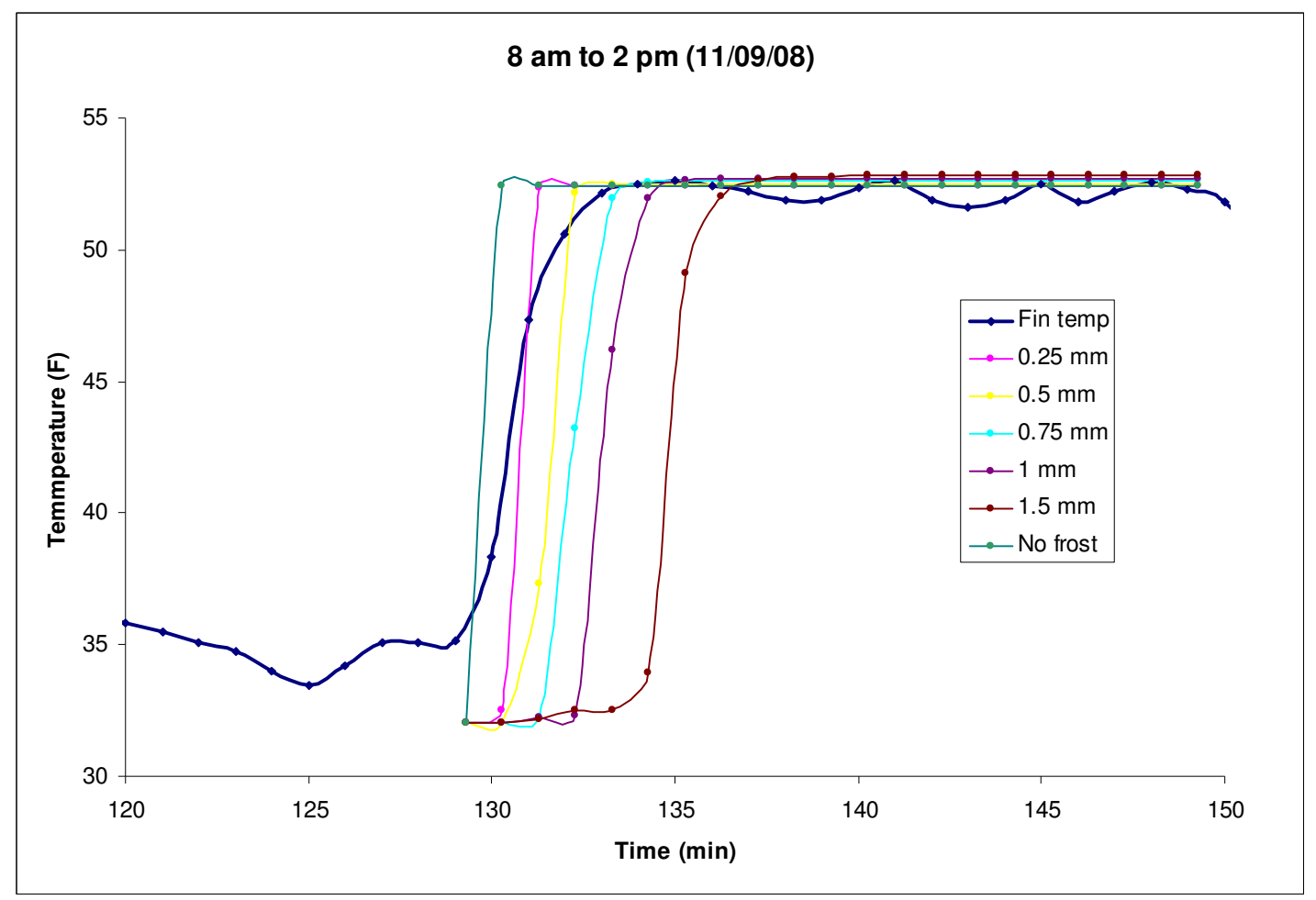

Figure 13: Comparison between temperature data and model 
Figure 13 shows measured data for the temperature of the fin (Fin temp), along with results from the finite difference model for frost layers with different thicknesses. The result for node 5 of the model (midway between tubes, see Figure 4b) was used for the comparison. For all the nodes, the initial temperature starts at the freezing point of water but experimentally none of the fin's temperature readings reached $32{ }^{\circ} \mathrm{F}$. This was done so the accumulation of frost could be modeled.

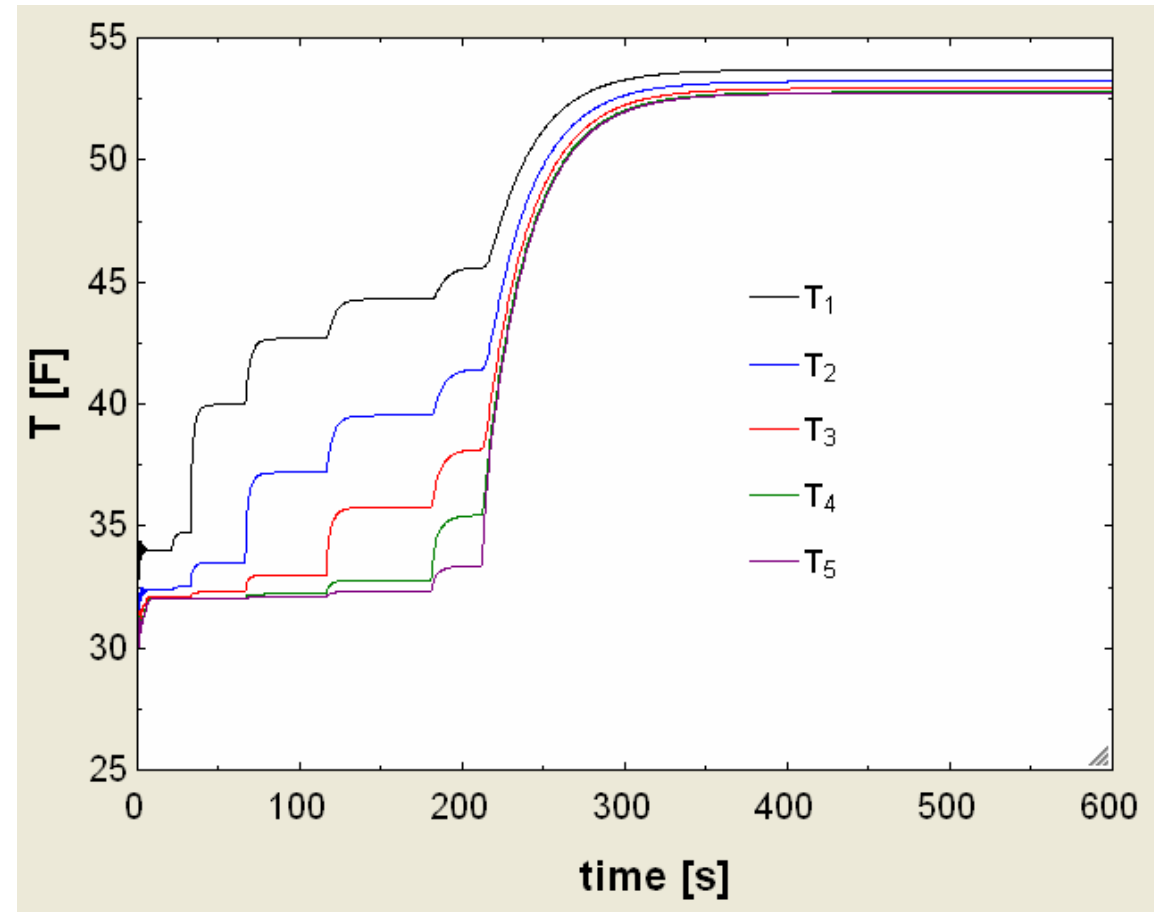

Figure 14: Fin temperature during hot gas defrost with $1 \mathrm{~mm}$ of frost 


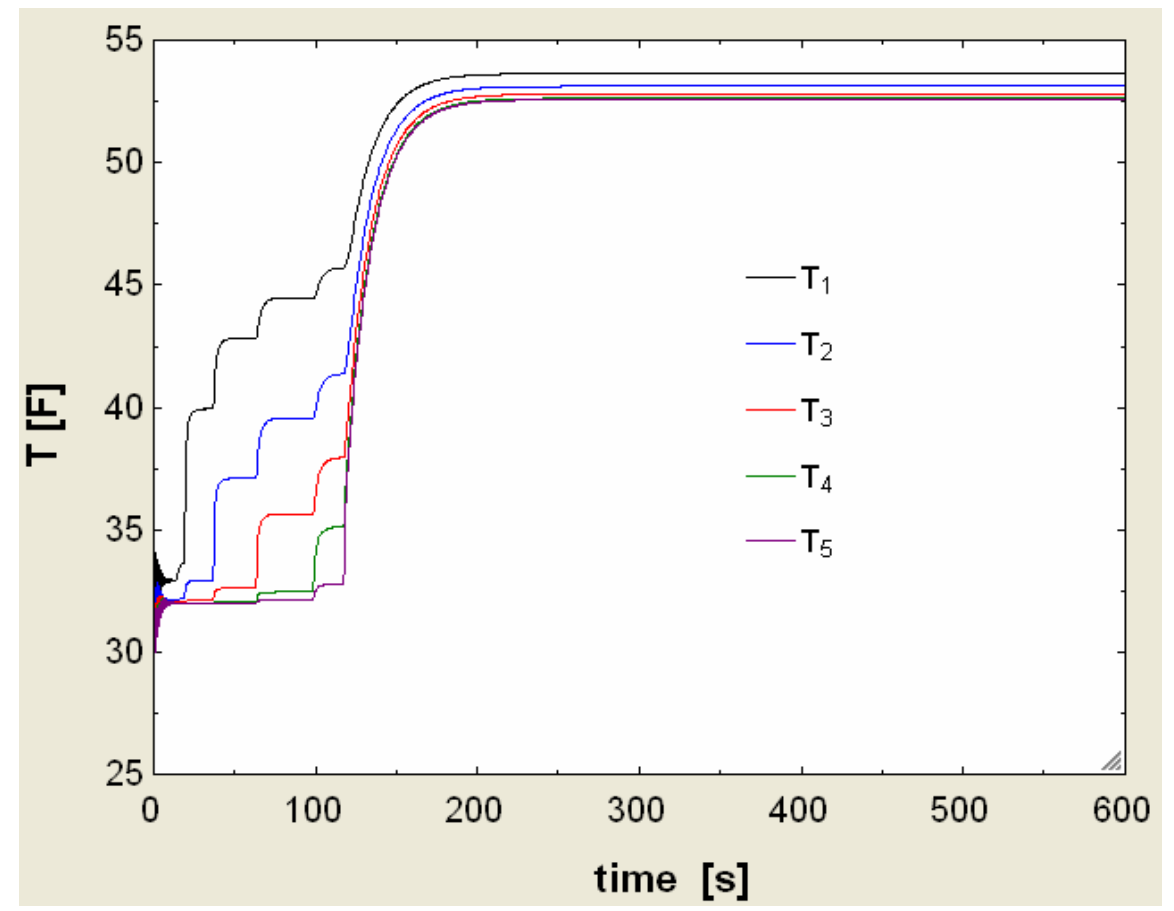

Figure 15: Fin temperature during hot gas defrost with $0.5 \mathrm{~mm}$ of frost

Figures 14 and 15 show the results of the nodal temperatures during a defrost simulation. The initial temperature for all nodes is $32 \mathrm{~F}$. Figure 14 is for a frost layer of $1 \mathrm{~mm}$ and Figure 15 is for a frost layer of $0.5 \mathrm{~mm}$. The subscript for each temperature is defined in Figure $4 \mathrm{~b}$ with the inner radius being 1 and the other radius being 5 . It takes approximately 250 seconds the temperatures to reach steady state with $0.5 \mathrm{~mm}$ of frost, while it takes about 400 seconds for the temperature to reach steady state with $1 \mathrm{~mm}$ of frost. 


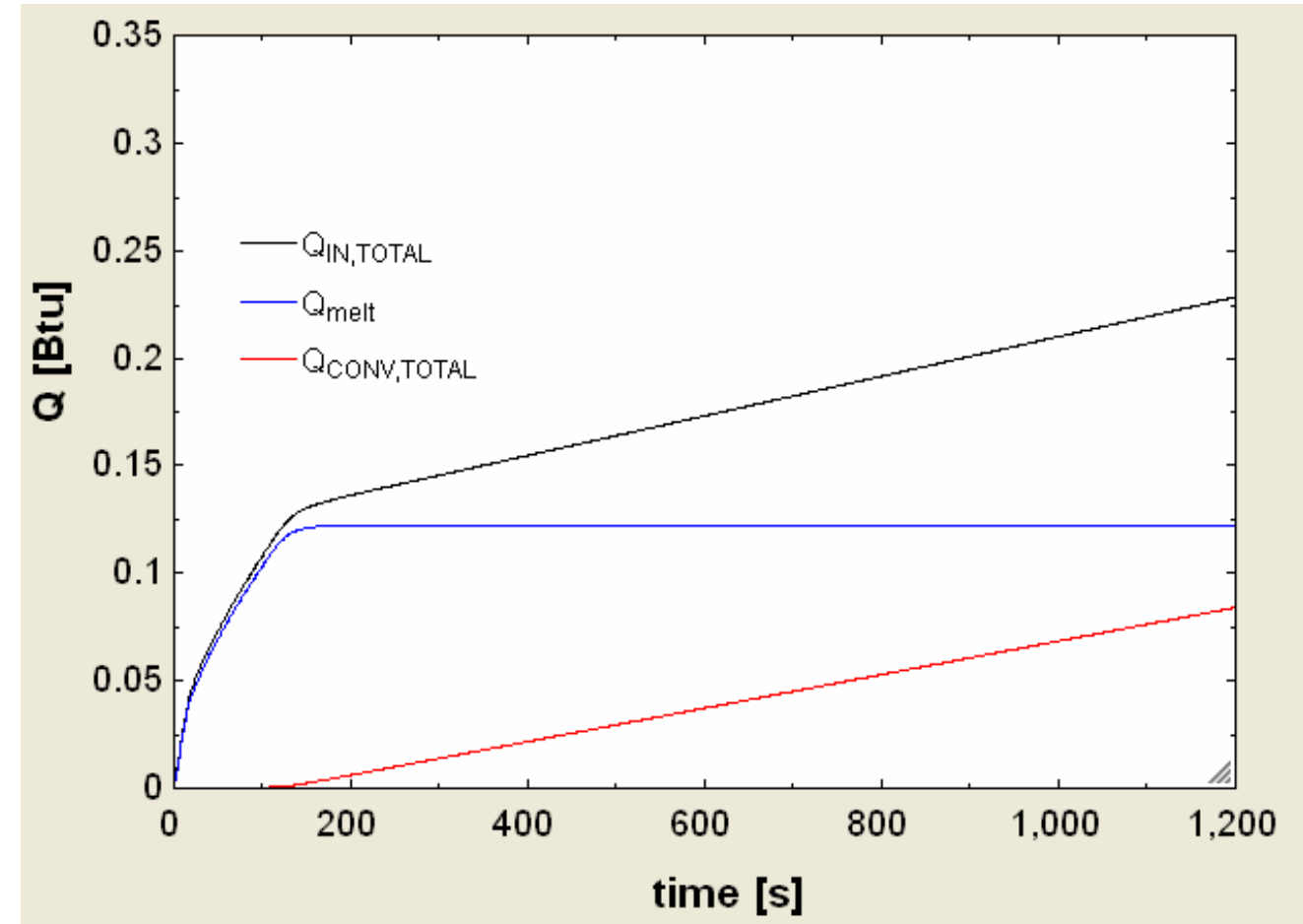

Figure 16: Heat transfer during hot gas defrost with $0.5 \mathrm{~mm}$ of frost

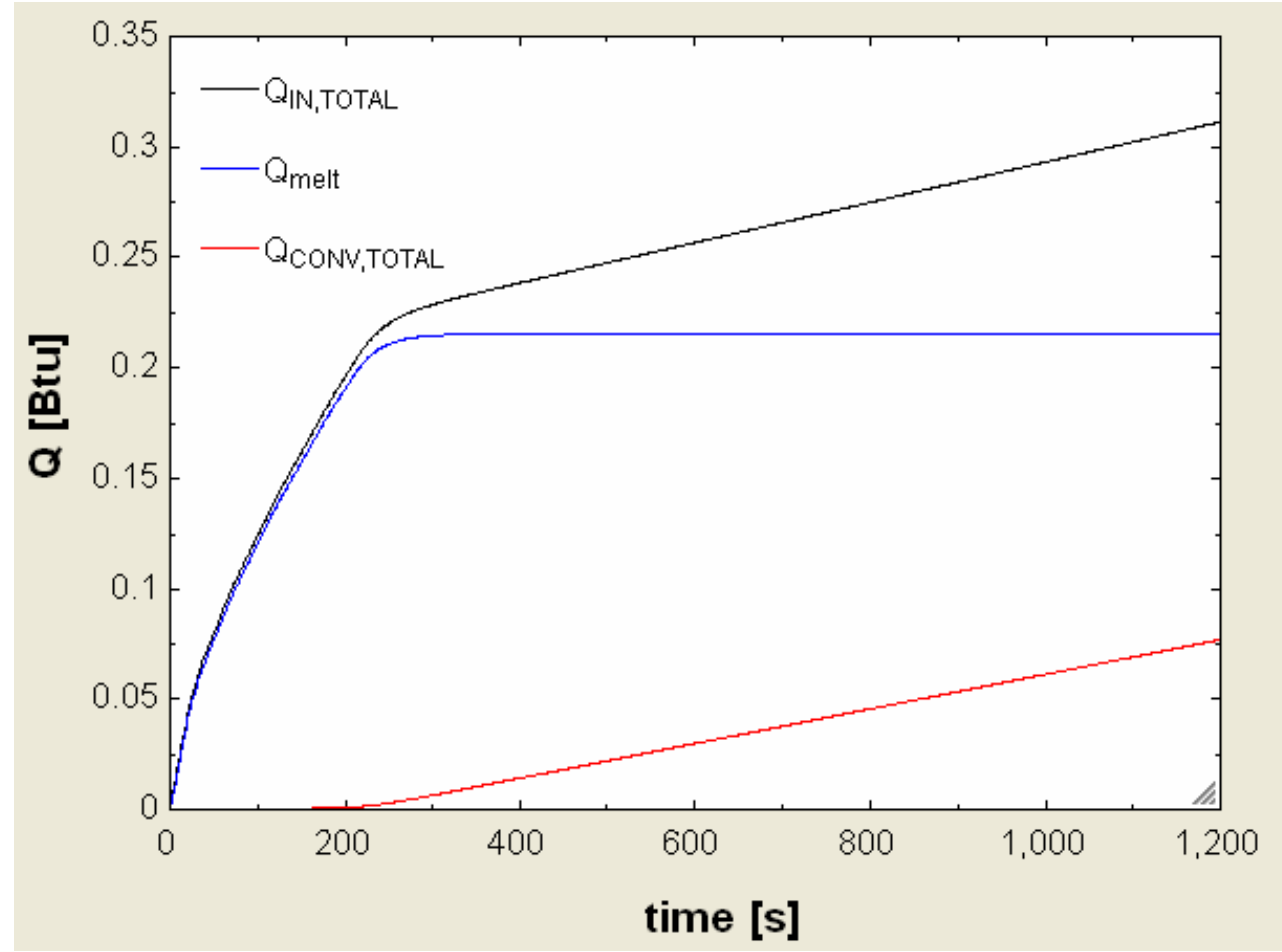

Figure 17: Heat transfer during hot gas defrost with $1 \mathrm{~mm}$ of frost 
Figures 16 and 17 show the resulting heat rates during a defrost simulation.

$\mathrm{Q}_{\text {in, total }}$ is defined as the total heat going into system from the hot gas. $\mathrm{Q}_{\text {conv, total }}$ is the heat lost due to convection and $\mathrm{Q}_{\text {melt }}$ is the heat required to melt the frost. The figures show the total energy integrated over time. The time to melt the frost can be observed from the figures by noting when $\mathrm{Q}_{\mathrm{melt}}$ becomes constant. After this point, heat from the hot gas is lost due to convection.

\section{Pressure drop}

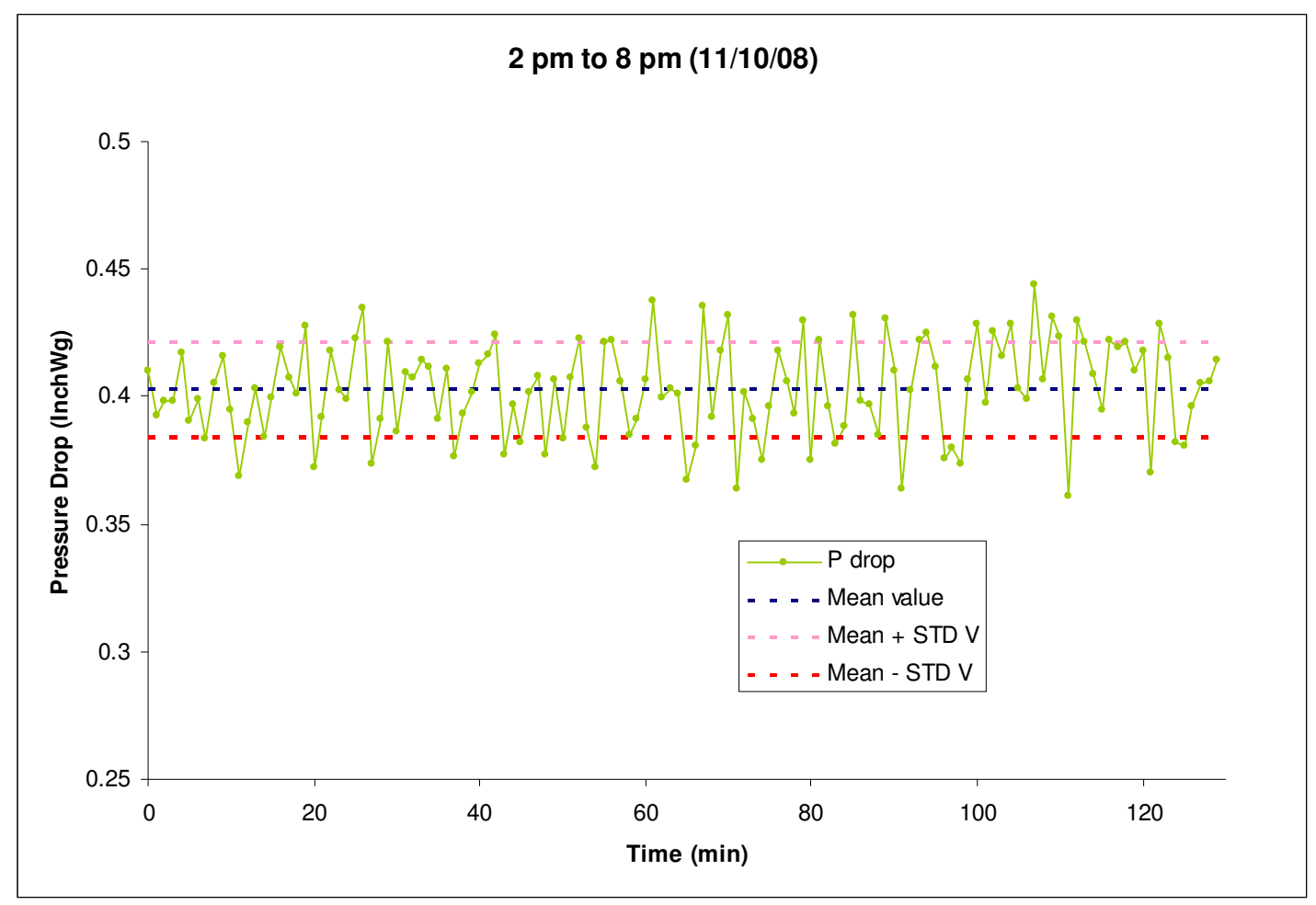

Figure 18: Sample of coil pressure drop data 
Figure 18 shows the measured pressure drop as a function of time during normal operation. The mean value, of the pressure for the period shown in Figure 18 is $0.403 \mathrm{InchWg}$. The standard deviation of the readings is $0.019 \mathrm{InchWg}$. The data is a representative of the data collected for the entire week.

There is significant scatter in the data, which may indicate the pressure tap was not rigidly fixed. Regardless, there is no general trend of increasing pressure drop with time, which would indicate the buildup of frost on the coil.

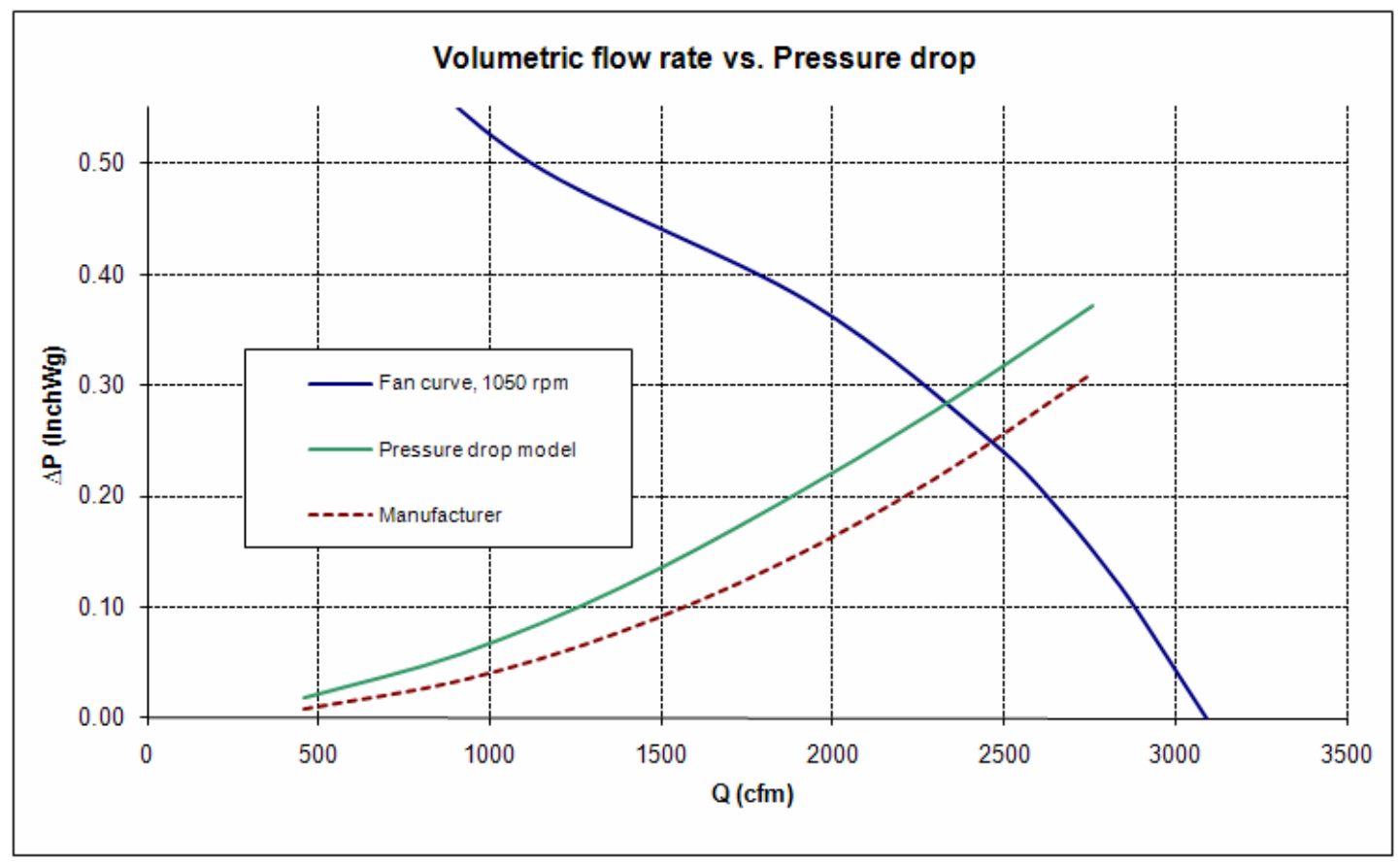

Figure 19: Pressure drop as a function of volumetric flow rate

Figure 19 shows system curves (different sources) and fan curve for the evaporator. The fan curve is based on data from the manufacturer (see Appendix A 
for more information). The "manufacturer" system curve is extrapolated from a single data point assuming $\Delta \mathrm{P} \alpha \mathrm{Q}^{2}$. The pressure drop as determined by the model is also shown over the range of flow rates.

Figure 19 shows reasonably good agreement between the manufacturer's data and the pressure drop model. The measured pressure drop exceeds the pressure drop from the manufacturer's data and the model. This may be due to foreign particles, such as cardboard fibers, which have buildup on the coil surface.

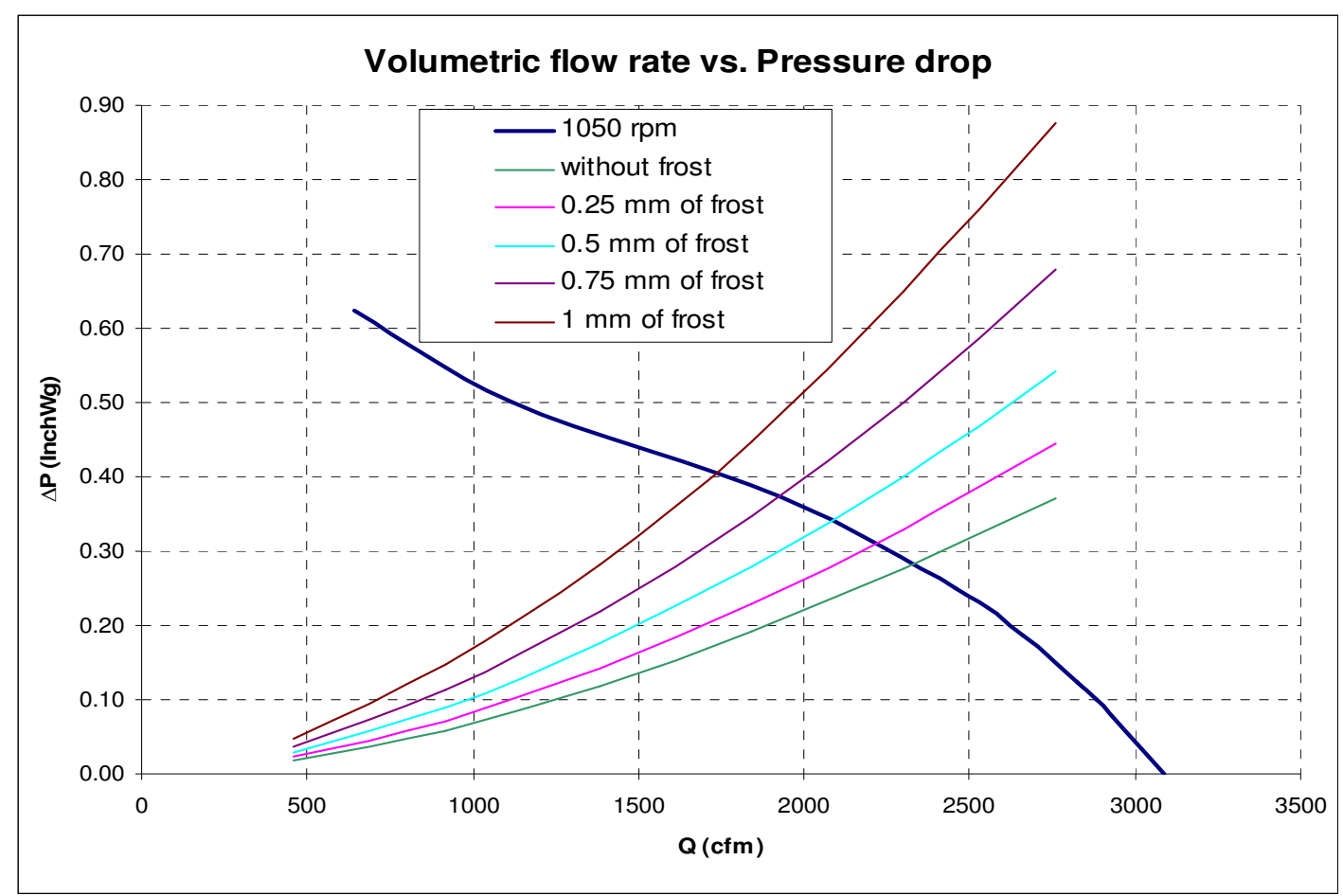

Figure 20: Pressure drop as a function of volumetric flow rate for different frost thicknesses 
Table 3: Evaporator coil flow rate and pressure drop as a function of frost thickness

\begin{tabular}{|c|c|c|}
\hline \multicolumn{3}{|c|}{ Evaporator's operating point } \\
\hline Frost $(\mathrm{mm})$ & $\mathrm{Q}(\mathrm{cfm})$ & $\Delta \mathrm{P}($ InchWg $)$ \\
\hline 1 & 1,740 & 0.408 \\
\hline 0.75 & 1,930 & 0.378 \\
\hline 0.5 & 2,090 & 0.343 \\
\hline 0.25 & 2,220 & 0.315 \\
\hline 0 & 2,330 & 0.282 \\
\hline
\end{tabular}

Figure 20 and Table 3 show the results from the pressure drop model for varying frost thicknesses. The results show that the volumetric flow rate decreases and the pressure drop increases as there is more frost accumulation on the coil. Table 3 shows that the pressure drop increases by approximately 0.03 InchWg for each increment of $0.25 \mathrm{~mm}$ of frost.

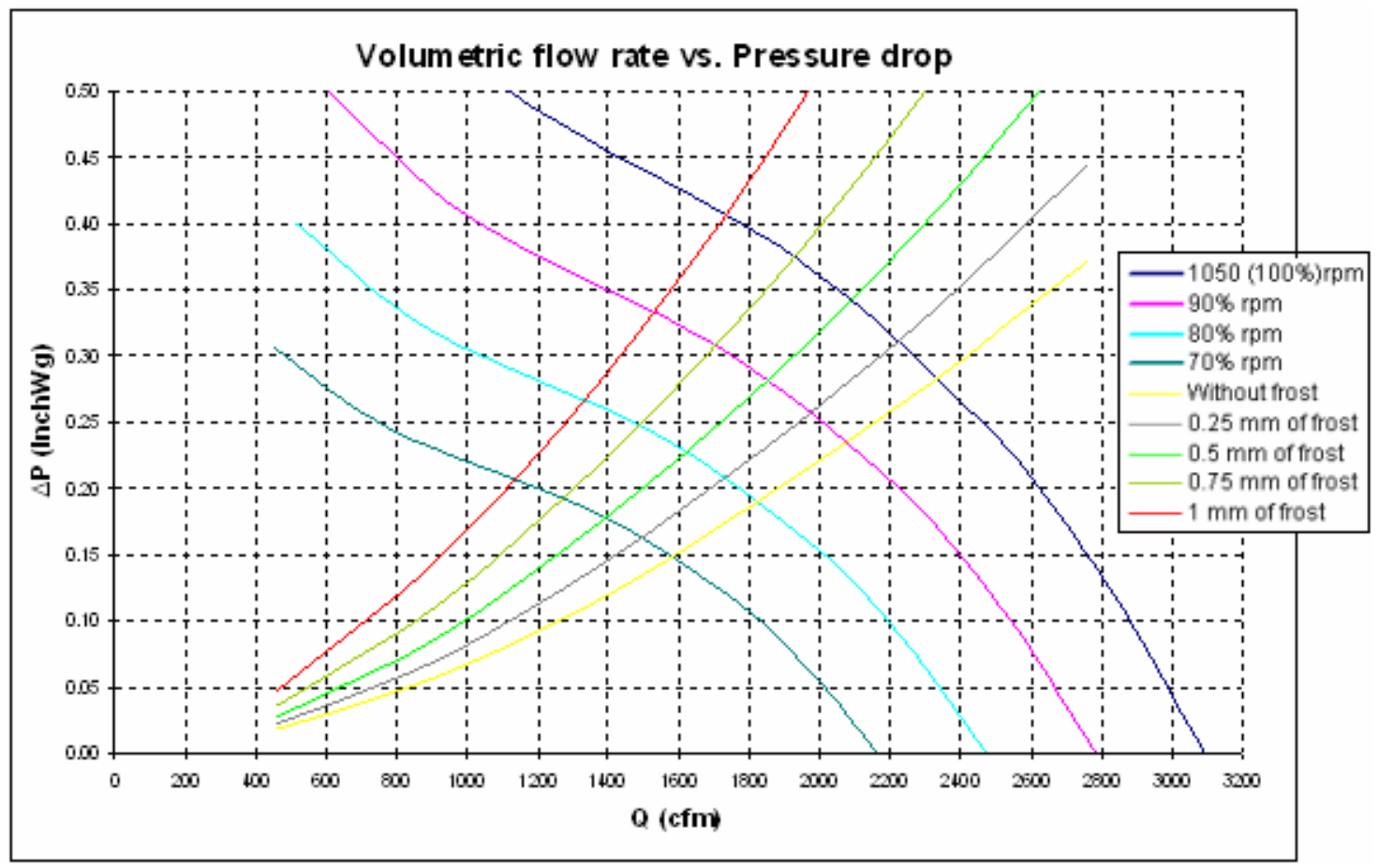

Figure 21: Pressure drop as a function of volumetric flow rate for different frost thicknesses and different fan speeds 
Figure 21 shows the same set of system curves from Figure 20 along with a set of fan curves at speeds varying from $70 \%$ to $100 \%$ of full speed (1050 rpm).The pressure drop will increase from 0.282 InchWg (dry coil) to 0.408 InchWg with 1 $\mathrm{mm}$ of frost when the system is operated at $100 \%$ fan speed. If the system operates at $70 \%$ of the fan speed $(735 \mathrm{rpm})$, then the pressure drop will increase from 0.147 InchWg (dry coil) to 0.205 InchWg with $1 \mathrm{~mm}$ of frost. This shows that as the fan speed decreases the difference in the pressure drop will also decrease. Therefore, it will be harder to detect the amount of frost on the coil using a pressure sensor when the system operates at lower fan speed.

\section{Efficiency and Cost}

The defrost efficiency is defined as

$$
\eta_{\text {defrost }}=\frac{\mathrm{Q}_{\text {melt }}}{\mathrm{Q}_{\text {total }}}
$$

Where $\mathrm{Q}_{\text {melt }}$ is total heat required to warm and melt the frost on the coil and $\mathrm{Q}_{\text {total }}$ is the total heat transfer to the coil during the defrost. A defrost efficiency closer to 1 indicates that a majority of the heat is used to melt the frost. 


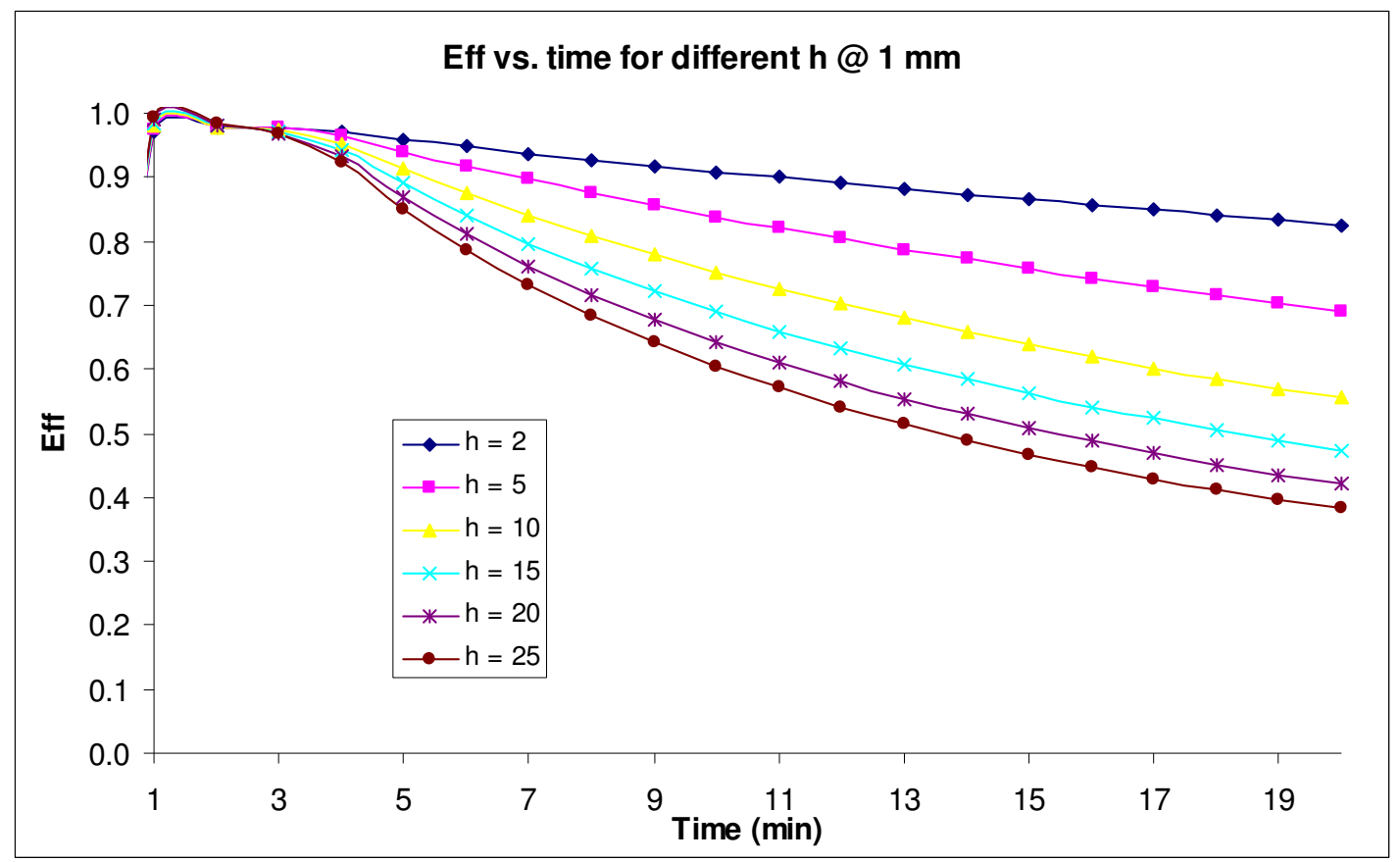

Figure 22: Hot gas defrost efficiency as a function of defrost time for different frost thickness

Figure 22 shows the defrost efficiency as a function of time for varying frost thicknesses. The results were obtained from the thermal model. Figure 22 shows that the efficiency of the hot gas defrost decreases with increasing time. Also, the efficiency of the defrost decreases as the frost thickness decreases. These results make sense because initially most of the energy is used to melt the frost. After that, heat is transferred to the space by convection. A thinner frost layer will defrost more rapidly and the defrost efficiency will be lower for a fixed defrost time. As mentioned previously, the thermal resistance of the frost layer was not reduced as the frost melted. Therefore, the efficiency of the real system will be lower than what is shown in Figure 22. 
The work input for a defrost system is defined as

$$
\mathrm{W}_{\text {cycle }}=\frac{\mathrm{Q}_{i \mathrm{n}}}{\beta},
$$

where $\mathrm{Q}_{\text {in }}$ is the excess heat generated from the hot gas after the frost has melted and $\beta$ is the coefficient of performance of the refrigeration system. $\mathrm{Q}_{\mathrm{in}}$ can be expressed as: $\mathrm{Q}_{\text {total }}-\mathrm{Q}_{\text {melt }}$. After substituting $\mathrm{Q}_{\text {melt }}=\eta_{\text {defrost }} \mathrm{Q}_{\text {total }}$ from equation 11, the work input can now be expressed as

$$
\mathrm{W}_{\text {cycle }}=\frac{\mathrm{Q}_{\text {total }}\left(1-\eta_{\text {defrost }}\right)}{\beta} .
$$

Therefore, the cost for a defrost cycle is defined as:

$$
\operatorname{Cost}=\frac{\$}{\mathrm{kWh}}\left(\frac{\mathrm{Q}_{\text {total }}\left(1-\eta_{\text {defrost }}\right)}{\beta}\right)
$$

For sample calculation, the coefficient of performance is assumed to be 3 and the electricity cost is assumed to be $\$ 0.12$ per $\mathrm{kWh}$, based on 2009 Energy Information Administration data [23]. 


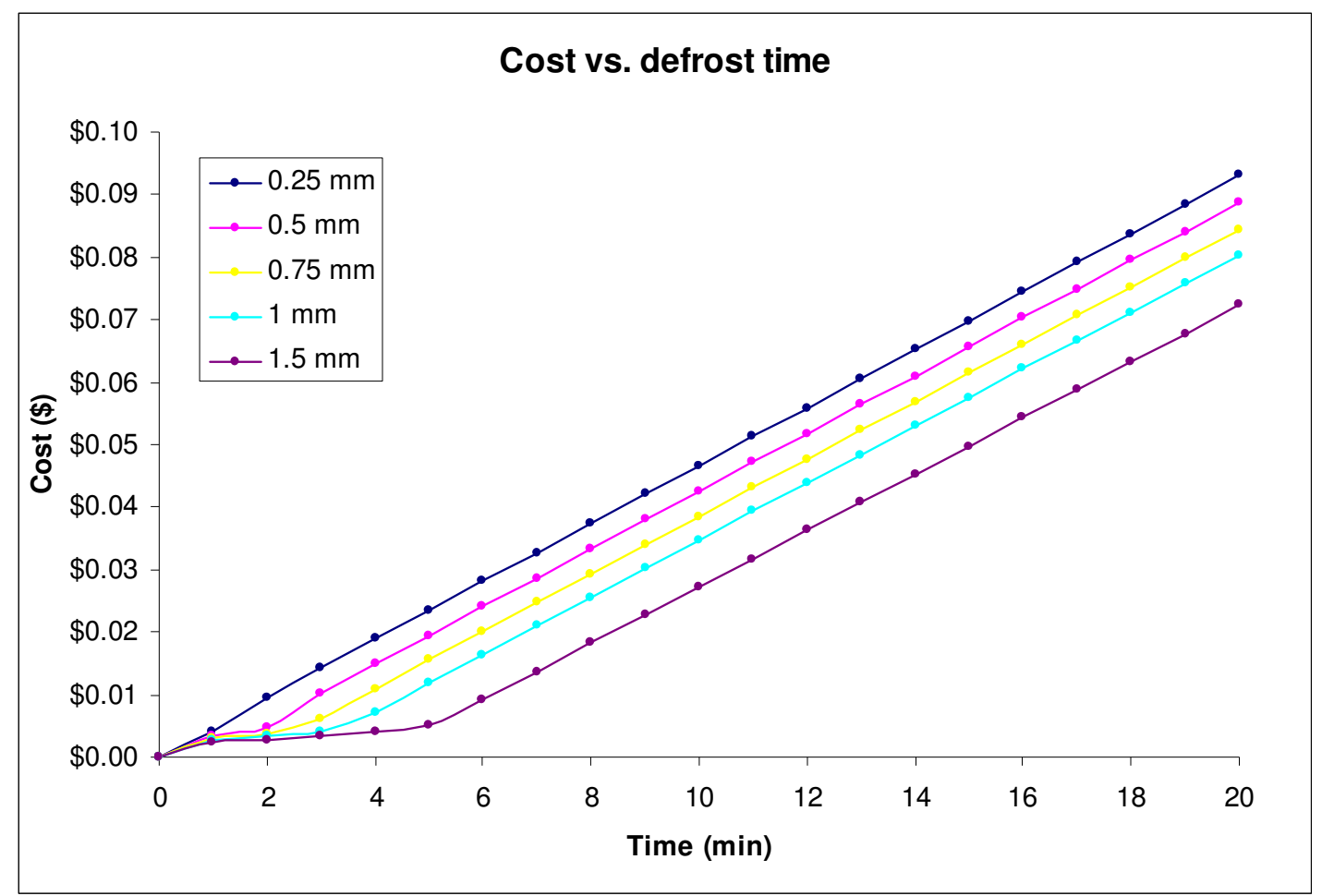

Figure 23: Hot gas defrost cost as a function of defrost time for different frost thickness

Figure 23 shows the cost of operation will consequently increase as the longer the system has to defrost. For thicker frost layers, all the energy from the hot gas is used to melt the frost and so the cost is low initially. Thinner frost layers are melted very quickly and the remaining heat goes to heat up the space instead. For 1 $\mathrm{mm}$ of frost, it costs about $\$ 0.08$ for 20 minutes of defrost. If the system is terminated 10 minutes sooner, it will cost only $\$ 0.035$, which will save $\$ 0.045$ per defrost cycle. 


\section{Conclusions \& Recommendations}

Both the results from the measurements and the modeling indicate that there was no frost build up during the testing at the Classic Salads facility. Although there was scatter in the pressure measurements, there was no overall increase in the pressure measurement with time, which would indicate the presence of frost on the coil. The finite difference model with little or no frost was in good agreement with the measured temperatures during a defrost cycle.

The Opto 22 temperature measurement on the tube sheet was significantly different than the HOBO measurements on the fin and the tube sheet. First, the Opto22 sensor had a longer lag time. Second, at steady state, there was about a $5^{\circ} \mathrm{F}$ temperature difference between the measurements using the two systems. It may be possible to use a temperature measurement to terminate the defrost cycle. A sensor located on the fins should give a more accurate measure of the temperature of the coil surface and whether frost is present. However, the lag in the Opto22 sensor (due to the larger size) would make this measurement more conservative.

There was significant scatter in the pressure measurements, much larger than the accuracy of the transducer. It is believed that the exposed end of the tube between the fan and the coil was not properly attached and consequently was moving due to the turbulence within the air stream. Also, the measured pressure drop across 
the coil was higher than that measured by the manufacturer and predicted by the model. The reason for this could be due to cardboard fiber accumulation on the surfaces of the coil.

The purpose of the pressure measurement was to determine whether the defrost cycle could be initiated based on a measured increase in the pressure drop across the coil, indicating the presence or frost. This is a common technique in heat pump applications. Unfortunately, the experimental results could not prove the usefulness of this method since there was little or no frost during the testing.

The pressure drop model was used to determine the change in the coil pressure drop as a function of frost thickness and fan speed. The changes in the pressure drop are much greater than the repeatability of the transducer, indicating that this method could prove useful. Also, the fans do not have to be maintained at fixed speed in order to accurately detect the presence of frost since this can be modeled.

The results from the testing indicate that the defrost cycle could be terminated sooner. If the defrost cycle could be terminated 10 minutes sooner during a regularly scheduled 20 minute defrost cycle, the savings per defrost are estimated to be $\$ 0.045$ per coil. Extending this to the entire facility, and assuming the Classic Salads facility is operated for 9 months during the year and each of the 26 evaporator 
coils are scheduled to defrost 6 times per day for 20 minutes, the annual savings would be approximately $\$ 1,900$ per year.

Many things can be done to improve the experimental testing. First, it is necessary to repeat the testing under conditions where frost will form. Second, photographic evidence would be very helpful in determining the presence of frost. It should also be possible to use this to determine the thickness of the frost layer. It is also recommended that the testing be conducted at a location on campus. This would facilitate easy access to the testing facility and the ability to run multiple tests under different, and hopefully more controllable, conditions.

Also, the models need to be verified with experimental testing. While this investigation was an important first step, both the thermal and pressure drop models need to be tested against measurements on a coil, under frosting conditions, with a known layer of frost. 


\section{References}

[1] N. F. Aljuwayhel, Reindl, D. T., S. A. Klein, and G. F. Nellis. "Comparison of parallel- and counter-flow circuiting in an industrial evaporator under frosting conditions." International Journal of Refrigeration 30 (2007): 1347-1357.

[2] Aljuwayhel, N. F., D. T. Reindl, S. A. Klein, and G. F. Nellis. "Experimental investigation of the performance of industrial evaporator coils operating under frosting conditions." International Journal of Refrigeration 31 (2008): 98-106.

[3] Norton, Ellis. "A Look at Hot Gas Defrost." ASHRAE Journal (2000): 88.

[4] Lenic, Kristian, Anica Trp, and Bernard Frankovic. "Transient two-dimensional model of frost formation on a fin-and-tube." International Journal of Heat and Mass Transfer 52 (2009): 22-32.

[5] Sekar, Deniz, Hakan Karatas, and Nilufer Egrican. "Frost formation on fain-andtube heat exchangers. Part I-Modeling of frost formation on fin-and-tube heat exchangers." International Journal of Refrigeration 27 (2004): 367-374.

[6] Sherif, S. A., S. P. Raju, M. M. Padki, and A. B. Chan. "A semi-empirical transient method for modelling frost formation on a flat plate." Internation Journal of Refrigeration 16 (1993): 321-329.

[7] Lee, Kwan-Soo, Sung Jhee, and Dong-Keun Yang. "Prediction of the frost formation on a cold flat surface." Internation Journal of Heat and Mass Transfer 46 (2003): 3789-796. 
[8] Ismail, K.A. R., and C. S. Salinas. "Modeling of frost formation over parallel cold plates." International Journal of Refrigeration 22 (1999): 425-441.

[9] Fossa, Marco, and Giovanni Tanda. "Study of free convection frost formation on a vertical plate." Experimental Thermal and Fluid Science 26 (2002): 661-668.

[10] Kim, Jung-Soo, Dong-Keun Yang, and Kwan-Soo Lee. "Dimensionless correlations of frost properties on a cold cylinder surface." International Journal of Heat and Mass Transfer 51 (2008): 3946-3952.

[11] Tso, C. P., Y. C. Cheng, and A.C. K. Lai. "An improved model for predicting performance of finned tube heat exchanger under frosting condition, with frost thickness variation along fin." Applied Thermal Engineering 26 (2006): 111-120.

[12] Lenic, Kristian, Anica Trp, and Bernard Frankovic. "Prediction of an effective cooling output of the fin-and-tube heat exchanger under frosting conditions." Applied Thermal Engineering 29 (2009): 2534-2543.

[13] Hoffenbecker, N., S. A. Klein, and D. T. Reindl. "An improved model for predicting performance of finned tube heat exchanger under frosting condition, with frost thickness variation along fin." International Journal of Refrigeration 28 (2005): 605-615.

[14] Yao, Yang, Yiqiang Jiang, Shiming Deng, and Zuiliang Ma. "A study on the performance of the airside heat exchanger under frosting in an air source heat pump water heater/chiller unit." International Journal of Heat and Mass Transfer 47 (2004): 3745-3756. 
[15] Liu, Zhiqiang, Hongtao Zhu, and Hanqing Wang. "Study on Transient Distributed Model of Frost on Heat Pump Evaporator." International of Asian Architecture and Building Engineering 4 (2005): 265-270.

[16] Cole, R. A. "Refrigeration Loads in a Freezer Due to Hot Gas Defrost and Their Associated Costs." ASHRAE Transition 95 (1989): 1149-1154.

[17] Mills, Anthony F. Mass transfer. Upper Saddle River, N.J: Prentice Hall, 2001. [18] Klein, S. A., and F. L. Alvarado. Engineering equation solver. Computer software. F-Chart Software. 2003. Nov. \& dec. $2008<$ www.fchart.com>.

[19] Gray, D. L., and R. L. Webb. Proc. of Heat Transfer and Friction Correlations for Plate Finned-Tube Heat Exchangers Having Plain Fins. Vol. 6. San Francisco, 1986. 2745-750.

[20] Incropera, Frank P., and David P. DeWitt. Introduction to heat transfer. 4th ed. New York: Wiley, 2002.

[21] OPTO 22. 1995. OPTO 22. Fall $2008<$ http://www.opto22.com/>.

[22] Onset. 1996. Onset Computer Corporation. Fall 2008

$<$ http://www.onsetcomp.com/>.

[23] Energy Information Administration. EIA. 29 May 2009 <http://www.eia.doe.gov/cneaf/electricity/epm/table5_6_b.html>. 


\section{Appendix A: LRC evaporator specifications}

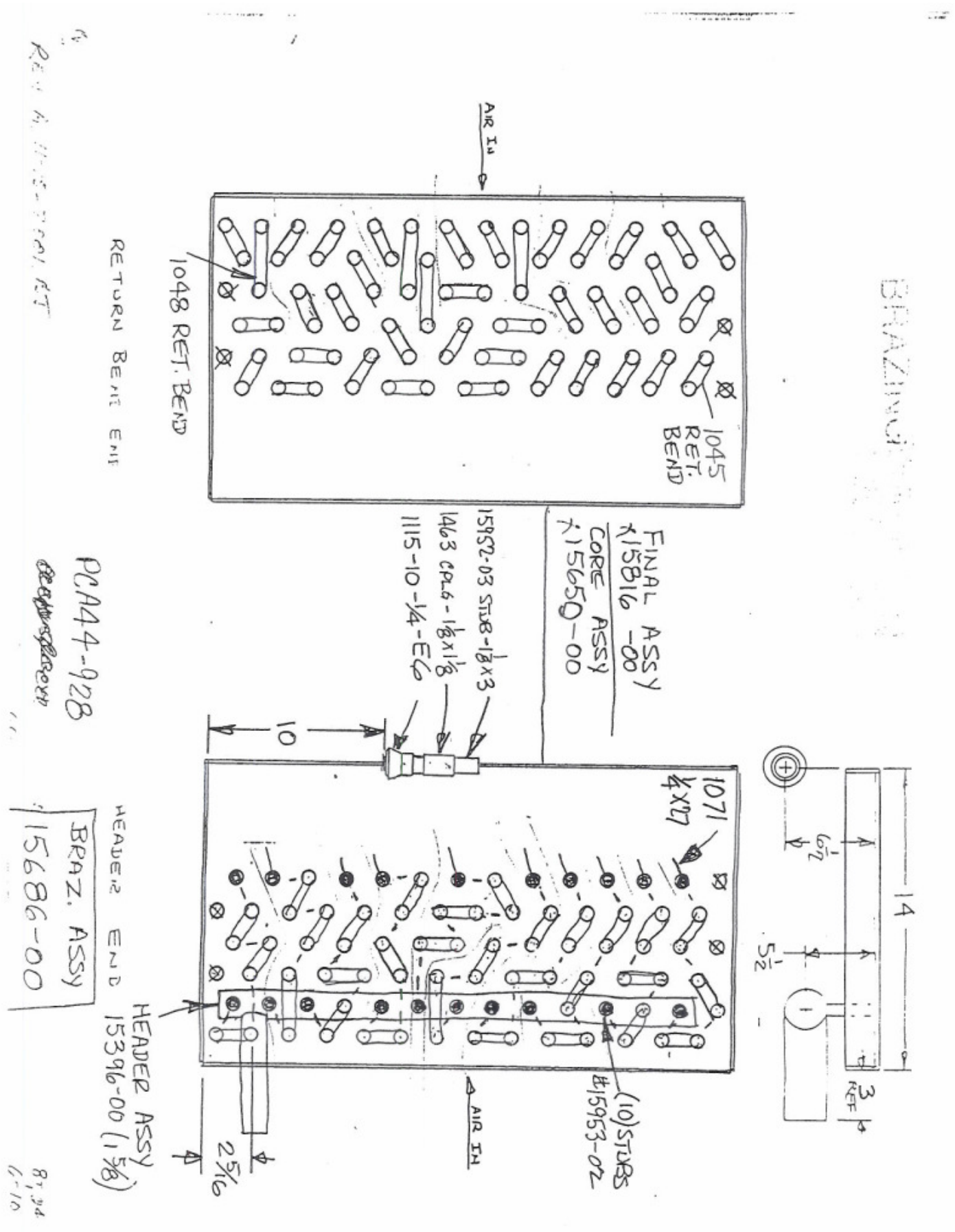


49

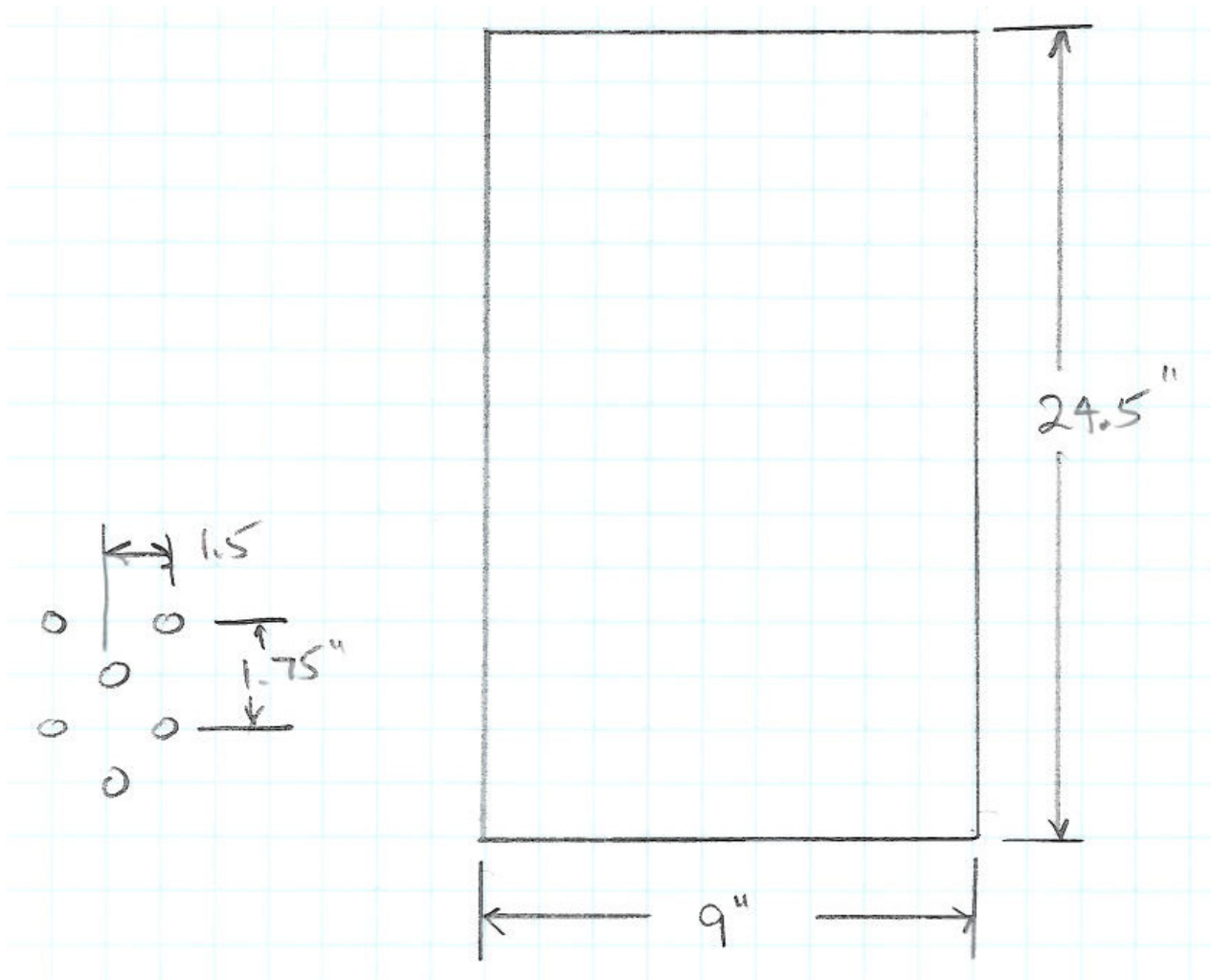

Fin Dimensions

Fin length of int - $108^{\prime \prime}$

expected static pressure drop os coil $\Rightarrow .297 \mathrm{~N} \mathrm{H}_{2} \mathrm{O}$

Motor rpm - 1040 


\title{
Evaporator Coil
}

\author{
Model \\ LRC (5/8" tube) \\ $610 \times 27436 r$ ff $10 \mathrm{c}$
}

\section{Air}

Barometer

Altitude

Airflow

Velocity

On Coil

Off Coil

Cond Rate

Pressure drop

29.891

$-0.114$

10800

600

$38.0 / 31.9$

$32.0 / 28.4$

0

0.297
Inch Hg

$\mathrm{ft}$

$\mathrm{cfm}$

fpm

${ }^{\circ} \mathrm{F}$

${ }^{\circ} \mathrm{F}$

$\mathrm{g} / \mathrm{s}$

InchWg

Refrigerant (Evaporating R22)

Temperature

Abs. Press

Density

Enthalpy Change

Mass Flow

dP Rate

Press Drop

Pipe Conn

Performance

Sensible Duty

Total Duty
25.0

63.3

80.5

71.5

1040

0.00532

0.561

1.38

74354

74354
${ }^{\circ} \mathrm{F}$

Psi

$\mathrm{lb} / \mathrm{ft}^{3}$

Btu/lb

$\mathrm{lb} / \mathrm{hr}$

Psi/ft

Psi

inch

DXC 1.2.1.0 registered to LRC Coil Co., Mike Williams 
AIR DRIVE, INC.

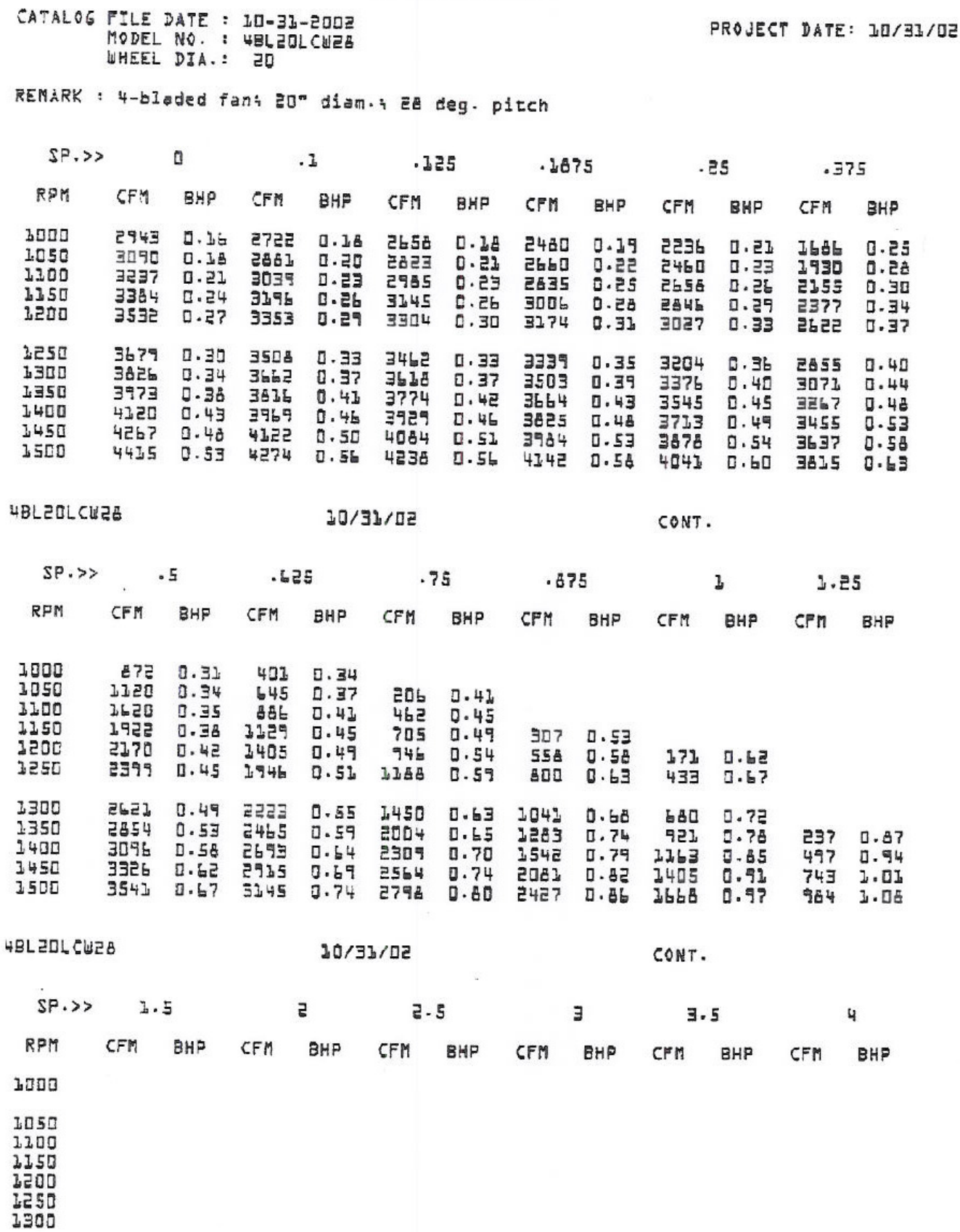




\section{Appendix B: Opto22 system and ICTD temperature probe specifications}

\section{I/O MODULES \\ STANDARD \\ ANALOG INPUT}

\section{DATA SHEET}

Form 446-060803

\section{Description}

The AD4 module provides a single channel of opticallyisolated temperature-to-digital conversion. Modules plug into any 0 pto 22 standard analog $1 / 0$ rack and are secured by a captive screw. Field connections to the moduleare made via two terminals on the analog $1 / 0$ rack.

The AD4 module is designed for use with an ICTD probefrom Opto 22 or from other vendors. The ICTD probe is encapsulated and completely isolated from ground loop possibilities. The ICTD can be used in energy management, freezer control, and similar applications.

\section{Specifications}

\begin{tabular}{|l|c|}
\hline $\begin{array}{c}\text { Part } \\
\text { Number }\end{array}$ & Description \\
\hline AD4 & ICTD Temperature Input \\
\hline ICTD & ICTD Temperature Probe \\
\hline
\end{tabular}

AD4

\begin{tabular}{|l|l|}
\hline Input Temperature Range & $-188.4^{\circ} \mathrm{C}$ to $150{ }^{\circ} \mathrm{C}$ \\
\hline Input Response Time & $\begin{array}{l}5 \% \text { full scale step change in } 7.8 \text { seconds } \\
63 \% \text { full scale step change in 150 seconds }\end{array}$ \\
\hline $\begin{array}{l}\text { Accuracy of AD4 } \\
\text { Accuracy with ICTD Probe }\end{array}$ & $\begin{array}{l} \pm 0.3^{\circ} \mathrm{C} \\
\pm 0.8{ }^{\circ} \mathrm{C}\end{array}$ \\
\hline Resolution with ICTD Probe & $0.083^{\circ} \mathrm{C}$ \\
\hline Power Requirements: & $\begin{array}{l}16 \mathrm{~mA} \text { at }+15 \mathrm{VDC} \\
11 \mathrm{~mA} \text { at }-15 \mathrm{VDC} \\
1.6 \mathrm{~mA} \text { at } 5 \mathrm{VDC}\end{array}$ \\
\hline Thermal Time Constant & $2.5 \mathrm{minutes}$ typical (still air) \\
\hline Cable Length & $>2,000$ feet (610 meters) \\
\hline $\begin{array}{l}\text { Isolation } \\
\text { Input-to-Output }\end{array}$ & $4,000 \mathrm{Vrms}$ \\
\hline $\begin{array}{l}\text { Ambient Temperature } \\
\text { Operating } \\
\text { Storage }\end{array}$ & $\begin{array}{l}{ }^{\circ} \mathrm{C} \text { to } 70^{\circ} \mathrm{C} \\
-25^{\circ} \mathrm{C} \text { to } 85^{\circ} \mathrm{C}\end{array}$ \\
\hline
\end{tabular}


I/O MODULES

(1) 022

DATA SHEET

Form 446-060003

\section{Specifications (continued)}

ICTD

\begin{tabular}{|l|l|}
\hline Input Temperature Range & $-40^{\circ} \mathrm{C}$ to $100^{\circ} \mathrm{C}$ \\
\hline Output & $233 \mu \mathrm{A} @-40^{\circ} \mathrm{C}$ \\
& $373 \mu \mathrm{A} @ 100^{\circ} \mathrm{C}$ \\
\hline Sensitivity & $1 \mu \mathrm{A} /{ }^{\circ} \mathrm{K}$ \\
\hline $\begin{array}{l}\text { Input Response Time } \\
\left(\% \text { of Span } / \Delta{ }^{\circ} \mathrm{C} / \Delta \text { Time }\right)\end{array}$ & $5 \% / 7^{\circ} \mathrm{C} / 7.8$ seconds \\
& $63 \% / 28^{\circ} \mathrm{C} / 33.6$ seconds \\
& $\pm 0.5^{\circ} \mathrm{C} @ 28.48^{\circ} \mathrm{C} / 150$ seconds \\
\hline Output Accuracy & $\pm 0.25^{\circ} \mathrm{C}$ \\
\hline Repeatability & 2.5 minutes typical (still air) \\
\hline Thermal Time Constant & $>2,000 \mathrm{ft}(610$ meters $)$ \\
\hline Cable Length & Overall length: $39^{\prime \prime}(1 \mathrm{~m})$ \\
\hline Dimensions & Cylinder tip: $0.70 "(1.78 \mathrm{~cm}) \mathrm{L}, 0.375^{\prime \prime}(0.95 \mathrm{~cm}) \mathrm{D}$ \\
\hline
\end{tabular}

\section{Connections}

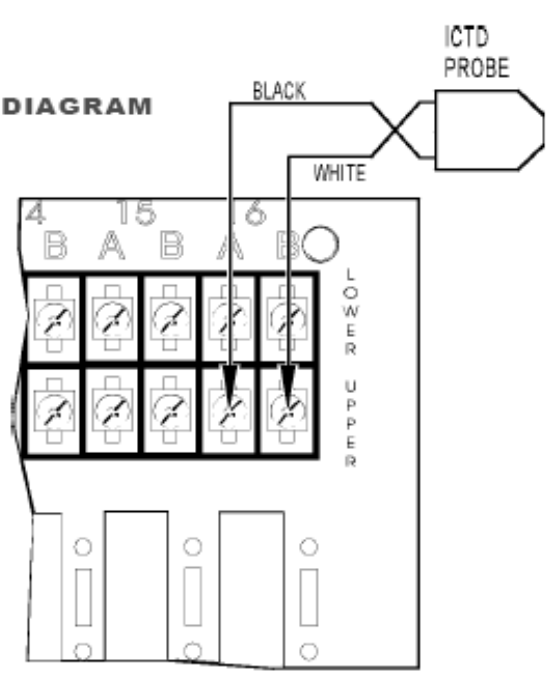




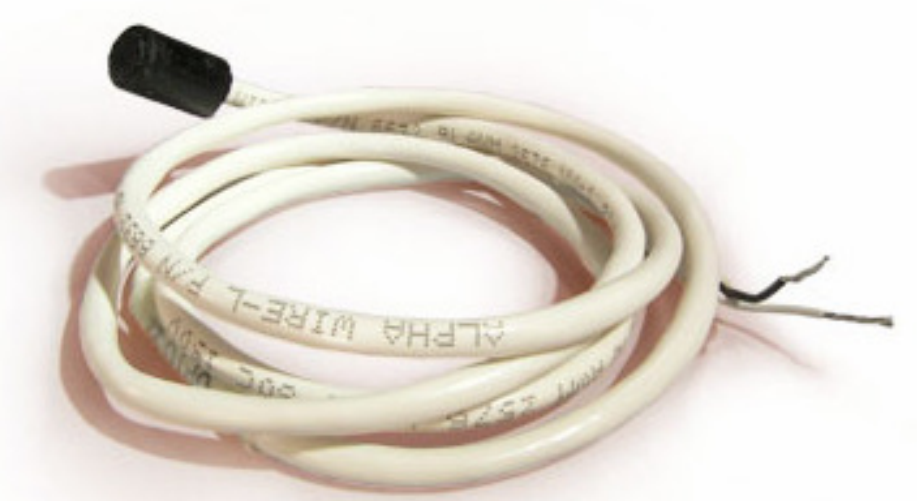

ICTD

\begin{tabular}{|c|c|}
\hline Input Temperature Range & $-40^{\circ} \mathrm{C}$ to $100^{\circ} \mathrm{C}$ \\
\hline Output & $\begin{array}{l}233 \mu \mathrm{A} @-40{ }^{\circ} \mathrm{C} \\
373 \mu \mathrm{A} @ 100{ }^{\circ} \mathrm{C}\end{array}$ \\
\hline Sensitivity & $1 \mu \mathrm{A} /{ }^{\circ} \mathrm{K}$ \\
\hline $\begin{array}{l}\text { Input Response Time } \\
\left(\% \text { of Span } / \Delta{ }^{\circ} \mathrm{C} / \Delta \text { Time }\right)\end{array}$ & $\begin{array}{l}5 \% / 7{ }^{\circ} \mathrm{C} / 7.8 \text { seconds } \\
20 \% / 28^{\circ} \mathrm{C} / 33.6 \text { seconds } \\
63.2 \% / 88.48{ }^{\circ} \mathrm{C} / 150 \text { seconds }\end{array}$ \\
\hline Output Accuracy & $\pm 0.5^{\circ} \mathrm{C} @ 25^{\circ} \mathrm{C}$ \\
\hline Repeatability & $\pm 0.25^{\circ} \mathrm{C}$ \\
\hline Thermal Time Constant & 2.5 minutes typical (still air) \\
\hline Cable Length & $>2,000 \mathrm{ft}$ (610 meters) \\
\hline Dimensions & $\begin{array}{l}\text { Overall length: } 39^{\prime \prime}(1 \mathrm{~m}) \\
\text { Cylinder tip: } 0.70^{\prime \prime}(1.78 \mathrm{~cm}) \mathrm{L}, 0.375^{\prime \prime}(0.95 \mathrm{~cm}) \mathrm{D}\end{array}$ \\
\hline
\end{tabular}




\section{Appendix C: HOBO data logger specifications}

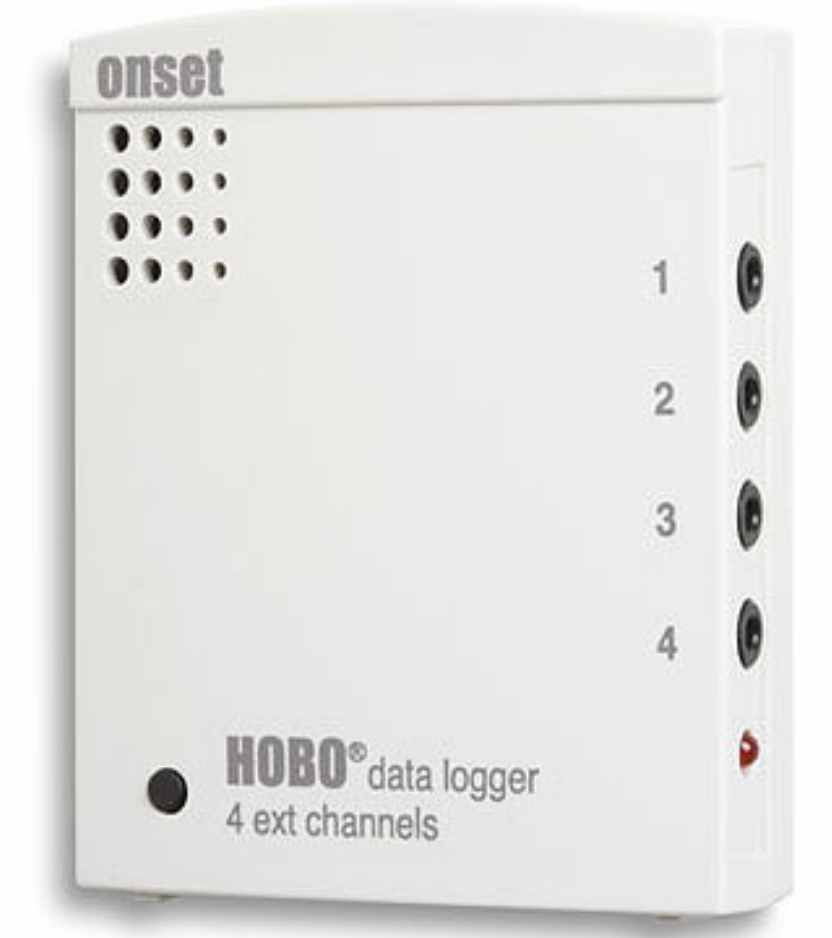

Overview

The HOBO U12 4-External Channel Data Logger accepts a wide range of external sensors, including temperature, $A C$ current, $A C$ voltage, $C O 2,4-20 \mathrm{~mA}$, and $0-2.5 \mathrm{vdc}$. 12-bit resolution provides great data accuracy.

\section{Features:}

- 12-bit resolution provides high accuracy

- Large memory for long-term deployments or fast sampling

- Five models to choose from, with flexible measurement options

- Programmable and push button start

\begin{tabular}{llll}
\hline Environment: & Indoor & Product ID: & U12-006 \\
Measurement: & AC Current & Product Name: & $4-$ Channel External \\
& Temperature & Product Type: & Data Loggers \\
& DC Voltage & & \\
& $4-20 \mathrm{~mA}$ & & \\
& AC Voltage & &
\end{tabular}




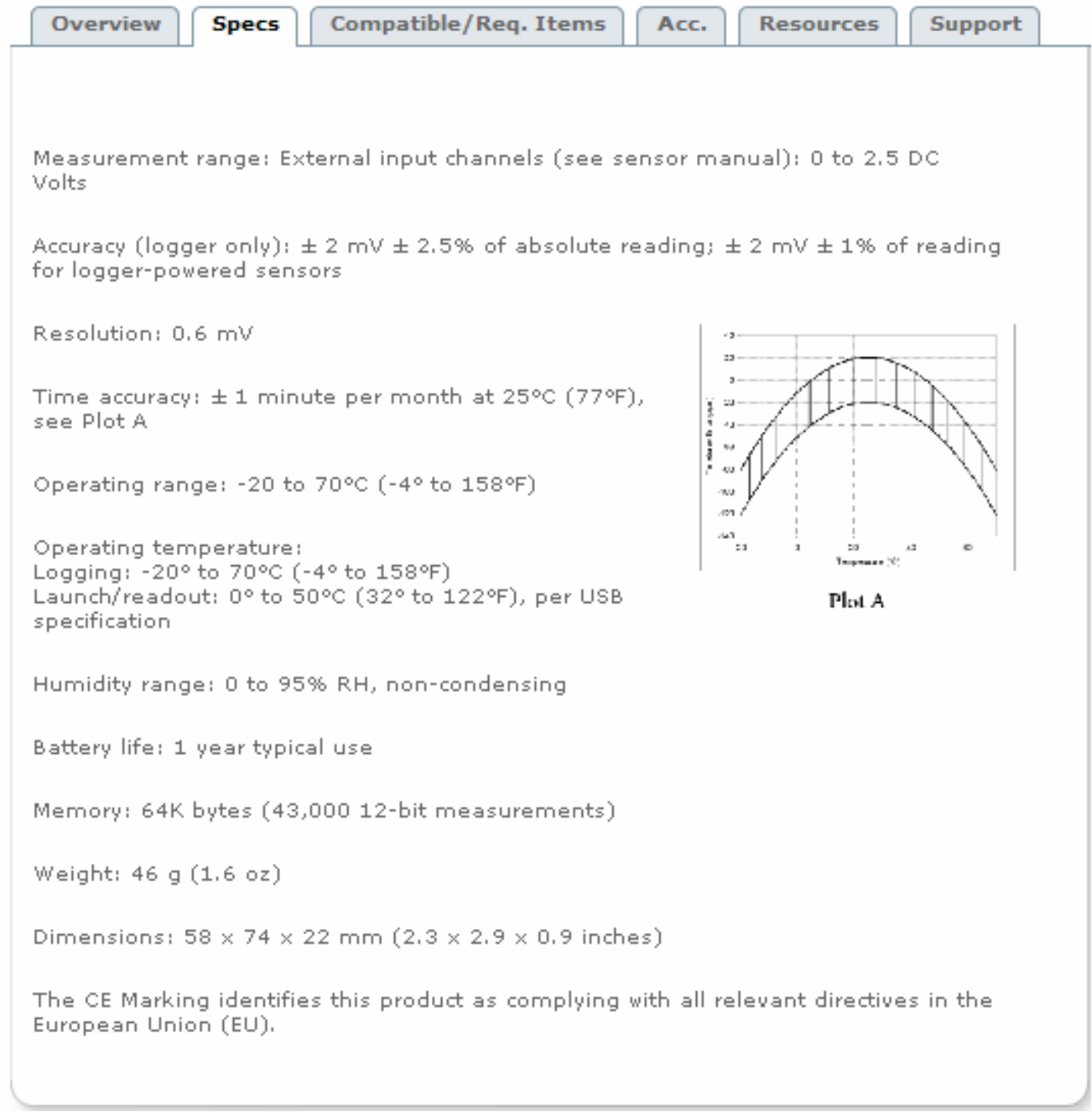




\section{Appendix D: Pressure transducer specifications}

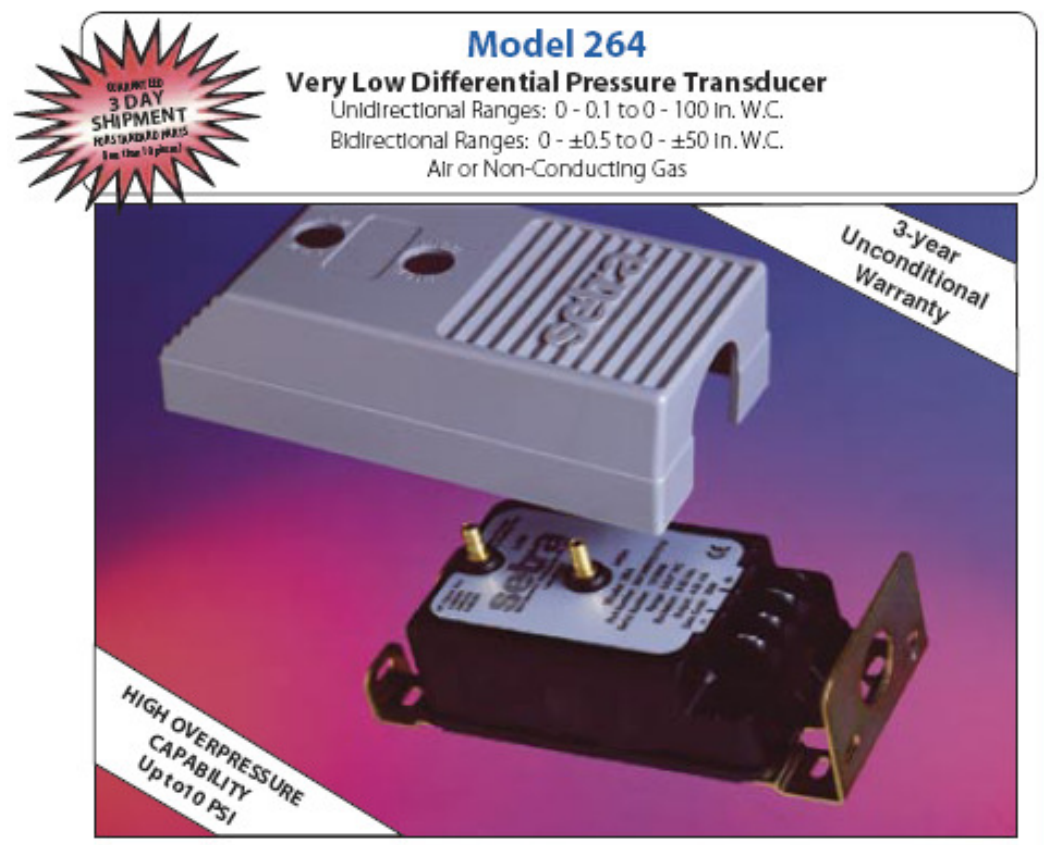

Cetra Systems 264 pressure transducers sense differentlal or gauge (static) pressure and convert this pressure difference to a proportional electrical output for elther unidirectional or bidirectional pressure ranges. The 264 Serles is offered with a high level analog 0 to $5 \mathrm{VDC}$ or 4 to 20 mA output.

Used In Bullding Energy Management Systems, these transducers are capable of measuring pressures and flows with the accuracy necessary for proper bullding pressurization and alr flow control.

The 264 Serles transducers are avallable for alr pressure ranges as low as $0.1 \mathrm{In}$. W.C. full scale to $100 \mathrm{in}$. W.C. full scale. Static standard accuracyls \pm 1.0 \% fullscale innormal ambient temperature environments, but higher accuracles are avallable. The units are temperature compensated to $0.033 \% \mathrm{FS} / \mathrm{F}$ thermal error over the temperature range of $0^{\circ} \mathrm{F}$ to $+150^{\circ} \mathrm{F}$.
The Model 264 utillzes an Improved all stainless steel micro-tig welded sensor. The tensioned stainless steel dlaphragm and Insulated stainless steel electrode, positioned close to the dlaphragm, form a varlable capacitor. Positive pressure moves the dlaphragm toward the electrode, IncreasIng the capacitance. A decrease in pressure moves the dlaphragm away from the electrode, decreasing the capacitance. The change in capacitance is detected and converted to a IInear DC electrical signal by Setra's unique electronic drcult.

The tensioned sensor allows up to $10 \mathrm{PSI}$ overpressure (in elther direction) with no damage to the unit. In addition, the parts that make up the sensor have thermally matched coefficlents, which promote improved temperature performance and excellent long term stabillity.

\section{Applications}

- Heating, Ventilating and Air Conditioning (HVAC)

- Energy Management Systems

- Variable Air Volume and Fan Control (VAV)

- Environmental Pollution Control

- Lab and Fume Hood Control

- Oven Pressurization and Fumace Draft Controls

\section{Features}

Up to 10 PSI Overpressure on All Ranges

- Installation Time

Minimized with Snap Track Mounting and Easy-ToAccess Pressure Ports and Electrical Connections

a 0 to 5 VDC or 2-wire 4 to $20 \mathrm{~mA}$ Analog Outputs Are Compatible with Energy Management Systems

- Reverse Wiring Protection

- Internal Regulation Permits Use with Unregulated DC Power Supplies

- Fire Retardent Case (UL 94 V-0 Approved)

- Meets $\ll$ Conformance Standards

When it comes to a product to rely on - choose the Model 264. When it comes to a company to trust - choose Setra.

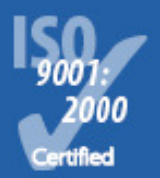

Visit Setra Online: http://wrww.setra.com

NOTE Setra qualty sandsends are based on ANStZ2540-1. The calibration of this product is NIST traceable.

US. Patert nos. 4003915; 4358914; 4434203; 6019502; 6014800. Other Pastents Pending

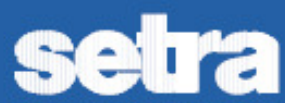

800-257-3872 
Performance Data Standar

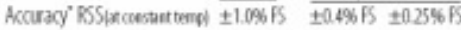
Non-Linearty, BFel Hysteresis Non-Pepeatability Themal Effects"* Compensated Range "Fic Zero/Span Shift offS/ FFO Naximum Line Pressure Overpeessure

Long Term Stabīty

Position Effect (Unit is factory clibrated at of To $0.5 \mathrm{in}$. WC $\frac{0.60}{0.50}$ effect in the vertical postion.) T010 in. WC 0.50 To2.5in. WC 0.22 Tosin WC 0.14

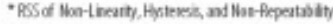

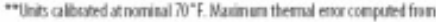
fis detum

0 to $+150(-18$ 10 +65$)$

$0.033(0.06)$

10 pri

(Range Dependent?

$0.5 \%$ F $/ 1$ YR
Model 264 Specifications Environmental Data

Temperature

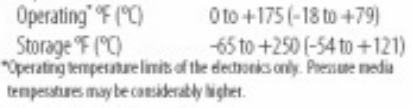

Storage $\mathrm{F}^{\circ}(\mathrm{C}) \mathrm{C}$

(O) $-65+0+250(-540+12)$

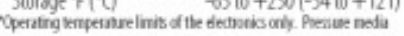

teapestures may be cansideatly vigte!

Physical Description

Case

Fre-Retardant Glass Filled

Mounting

Polyestar (UL 94 V-0 Aperoved)

Four screw boles on remontle sinc plated sted base (designed foc $2.75^{\circ}$ snap tradk]

Flectrical Connection Screw Teminal Strip

Pressure Ftting $\quad 3 / 16^{*} 0 . D$. barted trass

peessure fitting for $1 / 4^{*}$ pushir 0 tubing

Zeeo and Span Adjustments Accessible on top of case Weight(approx) $\quad 10$ ounces

Pressure Media

Typicaly air or similar non-conducting gases.

Specifcations subject to change without notice.
Electrical Data (Voltage)

Giruit 3-Wire (Com, Exc, Out)

Exitation $\quad 91030 \mathrm{VCC}$

Output" $\quad 0105$ VDC

Bidrectional output at zes

pressure: $2.5 \mathrm{VoC}$

Output Impedance $\quad 100$ ohms

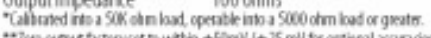

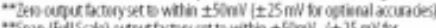

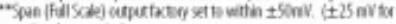

Electrical Data (Current)

ciruit 2-Wire

Outpui $\quad 4$ to $20 \mathrm{mh}^{*}$

Eidrectional output at zeso

pressure. $12 \mathrm{mh}$ "

Extemal load $\quad 0$ to 8000 obms

Minimum sepply volage (VDO) $=9+0.02 x$

(Resstance of rectiver plus line).

Marimum supplyvotage $(\mathrm{VDO})=300+0.004 x$

(Resistance of receiver plus line).

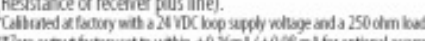
(a)

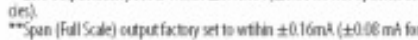

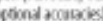

Outline Drawings

Optional 1/2" Conduit Electrical Enclosure Dimensions

Code T1 Electrical Termination Dimensions
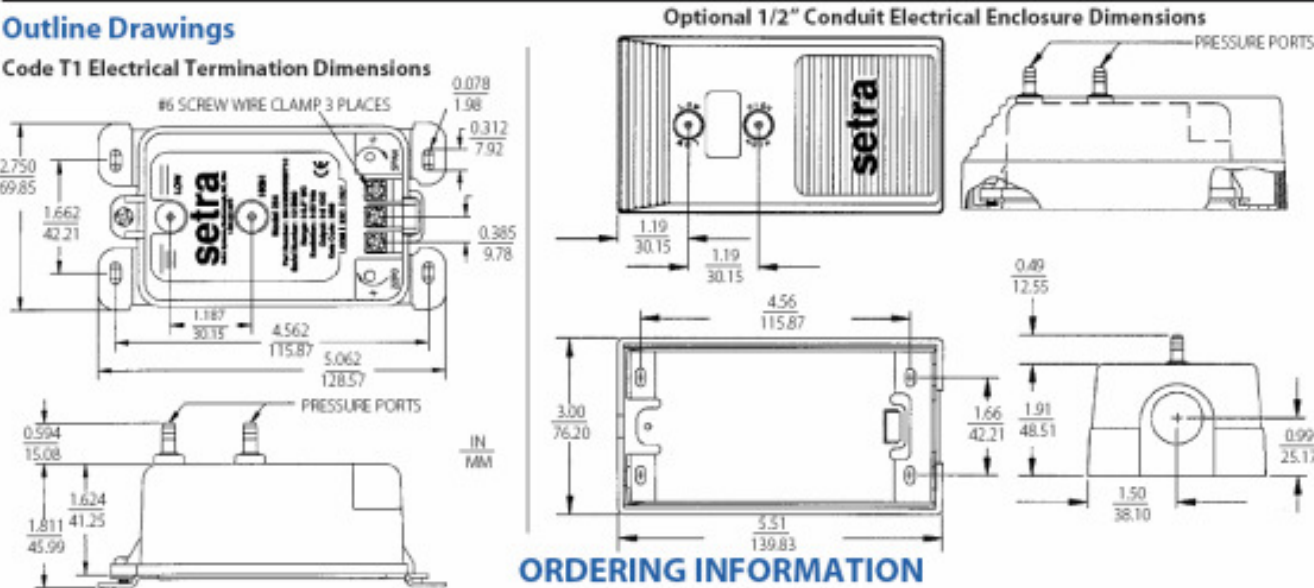

Eample: Part No. 26412

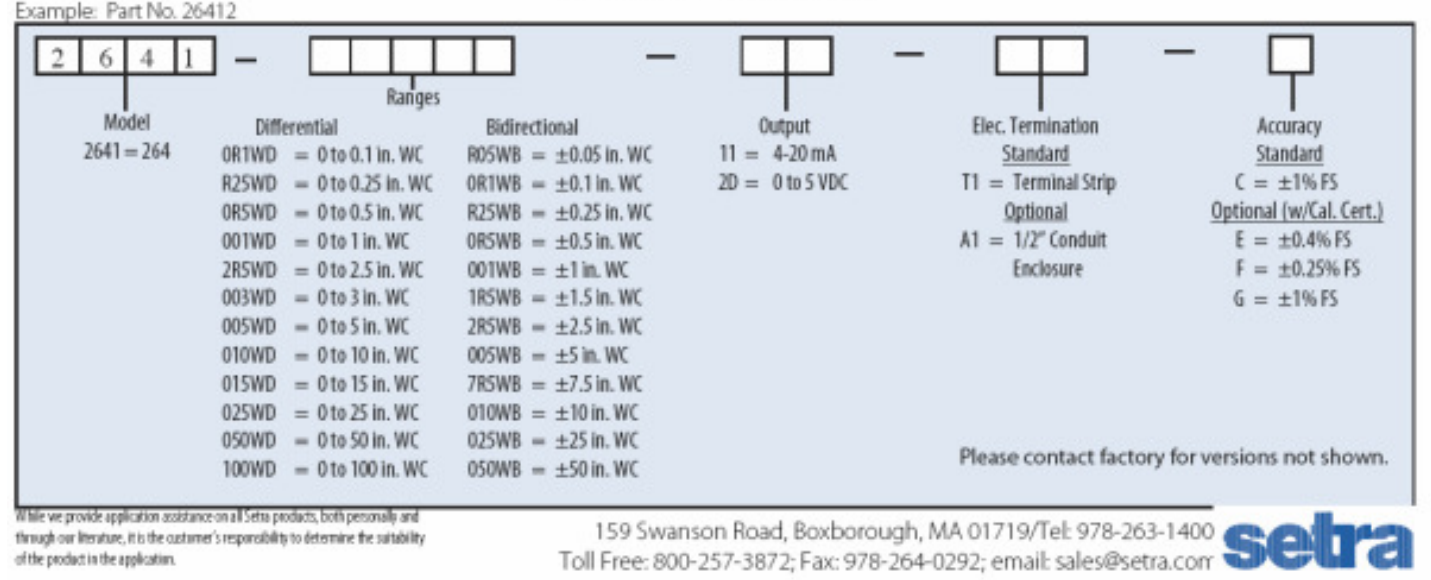




\title{
Appendix E: RTD sensor specifications
}

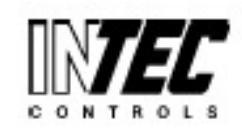

\section{Product Data}

\author{
Low Temperature Transmitters
}

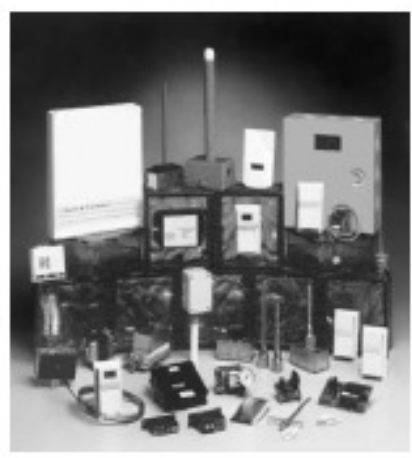

I/TT100-LT I/TT1000-LT

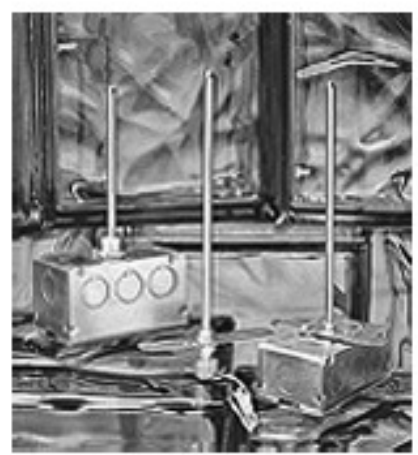

One of the most important features of the ITT100-LT and ITT1000-LT temperature transmitters is the use of a strain free wire wound RTD. This allows the sensor to have a more stable output since the sensing element isn't subjected to the constant expansion and contraction of the encapsulation materials. The sensors are mounted in a $1 / 4$ " diameter stainless steel probe and come with standard 24" Teflon leads, except for the remote probes which come with 6' Teflon leads.

Some of the typical applications are for Freezers, Chemical Plants, Fuel Processing Facilities, Meat Packing Plants, and Scientific Laboratories.

These units are offered in Duct, Duct without box, Immersion, and Remote Probe configurations.

\section{Product Specifications}

\begin{tabular}{|l|l|l|l|}
\hline Input & 2-wire, Plativum 100/1000IRTD & Transmitter Accuracy & $+-0.1 \%$ of span \\
\hline Output & 2-wire, Linear 4 - 20mA DC Current & Sensor Accuracy & $+--0.3^{\circ} \mathrm{C}(a) 0^{\circ} \mathrm{C}$ Single Point \\
\hline Supply Voltage & 7 to $35 \mathrm{VDC}$, No Polarity Sensitivity & Temperature Sensor Range & -328 to $392^{\circ} \mathrm{F}\left(-200\right.$ to $\left.200^{\circ} \mathrm{C}\right)$ \\
\hline Linearity & $+j-0.05 \%$ of span & Transmitter Operating Range & 32 to $158^{\circ} \mathrm{F}$ \\
\hline
\end{tabular}




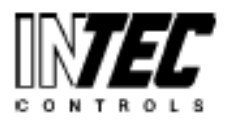

Dimensions

DUCT

IMMERSION
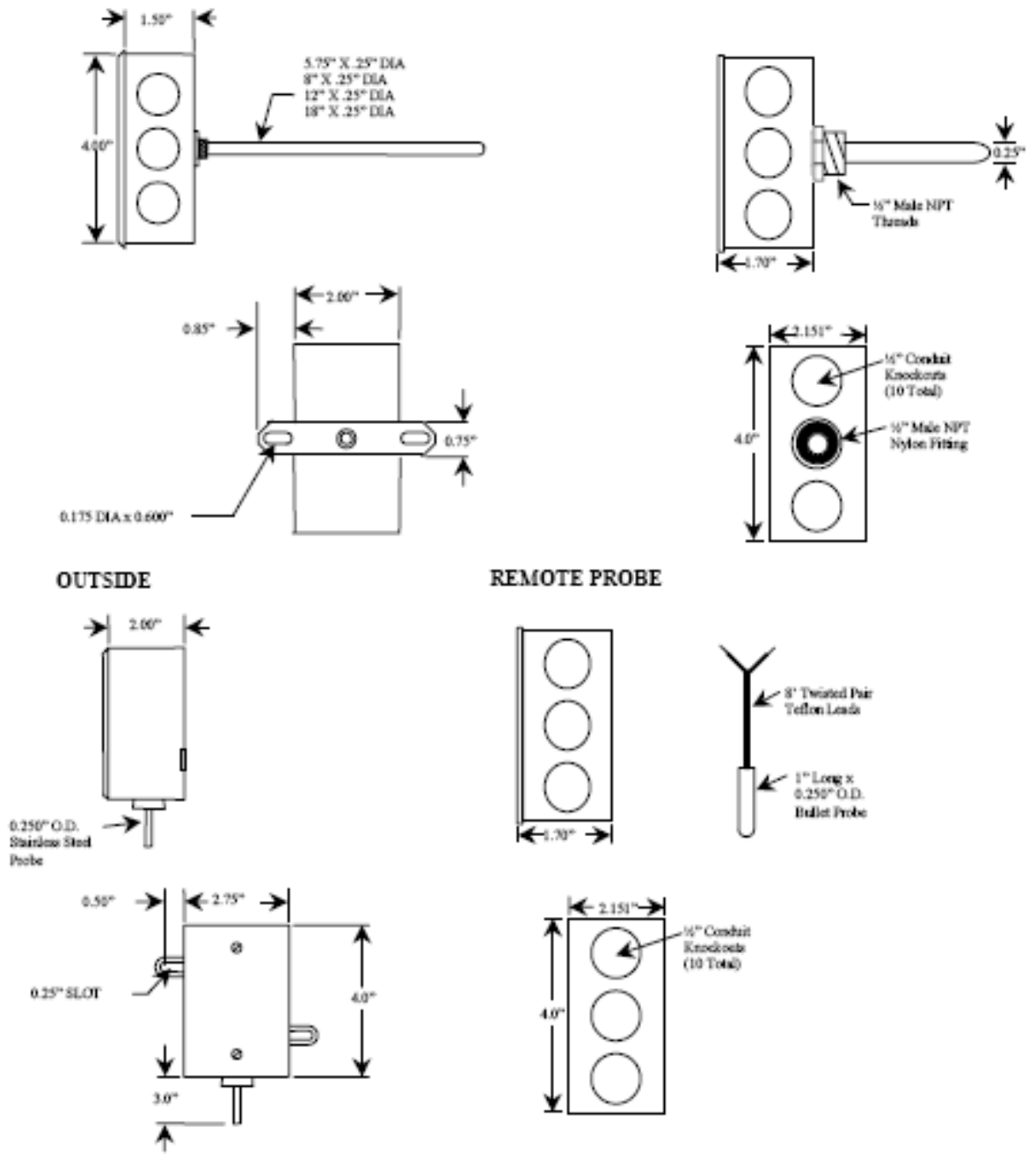

REMOTE PROBE

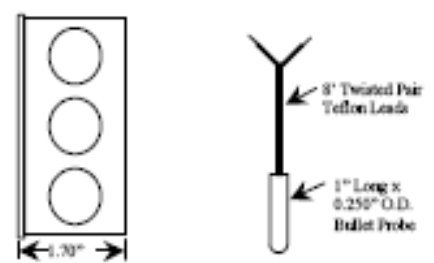

\section{Ordering Information}

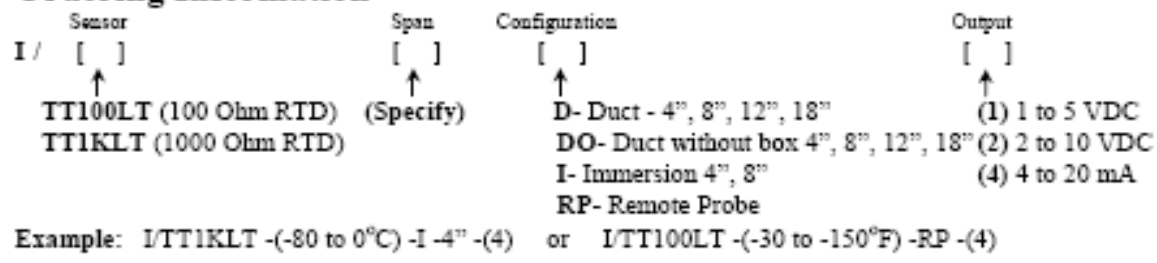




\section{Appendix F: EES file for temperature model}

"Determination of the relationship between temperature vs. time during the defrost"

"Known Information for aluminum fin"

rho_fin $=173\left[\mathrm{lb} / \mathrm{ft}^{\wedge} 3\right]$

thickness $=0.0003333333333$ [feet]

$\mathrm{h} \_\mathrm{c}=0.88\left[\mathrm{Btu} / \mathrm{hr} \mathrm{ft}^{\wedge} 2 \mathrm{~F}\right]$

T_amb $=35[\mathrm{~F}]$

Cp_fin $=0.21\left[\mathrm{Btu} / \mathrm{lbm}{ }^{*} \mathrm{~F}\right]$

through out the fin"

$\mathrm{k} \_$fin $=101\left[\mathrm{Btu} / \mathrm{hr}^{\star} \mathrm{ft} \mathrm{t}^{\star} \mathrm{F}\right]$

T_hot_gas $=55[\mathrm{~F}]$

$\mathrm{T} \_\mathrm{i}=35[\mathrm{~F}]$
"Assume density of the fin is constant through out"

"This must change to feet"

"Using natural convection"

"Temperature of the room"

"Assume specific heat to be the same

"Assume Thermal conductivity to be the same throughout the fin"

"This takes into account of $Q$ in by knowing boundary condition temperature"

"Initial condition"

"Known Information for copper tube wall"

$$
\begin{aligned}
& \text { rho_copper }=557.7\left[\mathrm{lb} / \mathrm{ft}^{\wedge} 3\right] \\
& \text { out" } \\
& \text { h_R22 }=440.3\left[\mathrm{Btu} / \mathrm{h} \mathrm{ft} \mathrm{f}^{\wedge} \mathrm{F}\right] \\
& \text { condensation" } \\
& \text { fin_pitch }=0.018 \text { [feet] } \\
& \text { Cp_copper }=0.0906\left[\mathrm{Btu} / \mathrm{lbm}^{\star} \mathrm{F}\right] \\
& \text { the copper" } \\
& \text { k_copper }=234\left[\mathrm{Btu} / \mathrm{hr}^{\star} \mathrm{ft}^{\star} \mathrm{F}\right] \\
& \text { through out the copper" } \\
& \text { "Radius of the copper tube" } \\
& \text { r_a }=0.025125 \\
& r \_b=0.026375 \\
& \text { r_c }=0.027625
\end{aligned}
$$

"Assume density of the copper is constant through$$
\text { "Using convection with phase change }
$$

"Assume specific heat to be the same through out

"Assume Thermal conductivity to be the same 
"Volume of copper tube"

volume_tube_a $=\mathrm{pi}^{*}\left(\left(\left(r \_a+r \_b\right) / 2\right)^{\wedge} 2-r \_a^{\wedge} 2\right)^{\star}($ fin_pitch/2)

volume_tube_b $=\mathrm{pi}^{*}\left(\left(\left(r \_b+r \_c\right) / 2\right)^{\wedge} 2-\left(\left(r \_a+r \_b\right) / 2\right)^{\wedge} 2\right)^{\star}($ fin_pitch/2)

volume_tube_c $=\mathrm{pi}^{*}\left(r \_c^{\wedge} 2-\left(\left(\mathrm{r} \_b+r \_c\right) / 2\right)^{\wedge} 2\right)^{*}($ fin_pitch/2)

volume_fin_0 $=\mathrm{pi}^{*}\left(\left(\left(\mathrm{r}_{-} \mathrm{c}+\mathrm{r} \_1\right) / 2\right)^{\wedge} \overline{2}-\mathrm{r} \_\mathrm{c}^{\wedge} 2\right)^{*}($ thickness $/ 2)$

"Solving Equation at the tube wall"

$\mathrm{f} \_\mathrm{tTa}=\left(\mathrm{Q} \_\right.$conv_R22_to_a - Q_cond_a_to_b)/(rho_copper*volume_tube_a*Cp_copper)

$T \_a=T \_i+$ integral $\left(f \_t T a, t\right)$

$f \_t T b=\left(Q \_c o n d \_a \_t o \_b-Q \_c o n d \_b \_t o \_c\right) /\left(\right.$ rho_copper ${ }^{*}$ volume_tube_b $\left.{ }^{*} C p \_c o p p e r\right)$

$T \_b=T \_i+$ integral(f_tTb, $\left.t\right)$

$f \_t T c=\left(Q \_c o n d \_b \_t o \_c-Q\right.$ Q conv_c_to_amb - Q_cond_c_to_1 -

Q_cond_c_f0)/(rho_copper*volume_tube_c ${ }^{*} \mathrm{Cp} \_$copper + rho_fin ${ }^{*}$ volume_fin_0*Cp_fin)

$T \_c=T \_i+$ integral $\left(f \_t T c, t\right)$

"Radius of the Rings"

$\begin{array}{ll}r \_0=0.027625 & \text { [feet] } \\ \text { r_1 }=0.038768 & \text { [feet] } \\ \text { r_2 }=0.049913 & \text { [feet] } \\ \text { r_3 }=0.061056 & \text { [feet] } \\ \text { r_4 }=0.072200 & \text { [feet] } \\ \text { r_5 }=0.083344 & \text { [feet] }\end{array}$

"Volume of the Rings"

volume_fin_1 $=\mathrm{pi}^{*}\left(\left(\left(r_{-} 1+\mathrm{r} \_2\right) / 2\right)^{\wedge} 2-\left(\left(r_{-} c+r \_1\right) / 2\right)^{\wedge} 2\right)^{*}($ thickness/2)

volume_fin_2 $=\mathrm{pi}^{*}\left(\left(\left(\mathrm{r}_{-} 2+\mathrm{r} \_3\right) / 2\right)^{\wedge} 2-\left(\left(r_{-} 1+\mathrm{r}_{-} 2\right) / 2\right)^{\wedge} 2\right)^{*}($ thickness $/ 2)$

volume_fin_3 $=\mathrm{pi}^{*}\left(\left(\left(\mathrm{r}_{-} 3+\mathrm{r} \_4\right) / 2\right)^{\wedge} 2-\left(\left(r_{-} 2+\mathrm{r} \_3\right) / 2\right)^{\wedge} 2\right)^{\star}($ thickness $/ 2)$

volume_fin_4 $=\mathrm{pi}^{\star}\left(\left(\left(\mathrm{r}_{-} 4+\mathrm{r} \_5\right) / 2\right)^{\wedge} 2-\left(\left(r_{-} 3+\mathrm{r}_{-} 4\right) / 2\right)^{\wedge} 2\right)^{\star}($ thickness/2)

volume_fin_5 $=\mathrm{pi}^{\star}\left(r \_5^{\wedge} 2-\left(\left(r \_5+r \_4\right) / 2\right)^{\wedge} 2\right)^{\star}($ thickness/2)

"Solving for temperature at fin"

"Ring \#1"

f_tT1 $=(Q$ Qcond_c_to_1 - Q_cond_1_to_2 -

Q_cond_1_to_f1)/(rho_fin*volume_fin_1 ${ }^{\star} \mathrm{Cp}$ fin $)$

$\mathrm{T} \_1=\mathrm{T} \_\mathrm{i}+\operatorname{integral}\left(\mathrm{f} \_\mathrm{t} 1, \mathrm{t}\right)$ 
"Ring \#2"

f_tT2 $=(\mathrm{Q}$ _cond 11_to_2 - $\mathrm{Q}$ ccond_2_to_3 -

Q_cond_2_to_f2)/(rho_fin*volume_fin_2 ${ }^{*} \mathrm{Cp}$ _fin)

T_2 = T_i + integral(f_tT2, t)

"Ring \#3"

f_tT3 $=(\mathrm{Q}$ _cond_2_to_3 - $\mathrm{Q}$ ccond_3_to_4 -

Q_cond_3_to_f3)/(rho_fin*volume_fin_3* $\left.{ }^{*} p \_f i n\right)$

T_3 = T_i + integral $\left(f \_t T 3, t\right)$

"Ring \#4"

f_tT4 = ( Q_cond_3_to_4 - Q_cond_4_to_5 -

Q_cond_4_to_f4 $) /\left(\right.$ rho_fin*volume_fin_4 ${ }^{*} \mathrm{Cp}$ _fin)

T_4 $=T \_i+$ integral $\left(f \_t T 4, t\right)$

"Ring \#5"

f_tT5 $=\left(Q\right.$ _cond_4_to_5 - Q_cond_5_to_f5) $/\left(\right.$ rho_fin*volume_fin $5{ }^{*} \mathrm{Cp}$ f in $)$

T_5 = T_i + integral $\left(f \_t T 5, t\right)$

"Solving for the frost Temperature"

"Information about frost"

$\mathrm{k} \_$frost $=1.283\left[\mathrm{Btu} / \mathrm{hr}^{\star} \mathrm{ft}^{\star} \mathrm{F}\right]$

"Get the info from online: http://www.engineeringtoolbox.com/ice-thermal-propertiesd_576.html"

frost_thickness $=0.5^{\star} 0.003281$ [feet] "Convert from 1 milimeter of thickness"

rho_frost $=18.7[\mathrm{lb} / \mathrm{ft} \wedge 3]$

"Get the info from online: http://www.engineeringtoolbox.com/ice-thermal-propertiesd_576.html"

g_md $=0.000369\left[\mathrm{lbm} / \mathrm{ft}^{\wedge} 2 \mathrm{~s}\right]$

"Calculate from the mass transfer book by Mills page 53 to $54 "$

m_H2O_s $=0.003745$

"Calculate from the mass transfer book by Mills page 53 to $54 "$

m_H2O_e $=0.003476$

"Calculate from the mass transfer book by Mills page 53 to $54 "$ 
$\mathrm{h} \_\mathrm{ig}=143.4[\mathrm{Btu} / \mathrm{lbm}] \quad$ "Enthalpy fusion of water"

$\mathrm{h} \_\mathrm{i}=$ Enthalpy $($ Water $, \mathrm{T}=30, \mathrm{p}=1)$

"Q_evap ring"

Q_evap_0 $=\left(g \_m d^{*} \mathrm{pi}^{*}\left(\left(\left(\mathrm{r} \_1+\mathrm{r} \_\mathrm{c}\right) / 2\right)^{\wedge} 2-\left(\mathrm{r} \_\mathrm{c}\right)^{\wedge} 2\right)^{*}\left(\mathrm{~m} \_\mathrm{H} 2 \mathrm{O} \_\mathrm{s}-\mathrm{m} \_\mathrm{H} 2 \mathrm{O} \_\mathrm{e}\right)^{*} \mathrm{~h}\right.$ ig $)$

Q_evap_1 $=\left(g \_\mathrm{md}^{*} \mathrm{pi}^{*}\left(\left(\left(\mathrm{r}_{-} 2+\mathrm{r}_{-} 1\right) / 2\right)^{\wedge} 2-\left(\left(\mathrm{r}_{-} 1+\mathrm{r} \_\mathrm{c}\right) / 2\right)^{\wedge} 2\right)^{\bar{*}}\left(\mathrm{~m} \_\mathrm{H} 2 \mathrm{O} \_\mathrm{s}-\mathrm{m} \_\mathrm{H} 2 \mathrm{O} \_\mathrm{e}\right)^{*} \mathrm{~h}\right.$ ig $)$

Q_evap_2 $=\left(g \_\mathrm{md}^{*} \mathrm{pi}^{*}\left(\left(\left(\mathrm{r} \_3+\mathrm{r} \_2\right) / 2\right)^{\wedge} 2-\left(\left(\mathrm{r} \_2+\mathrm{r} \_1\right) / 2\right)^{\wedge} 2\right)^{*}\left(\mathrm{~m} \_\mathrm{H} 2 \mathrm{O} \_\mathrm{s}-\mathrm{m} \_\mathrm{H} 2 \mathrm{O} \_\mathrm{e}\right)^{*} \mathrm{~h}\right.$ ig $)$

Q_evap_3 $=\left(g \_\mathrm{md}^{*} \mathrm{pi}^{*}\left(\left(\left(\mathrm{r} \_4+\mathrm{r} \_3\right) / 2\right)^{\wedge} 2-\left(\left(\mathrm{r} \_3+\mathrm{r} \_2\right) / 2\right)^{\wedge} 2\right)^{\star}\left(\mathrm{m} \_\mathrm{H} 2 \mathrm{O} \_\mathrm{s}-\mathrm{m} \_\mathrm{H} 2 \mathrm{O} \_\mathrm{e}\right)^{*} \mathrm{~h}\right.$ ig $)$

Q_evap_4 $=\left(g \_\mathrm{md}^{*} \mathrm{pi}^{*}\left(\left(\left(\mathrm{r} \_5+\mathrm{r} \_4\right) / 2\right)^{\wedge} 2-\left(\left(\mathrm{r} \_4+\mathrm{r} \_3\right) / 2\right)^{\wedge} 2\right)^{*}\left(\mathrm{~m} \_\mathrm{H} 2 \mathrm{O} \_s-\mathrm{m}_{-} \mathrm{H} 2 \mathrm{O} \_\mathrm{e}\right)^{*} \mathrm{~h}\right.$ ig $)$

Q_evap_5 $=\left(\right.$ g_md $\left.{ }^{*} i^{*}\left(r \_5^{\wedge} 2-\left(\left(\bar{r} \_5+r \_4\right) / 2\right)^{\wedge} \overline{2}\right)^{*}\left(m \_H 2 O \_s-m \_H 2 O \_e\right)^{*} h \_\overline{i g}\right)$

"Frost ring"

volume_frost_ $0=\mathrm{pi}^{*}\left(\left(\left(\mathrm{r} \_\mathrm{c}+\mathrm{r} \_1\right) / 2\right)^{\wedge} 2-\left(\mathrm{r} \_\mathrm{c}\right)^{\wedge} 2\right)^{*}(($ fin_pitch/2)-(thickness/2))

volume_frost_1 $=\mathrm{pi}^{*}\left(\left(\left(\mathrm{r}_{-} 1+\mathrm{r}_{-} 2\right) / 2\right)^{\wedge} 2-\left(\left(r_{-} \mathrm{c}+\mathrm{r}_{-} 1\right) / 2\right)^{\wedge} 2\right)^{\star}$ frost_thickness

volume_frost_2 $=\mathrm{pi}^{\star}\left(\left(\left(\mathrm{r} \_2+\mathrm{r} \_3\right) / 2\right)^{\wedge} 2-\left(\left(r_{-} 1+r_{-} 2\right) / 2\right)^{\wedge} 2\right)^{*}$ frost_thickness

volume_frost_3 $=\mathrm{pi}^{*}\left(\left(\left(\mathrm{r} \_3+\mathrm{r} \_4\right) / 2\right)^{\wedge} 2-\left(\left(r_{-}+r_{-} 3\right) / 2\right)^{\wedge} 2\right)^{*}$ frost_thickness

volume_frost_4 $=\mathrm{pi}^{*}\left(\left(\left(\mathrm{r} \_4+\mathrm{r} \_5\right) / 2\right)^{\wedge} 2-\left(\left(r_{-} 3+r_{-} 4\right) / 2\right)^{\wedge} 2\right)^{*}$ frost_thickness

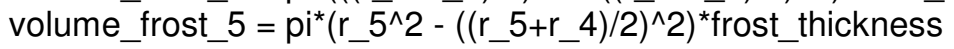

"Ring \#0"

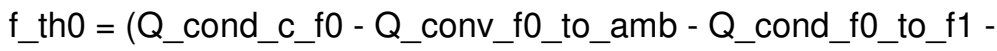

Q_evap_0)/(rho_frost ${ }^{*}$ volume_frost_0)

h_f_0 $=$ h_i + integral $\left(f \_t h 0, t\right)$

$\left\{T \_f 0=\right.$ TEMPERATURE $\left(\right.$ Water, $\left.\left.h=h \_f \_1, p=1\right)\right\}$

T_f_0=Interpolate1 ('Lookup 1', 'T', 'h', h=h_f_0)

"Ring \#1"

f_th1 = (Q_cond_f0_to_f1 - Q_conv_f1_to_amb - Q_cond_f1_to_f2 + Q_cond_1_to_f1 -

Q_evap_1)/(rho_frost ${ }^{*}$ volume_frost_1)

h_f_1 = h_i + integral(f_th1,t)

$\left\{T \_f \_1=\right.$ TEMPERATURE $\left(\right.$ Water, $\left.\left.h=h \_f \_1, p=1\right)\right\}$

T_f_1=Interpolate1('Lookup 1', 'T', 'h', $\left.h=h \_f \_1\right)$

"Ring \#2"

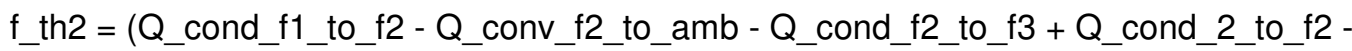
Q_evap_2)/(rho_frost ${ }^{*}$ volume_frost_2)

h_f_2 $=h \_i+$ integral $\left(f \_t h 2, t\right)$

$\left\{T \_f 2=\right.$ TEMPERATURE $\left(\right.$ Water, $\left.\left.h=h \_f \_2, p=1\right)\right\}$

T_f_2=Interpolate1('Lookup 1', 'T', 'h', h=h_f_2)

"Ring \#3" 
f_th3 $=$ (Q_cond_f2_to_f3 - Q_conv_f3_to_amb - Q_cond_f3_to_f4 + Q_cond_3_to_f3 Q_evap_3)/(rho_frost ${ }^{*}$ volume_frost_3)

h_f_3 $=$ h_i + integral $\left(f \_t h 3, t\right)$

\{T_f_3 = TEMPERATURE $($ Water,h=h_f_3,p=1)\}

T_f_3=Interpolate1('Lookup 1', 'T', 'h', h=h_f_3)

"Ring \#4"

f_th4 $=$ (Q_cond_f3_to_f4 - Q_conv_f4_to_amb - Q_cond_f4_to_f5 + Q_cond_4_to_f4 Q_evap_4)/(rho_frost ${ }^{*}$ volume_frost_4)

h_f_4 $=$ h_i + integral(f_th4,t)

$\left\{T \_f 4=\right.$ TEMPERATURE $\left(\right.$ Water, $\left.\left.h=h \_f \_4, p=1\right)\right\}$

T_f_4=Interpolate1('Lookup 1', 'T', 'h', h=h_f_4)

"Ring \#5"

$f \_$th5 $=(Q$ Qcond $f 4$ _to $f 5-Q$ _conv_f5_to_amb + Q_cond _5_to_f5 -

Q_evap_5)/(rho_frost ${ }^{*}$ volume_frost_5)

h_f_5 $=$ h_i + integral $\left(f \_t h 5, t\right)$

$\left\{T \_f 5=\right.$ TEMPERATURE $($ Water,h=h_f_5,p=1)\}

T_f_5=Interpolate1('Lookup 1', 'T', 'h', $\left.h=h \_f \_5\right)$

"List of all the Heat energy terms"

Q_conv_R22_to_a $=\left(h \_R 22^{*}\right.$ pi $^{*}$ _a* fin_pitch $\left.{ }^{*}\left(T \_h o t \_g a s-T \_a\right)\right) / 3600$

Q_CONV_R22_to_a_sum $=$ integral $(Q$ _conv_R22_to_a, t $)$

Q_cond_a_to_b $=\left(k \_c o p p e r^{*}{ }^{*}{ }^{*} f i n \_p i t c{ }^{*}\left(T \_a-T \_b\right) / I n\left(r \_b / r \_a\right)\right) / 3600$

Q_COND_a_to_b_sum $=$ integral $\left(Q \_c o n d \_a \_t o \_b, t\right)$

Q_cond_b_to_c $=\left(k \_c o p p e{ }^{*}{ }^{*}{ }^{*} f i n \_p i t c h{ }^{*}\left(T \_b-T \_c\right) / I n\left(r \_c / r \_b\right)\right) / 3600$

Q_COND_b_to_c_sum $=$ integral $(Q$ _cond_b_to_c, t $)$

Q_conv_c_to_amb $=\left(\text { h_c }{ }^{*} \text { pi }^{*} \text { _c }{ }^{*}((\text { fin_pitch }) / 2 \text { - (thickness }) / 2 \text { - frost_thickness) }\right)^{*}\left(T \_c-\right.$

T_amb) $) / 3600$

Q_CONV_c_to_amb_sum $=$ integral $(Q$ _conv_c_to_amb, $\mathrm{t})$

Q_cond_c_to_1 $=\left(k \_f i{ }^{*}\right.$ pi $^{*}$ thickness $\left.{ }^{*}\left(T \_c-T \_1\right) / \ln \left(r \_1 / r \_c\right)\right) / 3600$

Q_COND_c_to_1_sum $=$ integral $($ Q_cond_c_to_1, t $)$

Q_cond_c_f $0=\left(\left(\left(2^{*} \mathrm{pi}^{*}\left(\left(\left(\mathrm{r} \_1+\mathrm{r} \_\mathrm{c}\right) / 2\right)^{\wedge} 2-\left(\mathrm{r} \_\mathrm{c}\right)^{\wedge} 2\right)^{*}\left(T \_\mathrm{c}-\right.\right.\right.\right.$

$\left.T \_f \_0\right)^{*}\left(\bar{k} \_\right.$fin ${ }^{*} k$ frost $\left.)\right) /\left(\left(\right.\right.$ thickness* ${ }^{*}$ frost $)+\left(2^{*}\right.$ frost_thickness* ${ }^{*}$ _fin $\left.\left.\left.)\right)\right) / 3600\right) "+$ $\left(\left(\bar{k} \_\right.\right.$frost ${ }^{*} \overline{2}^{*} \mathrm{pi}^{*}\left(\overline{\mathrm{fin}} \_\mathrm{pitch} / 2\right.$ - thickness/2)*$\left.\left.\left(T \_c-T \_f \_0\right) / L N\left(r \_0 / r \_c\right)\right) / 3600\right) "$ 
Q_COND_c_f0_sum $=$ integral(Q_cond_c_f0,t)

Q_cond_1_to_2 $=\left(\mathrm{k}\right.$ _fin ${ }^{*} \mathrm{pi}^{*}$ thickness $\left.{ }^{*}\left(T \_1-T \_2\right) / \mathrm{ln}\left(\mathrm{r} \_2 / \mathrm{r} \_1\right)\right) / 3600$

Q_COND_1_to_2_sum $=$ integral $(\mathrm{Q}$ _cond_1_to_2, t $)$

Q_cond_1_to f $1=\left(\left(2^{*} \mathrm{pi}^{*}\left(\left(\left(\mathrm{r} \_2+\mathrm{r} \_1\right) / 2\right)^{\wedge} 2-\left(\left(\mathrm{r} \_1+\mathrm{r} \_\mathrm{c}\right) / 2\right)^{\wedge} 2\right)^{*}\left(T \_1-\right.\right.\right.$

T_f_1 $)^{*}\left(\bar{k} \_\right.$fin ${ }^{*} k$ frost $\left.)\right) /\left(\left(\right.\right.$ thickness ${ }^{*} k \_$frost $)+\left(\overline{2}^{*}\right.$ frost_thickness $\left.\left.\left.{ }^{*} k \_f i n\right)\right)\right) / 3600$

Q_COND_1_to_f1_sum $=$ integral $\left(Q \_c o n d \_1\right.$ to_f1, t $)$

Q_cond_2_to_3 $=\left(k \_f i{ }^{*} \mathrm{pi}^{*}\right.$ thickness $\left.{ }^{*}\left(T \_2-T \_3\right) / \ln \left(r \_3 / r \_2\right)\right) / 3600$

Q_COND_2_to_3_sum $=$ integral $(\mathrm{Q}$ _cond_2_to_3, t $)$

Q_cond_2_to_f2 $=\left(\left(2^{*} \mathrm{pi}^{*}\left(\left(\left(\mathrm{r} \_3+\mathrm{r} \_2\right) / 2\right)^{\wedge} 2-\left(\left(\mathrm{r} \_2+\mathrm{r} \_1\right) / 2\right)^{\wedge} 2\right)^{*}\left(T \_2-\right.\right.\right.$

$\left.T \_f \_2\right)^{*}\left(\mathbf{k} \_\right.$fin ${ }^{*} k \_$frost $\left.)\right) /\left(\left(\right.\right.$thickness ${ }^{*} k \_$frost $)+\left(2^{\star}\right.$ frost_thickness ${ }^{*} k \_$fin $\left.\left.)\right)\right) / 3600$

Q_COND_2_to_f2_sum $=$ integral $\left(Q \_c o n d \_2\right.$ to_f2, t $)$

Q_cond_3_to_4 $=\left(\mathrm{k} \_\right.$fin ${ }^{*} \mathrm{pi}^{*}$ thickness ${ }^{*}\left(T \_3-T \_4\right) / \ln \left(r \_4 / r\right.$ _3 $\left.)\right) / 3600$

Q_COND_3_to_4_sum $=$ integral $(\mathrm{Q}$ _cond_3_to_4, t $)$

Q_cond_3_to_f3 $=\left(\left(2^{*} \mathrm{pi}^{*}\left(\left(\left(\mathrm{r} \_4+\mathrm{r} \_3\right) / 2\right)^{\wedge} 2-\left(\left(\mathrm{r} \_3+\mathrm{r} \_2\right) / 2\right)^{\wedge} 2\right)^{*}\left(\mathrm{~T} \_3-\right.\right.\right.$

T_f_3 $)^{*}\left(\bar{k} \_\right.$fin ${ }^{*} \bar{k}$ frost $\left.)\right) /\left(\left(\right.\right.$ thickness ${ }^{*} k \_$frost $)+\left(2^{*}\right.$ frost_thickness ${ }^{\star} k \_$fin $\left.\left.)\right)\right) / 3600$

Q_COND_3_to_f3_sum $=$ integral $(\mathrm{Q}$ _cond_3_to_f3, $\mathrm{t})$

Q_cond_4_to_5 $=\left(k \_f i{ }^{*}\right.$ pi $^{*}$ thickness $\left.{ }^{*}\left(T \_4-T \_5\right) / \ln \left(r \_5 / r \_4\right)\right) / 3600$

Q_COND_4_to_5_sum $=$ integral $(\mathrm{Q}$ _cond_4_to_5, t $)$

Q_cond_4_to_f $4=\left(\left(2^{*} \mathrm{pi}^{\star}\left(\left(\left(\mathrm{r} \_5+\mathrm{r} \_4\right) / 2\right)^{\wedge} 2-\left(\left(\mathrm{r} \_4+\mathrm{r} \_3\right) / 2\right)^{\wedge} 2\right)^{*}\left(T \_4-\right.\right.\right.$

$\left.T \_f \_4\right)^{*}\left(\bar{k} \_\right.$fin ${ }^{*} k \_$frost $\left.)\right) /\left(\left(\right.\right.$thickness ${ }^{*} k \_$frost $)+\left(2^{*}\right.$ frost_thickness ${ }^{*} k \_$fin $\left.\left.)\right)\right) / 3600$

Q_COND_4_to_f4_sum $=$ integral $(\mathrm{Q}$ _cond_4_to_f4, t $)$

Q_cond_5_to f5 $=\left(\left(2^{*} \mathrm{pi}^{*}\left(\left(\mathrm{r} \_5\right)^{\wedge} 2-\left(\left(\mathrm{r} \_5+\mathrm{r} \_4\right) / 2\right)^{\wedge} 2\right)^{*}\left(T \_5-\right.\right.\right.$

T_f_5 $)^{*}\left(\bar{k} \_\right.$fin $\left.\left.{ }^{\star} k \_f r o s t\right)\right) /\left(\left(\right.\right.$ thickness ${ }^{*} k \_$frost $)+\left(2^{*}\right.$ frost_thickness $\left.\left.\left.{ }^{*} k \_f i n\right)\right)\right) / 3600$

Q_COND_5_to_f5_sum $=$ integral $(\mathrm{Q}$ _cond_5_to_f5, t $)$

Q_cond_f0_to_f1 $=\left(\mathrm{k} \_\right.$frost $^{\star} 2^{*}$ pi $^{\star}$ frost_thickness $\left.{ }^{*}\left(T \_f \_0-T \_f \_1\right) / L N\left(r \_1 / r \_0\right)\right) / 3600$

Q_COND_f0_to_f1_sum $=$ integral $\left(\mathrm{Q} \_\right.$cond_f0_to_f1, t $)$

Q_conv_f0_to_amb $=\left(h \_c^{*} \mathrm{pi}^{*}\left(\left(\left(r \_1+r \_c\right) / 2\right)^{\wedge} 2-\left(r \_c\right)^{\wedge} 2\right)^{*}\left(T \_f \_0-T \_a m b\right)\right) / 3600+$ $\left(\left(\bar{h} \_c^{*} p^{*}\left(r \_\overline{1}+\bar{r} \_c\right) / 2\right)^{*}\left(\left(\right.\right.\right.$ fin $\left.\left.\_p i t c h / 2\right)-(\text { thickness/2) }- \text { frost_thickness })^{\star}\left(T \_f \_0-T \_a m b\right)\right) / 3600$

Q_CONV_f0_to_amb_sum $=$ integral(Q_conv_f0_to_amb,t)

Q_conv_f1_to_amb $=\left(h \_c^{*} \mathrm{pi}^{*}\left(\left(\left(\mathrm{r} \_2+r \_1\right) / 2\right)^{\wedge} 2-\left(\left(\mathrm{r} \_1+\mathrm{r} \_\mathrm{c}\right) / 2\right)^{\wedge} 2\right)^{*}\left(T \_f \_1-T \_a m b\right)\right) / 3600$

Q_CONV_f1_to_amb_sum $=$ integral $\left(Q \_c o n v \_f 1\right.$ to_amb, t $)$ 
Q_cond_f1_to_f2 $=\left(k \_f r o s t^{*} 2^{*}\right.$ pi $^{*}$ frost_thickness $\left.{ }^{*}\left(T \_f \_1-T \_f \_2\right) / L N\left(r \_2 / r \_1\right)\right) / 3600$

Q_COND_f1_to_f2_sum $=$ integral $\left(\mathrm{Q} \_\right.$cond_f1_to_f2, t $)$

Q_conv_f2_to_amb $=\left(h \_c^{*} \mathrm{pi}^{*}\left(\left(\left(r \_3+r \_2\right) / 2\right)^{\wedge} 2-\left(\left(r \_2+r \_1\right) / 2\right)^{\wedge} 2\right)^{*}\left(T \_f \_2-T \_a m b\right)\right) / 3600$

Q_CONV_f2_to_amb_sum $=$ integral(Q_conv_f2_to_amb, t $)$

Q_cond_f2_to_f3 $=\left(k\right.$ frost ${ }^{*}{ }^{*}$ pi $^{*}$ frost_thickness ${ }^{*}\left(T \_f 2-T \_f(3) / L N\left(r \_3 / r \_2\right)\right) / 3600$

Q_COND_f2_to_f3_sum $=$ integral $\left(Q \_\right.$cond_f2_to_f3, t $)$

Q_conv_f3_to_amb $=\left(\mathrm{h} \_\mathrm{c}^{*} \mathrm{pi}^{*}\left(\left(\left(\mathrm{r} \_4+\mathrm{r} \_3\right) / 2\right)^{\wedge} 2-\left(\left(\mathrm{r} \_3+\mathrm{r} \_2\right) / 2\right)^{\wedge} 2\right)^{*}\left(T \_f \_3-T \_a m b\right)\right) / 3600$

Q_CONV_f3_to_amb_sum $=$ integral $\left(Q \_c o n v \_3\right.$ _to_amb, t $)$

Q_cond_f3_to_f4 $=\left(k \_f r o s t^{*} 2^{*}\right.$ pi $^{*}$ frost_thickness $\left.{ }^{*}\left(T \_f 3-T \_f \_4\right) / L N\left(r \_4 / r \_3\right)\right) / 3600$

Q_COND_f3_to_f4_sum $=$ integral $\left(Q \_c o n d \_f 3 \_t o \_44, t\right)$

Q_conv_f4_to_amb $=\left(\mathrm{h} \_\mathrm{c}^{*} \mathrm{pi}^{*}\left(\left(\left(\mathrm{r} \_5+\mathrm{r} \_4\right) / 2\right)^{\wedge} 2-\left(\left(\mathrm{r} \_4+\mathrm{r} \_3\right) / 2\right)^{\wedge} 2\right)^{*}\left(\mathrm{~T} \_\mathrm{f} 44-\mathrm{T} \_\mathrm{amb}\right)\right) / 3600$

Q_CONV_f4_to_amb_sum $=$ integral $\left(Q \_c o n v \_f 4 \_t o \_a m b, t\right)$

Q_cond_f4_to_f5 $=\left(k\right.$ frost ${ }^{*}{ }^{*}$ pi $^{*}$ frost_thickness ${ }^{*}\left(T \_f\right.$ - $4-T \_$f 5$\left.) / L N\left(r \_5 / r \_4\right)\right) / 3600$

Q_COND_f4_to_f5_sum $=$ integral(Q_cond_f4_to_f5, t $)$

Q_conv_f5_to_amb $=\left(\mathrm{h} \_\mathrm{C}^{*} \mathrm{pi}^{*}\left(r \_5^{\wedge} 2-\left(\left(\mathrm{r} \_5+\mathrm{r} \_4\right) / 2\right)^{\wedge} 2\right)^{*}\left(T \_f \_5-T \_a m b\right)\right) / 3600$

Q_CONV_f5_to_amb_sum $=$ integral $\left(Q \_c o n v \_f 5 \_t o \_a m b, t\right)$

$Q$ Q conv $=\left(h \_c^{*} p^{*} r \_c^{*}\left(\text { fin } \_p i t c h-t h i c k n e s s\right)^{*}\left(T \_c-T \_a m b\right)+h \_c^{*} p i^{*}\left(\left(\left(r \_2+r \_1\right) / 2\right)^{\wedge} 2-\right.\right.$

$\left.\left(\left(r \_1+r \_c\right) / 2\right)^{\wedge} 2\right)^{\star}\left(T-f \_1-T \_a m b\right)+h c^{*} p^{*}\left(\left(\left(r \_3+r \_2\right) / 2\right)^{\wedge} 2-\left(\left(r \_2+r \_1\right) / 2\right)^{\wedge} 2\right)^{\star}\left(T \_f \_2-T \_a m b\right)$

$+\bar{h} \_c^{*} \overline{p i}^{*}\left(\left(\left(r \_4+r \_3\right) / 2\right)^{\wedge} 2-\left(\left(r \_3+r \_2\right) / 2\right)^{\wedge} 2\right)^{*}\left(T \_f \_3-T \_a m b\right)+\bar{h} \_c^{*} \overline{p i}^{*}\left(r \_5^{\wedge} 2-\right.$

$\left.\left.\left(\left(r \_5+r \_4\right) / 2\right)^{\wedge} 2\right)^{\star}\left(T \_f 5-T \_a m b\right)+h{ }^{*} c^{*} p^{*}\left(r \_5^{\wedge} 2-\left(\left(r \_5+r \_4\right) / 2\right)^{\wedge} 2\right)^{\star}\left(T \_f \_5-T \_a m b\right)\right) / 3600$

Q_CONV_TOTAL $=$ integral $\left(Q \_c o n v, t\right)$

Q_evap_sum $=($ Q_evap_1 + Q_evap_2 + Q_evap_3 + Q_evap_4 + Q_evap_5)

Q_EVAP_TOTAL $=$ integral(Q_evap_sum, $t)$

Q_in $=\left(h \_R 22^{*}\right.$ pi $^{*} r \_a^{*}$ fin_pitch $\left.{ }^{*}\left(T \_h o t \_g a s-T \_a\right)\right) / 3600$

Q_IN_TOTAL $=$ integral $\left(Q \_\right.$in, $\left.t\right)$

Q_tube=rho_copper ${ }^{*}$ volume_tube_a* $a^{*} p \_\operatorname{copper}^{*}\left(T \_a-\right.$

T_i)+rho_copper*volume_tube_b* ${ }^{*} p \_c o p p e r^{*}\left(T \_b-\right.$

T_i $)+r h o \_c o p p e{ }^{*}$ volume_tube_c* ${ }^{*} p \_c o p p e{ }^{*}\left(T \_c-T \_i\right)$

Q_fin=rho_fin*volume_fin_0*Cp_fin* $\left(T \_c-T \_i\right)+r h o \_f i{ }^{*} v o l u m e \_f i n \_1{ }^{*} \mathrm{Cp} \_f i^{*}\left(T \_1-\right.$

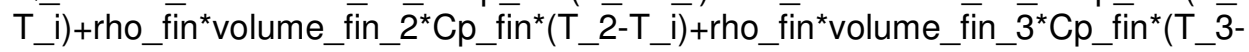

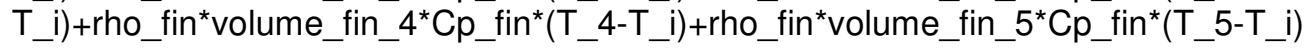


Q_melt=rho_frost ${ }^{*}$ volume_frost_0*(h_f_0-h_i $)+r h o \_f r o s t^{*}$ volume_frost $1{ }^{*}\left(\mathrm{~h} \_f\right.$ 1-

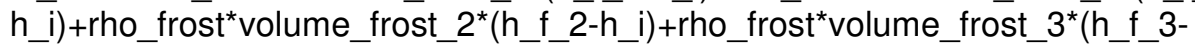

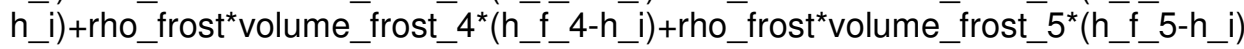

Q_Total=Q_tube+Q_fin $+Q \_$melt $+Q$ _evap_total $+Q$ _conv_total

ratio $=Q \_$total $/\left(Q \_\right.$in_total +.0000000001$)$

eff $=$ Q_melt $/\left(Q \_\right.$in_total +.0000000001$)$

number_elements $=70000$

Cost $=0.1^{*}\left(\left(Q \_ \text {IN_TOTAL }{ }^{*}(1-\text { eff })\right) / 3\right)^{*}($ number_elements/3412)

\begin{tabular}{|c|c|c|}
\hline \multicolumn{2}{|c|}{$\bar{F}_{\mathrm{S}}$ Lookup Table } & $-\square x$ \\
\hline Lookup 1 & & \\
\hline $\begin{array}{l}\text { Paste } \\
\text { Special }\end{array}$ & $\mathrm{T}$ & $\nabla$ \\
\hline Row 1 & 70 & 38.08 \\
\hline Row 2 & 65 & 33.09 \\
\hline Row 3 & 60 & 28.09 \\
\hline Row 4 & 55 & 23.09 \\
\hline Row 5 & 50 & 18.09 \\
\hline Row 6 & 45 & 13.09 \\
\hline Row 7 & 40 & 8.077 \\
\hline Row 8 & 35 & 3.051 \\
\hline Row 9 & 32 & 0.02635 \\
\hline Row 10 & 32 & -143.1 \\
\hline Row 11 & 30 & -144.1 \\
\hline Row 12 & 25 & -146.6 \\
\hline Row 13 & 20 & -149.2 \\
\hline
\end{tabular}




\section{Appendix G: EES file for pressure drop model}

"Known values from given information"

frost_thickness $=1{ }^{\star} 0.03937$ [inches]

$\mathrm{V} \_1=600 / 60[\mathrm{ft} / \mathrm{s}]$

fin_pitch $=0.216 \quad$ "Spacing between each fin"

fin_thickness $=0.004+2^{*}$ frost_thickness

A_c $=(\text { fin_pitch - fin_thickness })^{\star}\left(S \_T-D \_t u b e\right) \quad$ "Minimum free flow area"

A_c_t $=$ fin_pitch *(S_T - D_tube ) "For bare tube bank"

S_T $=1.75$ [inches] "Transverse pitch"

S_L $=1.5$ [inches] ～"Longitudianl pitch"

D_tube $=0.663+2^{*}$ frost_thickness

Viscosity_air $=0.041633[\mathrm{lb} / \mathrm{ft} \mathrm{h}]$

$\operatorname{Re}=(\text { rho_1 })^{*}(\text { V_max })^{\star}(\text { D_tube })^{\star} 3600^{*}(1 / 12)^{*}(1 /$ Viscosity_air $)$

"Known values from assumption"

specific_v_1 $=12.515\left[\mathrm{ft}^{\wedge} 3 / \mathrm{lb}\right] \quad$ "Assuming for air at $34 \mathrm{F"}$

rho_1 $=0.0799\left[\mathrm{lb} / \mathrm{ft}^{\wedge} 3\right]$

"From this website: http://www.denysschen.com/catalogue/density.asp"

specific_v_2 = $12.453\left[\mathrm{ft}^{\wedge} 3 / \mathrm{lb}\right] \quad$ "Assuming for air at $32 \mathrm{F"}$

A_tube $=$ pi $^{\star} D \_t u b{ }^{*}($ fin_pitch-fin_thickness $)$

A_fin $=2^{*}\left(\left(S \_T^{*} S \_L\right)-\left((p i / 4)^{*}\left(D \_t u b e\right)^{\wedge} 2\right)\right) \quad$ "Exchanger total heat transfer Area on one side"

sigma $=\left(\right.$ S_T $\left.{ }^{*} 0.212\right) /\left(\left(S \_T-D \_t u b e\right)^{*}(\right.$ fin_pitch-fin_thickness $\left.)\right)$

V_max $=$ V_1 ${ }^{*}$ sigma

$\mathrm{G}=$ rho_ $1{ }^{*} \mathrm{~V} \_\max$

"Calculate friction factor"

f_tube = INTERPOLATE1('Re_vs_f_tube','Re','f_tube',Re=Re) 
"Based on heat transfer textbook"

$f \_$fin $=\left(0.508^{*}(\operatorname{Re})^{\wedge}(-0.521)\right)^{*}\left(S \_T / D \_t u b e\right)^{\wedge}(1.318)$

"Solving for pressure drop"

$D E L T A P \_f i n=\left(f \_f i n^{*}\left(6^{*} A \_f i n / A \_c\right)^{*}\left(G^{\wedge} 2\right)^{*}(0.004015 / 0.020886)\right) /\left(64.4^{*}\right.$ rho_1 $)$

DELTAP_tube $=\left(f \_t u b e^{*}\left(6^{\star} A \_t u b e / A \_c \_t\right)^{\star}\left(G^{\wedge} 2\right)^{*}(0.004015 / 0.020886)\right) /\left(64.4^{\star} r h o \_1\right)$

DELTAP $=$ DELTAP_tube + DELTAP_fin

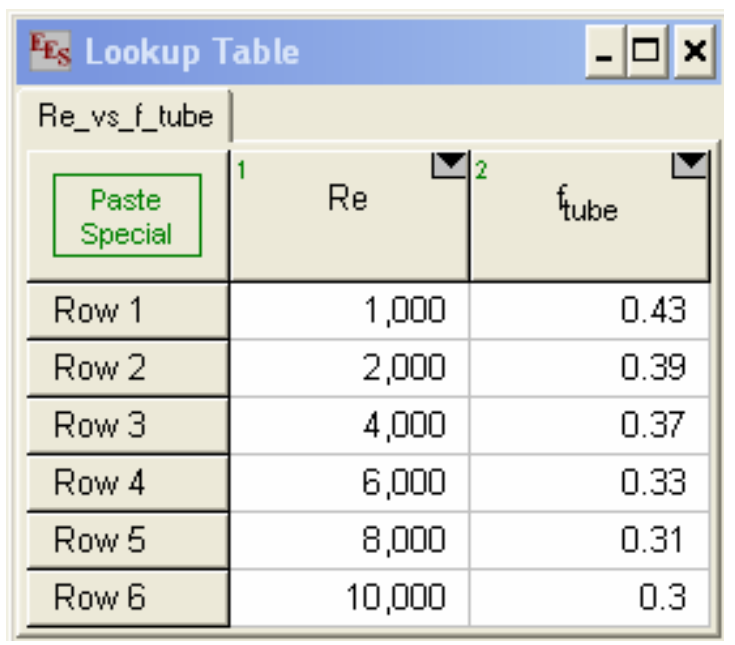




\section{Appendix H: Weather data during experiment}

\section{History for Salinas, CA}

Week of November 9, 2008 through November 15, 2008 - View Current Conditions

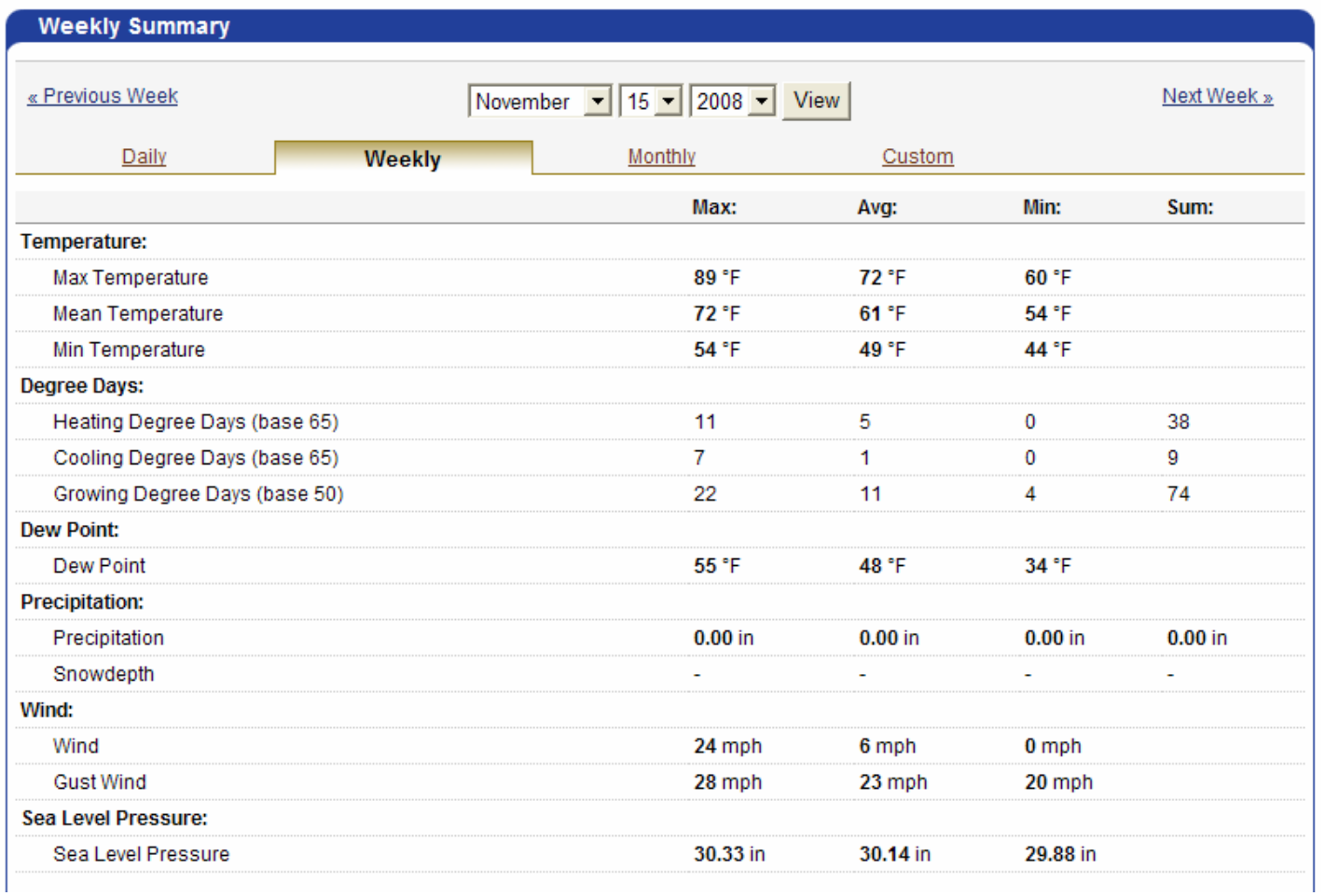

\begin{tabular}{|c|c|c|c|c|c|c|c|c|c|c|c|c|c|c|c|c|c|c|c|c|}
\hline \multirow{2}{*}{$\begin{array}{l}2008 \\
\text { November }\end{array}$} & \multicolumn{3}{|c|}{ Temp. $\left({ }^{\circ} \mathrm{F}\right)$} & \multicolumn{3}{|c|}{ Dew Point ( ${ }^{\circ} \mathrm{F}$ ) } & \multicolumn{3}{|c|}{ Humidity (\%) } & \multicolumn{3}{|c|}{ Sea Level Pressure (in) } & \multicolumn{3}{|c|}{ Visibility (mi) } & \multicolumn{2}{|c|}{ Wind $(\mathrm{mph})$} & \multirow{2}{*}{$\begin{array}{c}\text { Gust Speed (mph) } \\
\text { high }\end{array}$} & \multirow{2}{*}{$\begin{array}{c}\text { Precip (in) } \\
\text { sum }\end{array}$} & \multirow[t]{2}{*}{ Events } \\
\hline & high & avg & low & high & avg & low & high & avg & low & high & avg & low & high & avg & low & high & avg & & & \\
\hline$\underline{9}$ & 62 & 58 & 53 & 52 & 50 & 47 & 93 & 79 & 64 & 30.03 & 29.92 & 29.88 & 10 & 10 & 7 & 21 & 11 & 25 & 0.00 & \\
\hline 10 & 60 & 55 & 49 & 50 & 49 & 45 & 93 & 78 & 62 & 30.21 & 30.09 & 30.00 & 10 & 9 & 7 & 14 & 4 & 16 & 0.00 & \\
\hline 11 & 64 & 54 & 44 & 52 & 45 & 43 & 100 & 81 & 62 & 30.32 & 30.21 & 30.19 & 10 & 7 & 0 & 14 & 5 & 15 & 0.00 & Fog \\
\hline 12 & 72 & 60 & 47 & 55 & 48 & 46 & 100 & 79 & 57 & 30.33 & 30.28 & 30.21 & 10 & 6 & 0 & 15 & 5 & 18 & 0.00 & Fog \\
\hline 13 & 74 & 60 & 46 & 55 & 52 & 46 & 100 & 71 & 41 & 30.26 & 30.22 & 30.12 & 10 & 4 & 0 & 13 & 4 & 16 & 0.00 & Fog \\
\hline 14 & 86 & 67 & 47 & 55 & 49 & 41 & 96 & 60 & 23 & 30.15 & 30.11 & 30.04 & 10 & 9 & 7 & 17 & 3 & 20 & 0.00 & \\
\hline$\underline{15}$ & 89 & 72 & 54 & 49 & 43 & 34 & 72 & 43 & 14 & 30.14 & 30.12 & 30.06 & 10 & 10 & 10 & 24 & 9 & 28 & 0.00 & \\
\hline & & & & & & & & & & & Comma & elimited F & & & & & & & & \\
\hline
\end{tabular}

$\mathrm{F}$

Temperature Devou Point Normal High'Low

$\mathrm{C}$

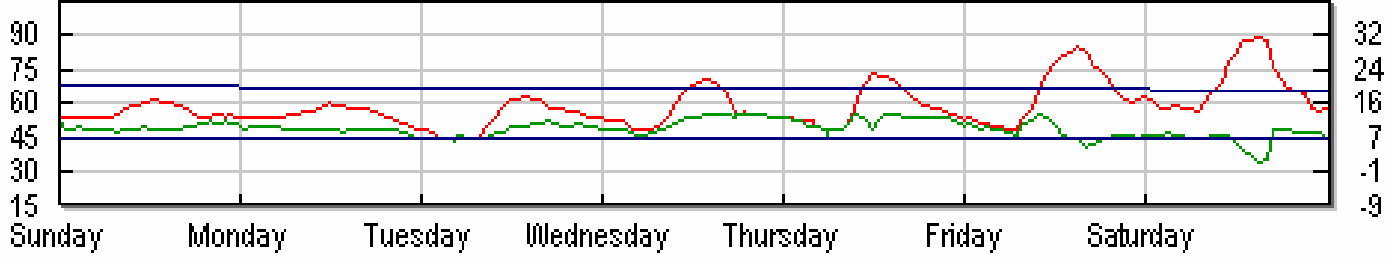

